\title{
NTP TECHNICAL REPORT ON THE TOXICITY STUDY OF \\ CHITOSAN \\ (CASRN 9012-76-4) \\ ADMINISTERED IN FEED TO \\ Sprague DaWley \\ [CRL:CD(SD)] RATS
}

NTP TOX 93

DECEMBER 2017 


\title{
NTP Technical Report on the Toxicity Study of Chitosan (CASRN 9012-76-4) Administered in Feed to Sprague Dawley [Crl:CD(SD)] Rats
}

Toxicity Report 93

December 2017

\author{
National Toxicology Program \\ Public Health Service \\ U.S. Department of Health and Human Services
}

ISSN: 2378-8992

Research Triangle Park, North Carolina, USA 


\section{Foreword}

The National Toxicology Program (NTP) is an interagency program within the Public Health Service (PHS) of the Department of Health and Human Services (HHS) and is headquartered at the National Institute of Environmental Health Sciences of the National Institutes of Health (NIEHS/NIH). Three agencies contribute resources to the program: NIEHS/NIH, the National Institute for Occupational Safety and Health of the Centers for Disease Control and Prevention (NIOSH/CDC), and the National Center for Toxicological Research of the Food and Drug Administration (NCTR/FDA). Established in 1978, NTP is charged with coordinating toxicological testing activities, strengthening the science base in toxicology, developing and validating improved testing methods, and providing information about potentially toxic substances to health regulatory and research agencies, scientific and medical communities, and the public.

The Toxicity Study Report series began in 1991. The studies described in the Toxicity Study Report series are designed and conducted to characterize and evaluate the toxicologic potential of selected substances in laboratory animals (usually two species, rats and mice). Substances selected for NTP toxicity studies are chosen primarily on the basis of human exposure, level of production, and chemical structure. The interpretive conclusions presented in the Toxicity Study Reports are based only on the results of these NTP studies. Extrapolation of these results to other species, including characterization of hazards and risks to humans, requires analyses beyond the intent of these reports. Selection per se is not an indicator of a substance's toxic potential.

NTP conducts its studies in compliance with its laboratory health and safety guidelines and FDA Good Laboratory Practice Regulations and must meet or exceed all applicable federal, state, and local health and safety regulations. Animal care and use are in accordance with the Public Health Service Policy on Humane Care and Use of Animals. Studies are subjected to retrospective quality assurance audits before being presented for public review.

NTP Toxicity Study Reports are indexed in the National Center for Biotechnology Information (NCBI) Bookshelf and are available free of charge electronically on the NTP website (http://ntp.niehs.nih.gov). Toxicity data are available through NTP's Chemical Effects in Biological Systems (CEBS) database:

https://www.niehs.nih.gov/research/resources/databases/index.cfm. 


\section{Table of Contents}

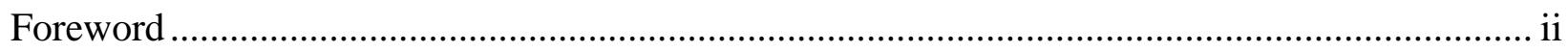

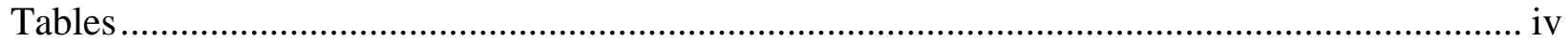

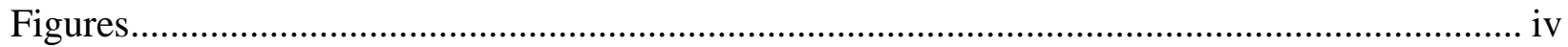

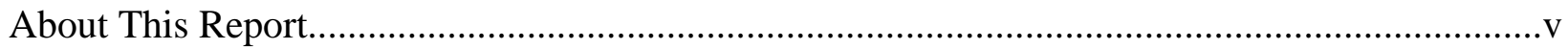

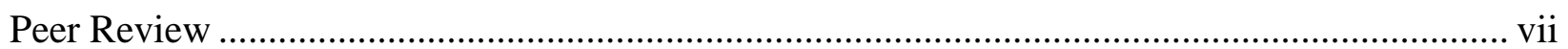

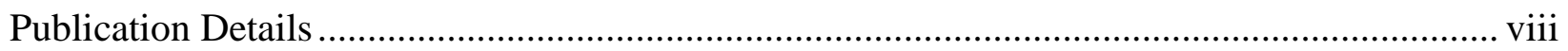

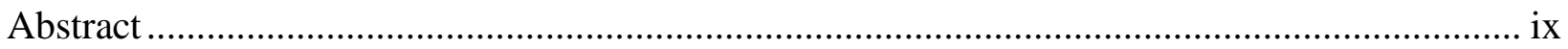

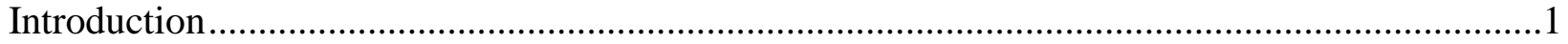

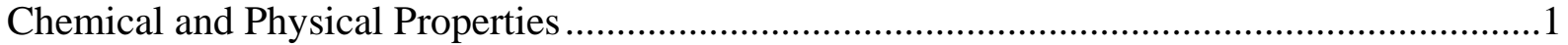

Production, Use, and Human Exposure …………..................................................................

Absorption, Distribution, Metabolism, Excretion, and Toxicokinetics ....................................2

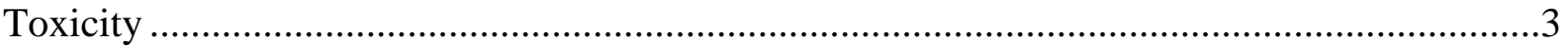

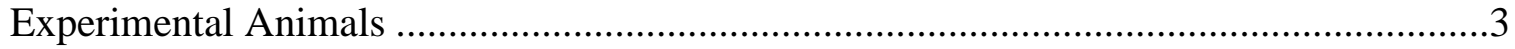

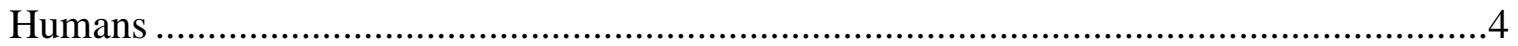

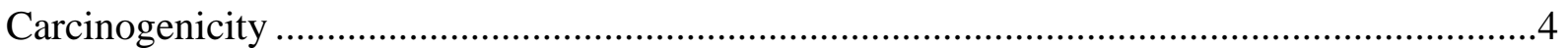

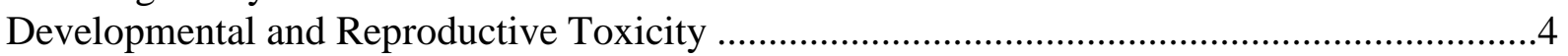

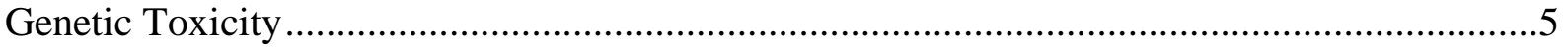

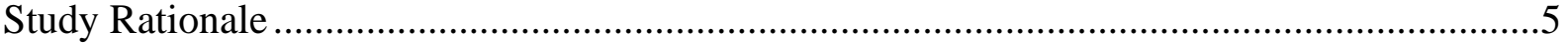

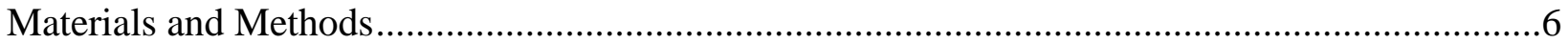

Procurement and Characterization of Chitosan.......................................................................6

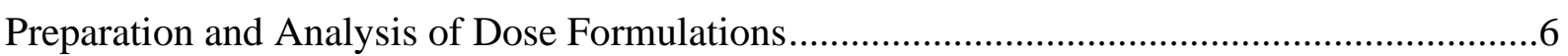

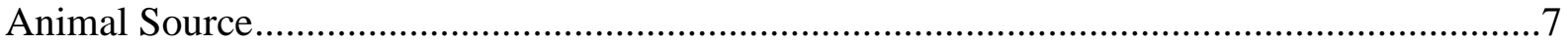

Animal Welfare

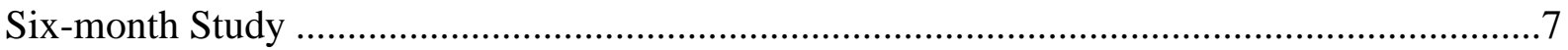

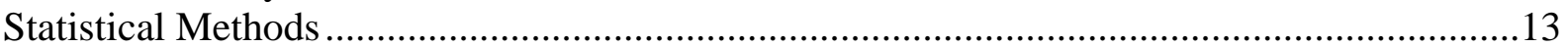

Calculation and Analysis of Lesion Incidences ..........................................................13

Analysis of Continuous Variables ..........................................................................13

Quality Assurance Methods ............................................................................................14

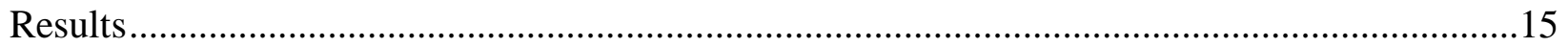

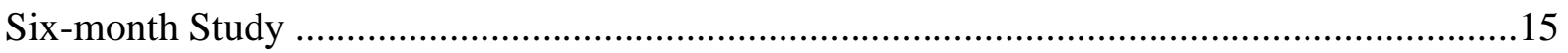

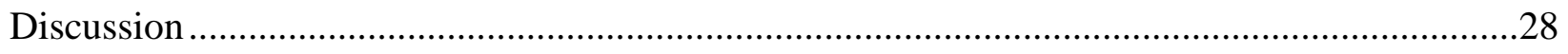

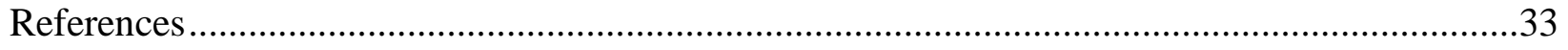

Appendix A. Summary of Lesions in Rats in the Six-month Feed Study of Chitosan................ A-1

Appendix B. Clinical Pathology Results .........................................................................

Appendix C. Vitamin Concentration and Bone Parameter Results .................................................

Appendix D. Organ Weights and Organ-Weight-to-Body-Weight Ratios ................................. D-1

Appendix E. Reproductive Tissue Evaluations ……………………..................................... 
Appendix F. Chemical Characterization and Dose Formulation Studies F-1

Appendix G. Feed and Compound Consumption in the Six-month Feed Study of Chitosan

Appendix H. Ingredients and Nutrient Composition in AIN-93M Maintenance Purified Diet $\mathrm{H}-1$

Appendix I. Sentinel Animal Program.

\section{Tables}

Summary of Findings Considered to be Toxicologically Relevant in Sprague Dawley Rats Exposed to Chitosan in Feed for Six Months ..............................................................

Table 1. Distribution of Evaluated Parameters ..............................................................................

Table 2. Experimental Design and Materials and Methods in the Six-month Feed Study of

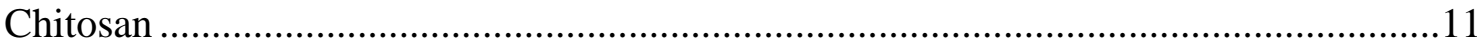

Table 3. Survival, Body Weights, and Feed Consumption of Group A Rats in the Sixmonth Feed Study of Chitosan

Table 4. Selected Clinical Chemistry and Urinalysis Data for Group C Rats in the Sixmonth Feed Study of Chitosan .18

Table 5. Serum and Hepatic Vitamin Concentration Data for Group B Rats in the Sixmonth Feed Study of Chitosan .................................................................................21

Table 6. Digestive Data for Group C Rats in the Six-month Feed Study of Chitosan ...................23

Table 7. Liver Parameter Data for Group A Rats in the Six-month Feed Study of Chitosan.........25

\section{Figures}

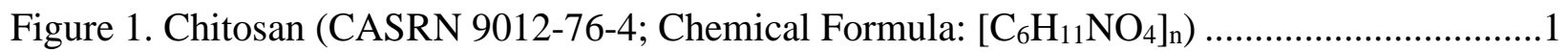

Figure 2. Growth Curves for Group A Rats Exposed to Chitosan in Feed for Six Months ...........16

Figure 3. Section of the Liver from a Control Male Sprague Dawley Rat from the Sixmonth Feed Study of Chitosan with a Moderate Degree of Fatty Change (H\&E) ........26

Figure 4. Higher Magnification of Figure 3 (H\&E) ………......................................................26

Figure 5. Section of the Liver with a Lack of Fatty Change from a Male Sprague Dawley Rat Exposed to 9\% Chitosan in Feed for Six Months (H\&E).

This report has been reformatted to meet new NTP publishing requirements; its content has not changed. 


\section{About This Report}

National Toxicology Program ${ }^{1}$

${ }^{1}$ Division of the National Toxicology Program, National Institute of Environmental Health

Sciences, Research Triangle Park, North Carolina, USA

\section{Collaborators}

K.A. Shipkowski, B.C. Sayers, S.A. Elmore, C.R. Blystone, M.C. Cora, L.M. Fomby, P.M. Foster, M.R. Hejtmancik, M.J. Hooth, A.P. King-Herbert, G.E. Kissling, D.E. Malarkey, B.S. McIntyre, J.T. Painter, T.A. Peace, K.R. Shockley, S.L. Smith-Roe, M.D. Stout, G.S. Travlos, R.W. Tyl, M.K. Vallant, D.Y. Vasconcelos, S. Waidyanatha, N.J. Walker, K.L. Witt

Division of the National Toxicology Program, National Institute of Environmental Health Sciences, Research Triangle Park, North Carolina, USA

Evaluated and interpreted results and reported findings

K.A. Shipkowski, Ph.D., Co-Study Scientist

B.C. Sayers, Ph.D., Co-Study Scientist

S.A. Elmore, D.V.M., Study Pathologist

C.R. Blystone, Ph.D.

M.C. Cora, D.V.M.

P.M. Foster, Ph.D.

M.J. Hooth, Ph.D.

A.P. King-Herbert, D.V.M.

G.E. Kissling, Ph.D.

D.E. Malarkey, D.V.M., Ph.D.

B.S. McIntyre, Ph.D.

K.R. Shockley, Ph.D.

S.L. Smith-Roe, Ph.D.

M.D. Stout, Ph.D.

G.S. Travlos, D.V.M.

M.K. Vallant, M.S., MT

S. Waidyanatha, Ph.D.

N.J. Walker, Ph.D.

K.L. Witt, M.S.

Battelle Columbus Operations, Columbus, Ohio, USA

Conducted study and evaluated pathology findings

M.R. Hejtmancik, Ph.D., Principal Investigator

L.M. Fomby, D.V.M., Ph.D.

T.A. Peace, D.V.M.

D.Y. Vasconcelos, D.V.M., Ph.D.

ILS, Inc., Research Triangle Park, North Carolina, USA

Coordinated NTP Pathology Peer Review (December 19, 2008)

J.T. Painter, D.V.M., Ph.D. 
RTI International, Research Triangle Park, North Carolina, USA

Provided sperm parameter data

R.W. Tyl, Ph.D., Principal Investigator

\section{Contributors}

NTP Pathology Peer Review, National Institute of Environmental Health Sciences, Research Triangle Park, North Carolina, USA

Participated in NTP Pathology Peer Review (December 19, 2008)

S.A. Elmore, D.V.M., National Toxicology Program

Experimental Pathology Laboratories, Inc., Research Triangle Park, North Carolina, USA

Supervised pathology review

M.H. Hamlin, II, D.V.M., Principal Investigator

RTI International, Research Triangle Park, North Carolina, USA

Supported sperm parameter data collection

K. Vick, B.S.

Dynamac Corporation, Research Triangle Park, North Carolina, USA

Prepared quality assessment audits

S. Brecher, Ph.D., Principal Investigator

S. Iyer, B.S.

V.S. Tharakan, D.V.M.

Social \& Scientific Systems, Inc., Research Triangle Park, North Carolina, USA

Provided statistical analyses

M.V. Smith, Ph.D., Principal Investigator

L.J. Betz, M.S.

S.F. Harris, B.S.

J.D. Krause, Ph.D.

C.G. Leach, M.S.

Biotechnical Services, Inc., Little Rock, Arkansas, USA

Prepared Toxicity Study Report

S.R. Gunnels, M.A., Principal Investigator

L.M. Harper, B.S.

T.S. Kumpe, M.A.

E.S. Rathman, M.S.

D.C. Serbus, Ph.D. 


\section{Peer Review}

The draft NTP Technical Report on the Toxicity Study of Chitosan (CASRN 9012-76-4) Administered in Feed to Sprague Dawley [Crl:CD(SD)] Rats was evaluated by the reviewers listed below. These reviewers served as independent scientists, not as representatives of any institution, company, or governmental agency. In this capacity, reviewers determined if the design and conditions of this NTP study were appropriate and ensured that this Toxicity Study Report presents the experimental results and conclusions fully and clearly.

\section{Peer Reviewers}

\section{Diane Birt, Ph.D.}

Iowa State University (Retired)

Ames, Iowa, USA

Melissa G. Rhodes, Ph.D.

Roivant Sciences, Inc.

Durham, North Carolina, USA 


\section{Publication Details}

Publisher: National Toxicology Program

Publishing Location: Research Triangle Park, NC

ISSN: 2378-8992

DOI: https://doi.org/10.22427/NTP-TOX-93

Report Series: NTP Toxicity Report Series

Report Series Number: 93

Official citation: National Toxicology Program (NTP). 2017. NTP technical report on the toxicity study of chitosan (CASRN 9012-76-4) administered in feed to Sprague Dawley [Crl:CD(SD)] rats. Research Triangle Park, NC: National Toxicology Program. Toxicity Report 93. 


\section{Abstract}

Chitosan is a cationic carbohydrate polymer that is commercially derived from the deacetylation of chitin obtained from seafood shells. The most widespread route of human exposure to chitosan is as a dietary supplement for body weight reduction. Chitosan was nominated by the National Cancer Institute for mechanistic studies designed to measure the potential for vitamin $\mathrm{E}$ depletion and osteoporosis following ingestion. Male and female Sprague Dawley rats were exposed to chitosan (86.5\% deacetylated, with an average molecular weight of approximately 82 kilodaltons and estimated to be approximately 94\% pure) in feed for 6 months.

In this 6-month study, groups of 10 male and 10 female core study rats (Group A) were fed control diets (AIN-93M) or diets containing chitosan at concentrations of $1 \%, 3 \%$, or $9 \%$, for up to 25 weeks. Two additional groups of 10 male and 10 female rats (Groups B and C) were given the same dietary concentrations for up to 26 weeks. All male and female Group A rats survived to the end of the study. Mean body weights and feed consumption of exposed Group A groups were similar to those of the control groups. Dietary concentrations of 1\%,3\%, and 9\% resulted in average daily doses of approximately 450, 1,500, and 5,200 $\mathrm{mg}$ chitosan $/ \mathrm{kg}$ body weight per day to males and $650,1,800$, and $6,000 \mathrm{mg} / \mathrm{kg}$ per day to females. There were no treatmentrelated clinical findings in core study animals.

The $9 \%$ male and female rats had significantly decreased cholesterol values ( $26 \%$ to $48 \%$ ), compared to the controls, at all time points. Triglycerides were significantly decreased in $9 \%$ male and female rats, but not at every time point. Phosphorus levels were significantly decreased in 9\% male rats at weeks 13,19, and 25; a decrease also occurred in 3\% males at week 13. Phosphorus levels were significantly decreased in 3\% and 9\% females at weeks 13 and 25.

Compared to those of the controls, serum vitamin A concentrations were significantly decreased (approximately 30\%) at weeks 13, 19, and 26 in 9\% males, at weeks 13 and 26 in 3\% males (approximately 15\%), and at weeks 19 and 26 in 9\% females (approximately 20\%). Serum vitamin E concentrations were significantly decreased at all time points in 3\% (33\% to 42\%) and $9 \%(79 \%$ to $82 \%)$ males, in $1 \%(17 \%)$ males at week 13 , and in $9 \%(62 \%$ to $65 \%)$ females at all time points. Hepatic vitamin E concentrations were significantly decreased at week 26 in $3 \%$ $(48 \%)$ and $9 \%(87 \%)$ males and $9 \%(80 \%)$ females. Serum concentrations of $1,25(\mathrm{OH})_{2}$ vitamin D were significantly increased in $9 \%$ (105\% to $142 \%)$ males and (100\% to $180 \%)$ females at weeks 7, 19, and 26.

Compared to the control groups, percent fat digested was significantly decreased during week 6 in $9 \%$ males and females, during week 12 in 3\% and 9\% males, during week 18 in 9\% males and females, and during week 24 in all exposed groups of males and females. Calcium absorption was significantly increased in $9 \%$ females during weeks 12 and 24 . Fecal weight was significantly increased in $3 \%$ and $9 \%$ males and females during each collection period, and in $1 \%$ females during weeks 12,18 , and 24 . Fecal moisture was significantly increased in $9 \%$ males (up to 170\%) and 9\% females at all time points, in 3\% males during week 6, and in 3\% females during weeks 12 and 18.

Results of this study did not support chitosan as a cause of bone resorption. Significant elevation of parathyroid hormone levels occurred occasionally and inconsistently, while calcium levels remained relatively stable. Bone calcium, bone length, and the histology findings did not indicate calcium loss from the bone following chitosan exposure. 
The absolute and relative liver weights of $9 \%$ males and females and the absolute and relative thymus weights of 3\% males and $9 \%$ males and females were significantly less than those of the control groups.

There was a treatment-related decrease in the incidence of periportal fatty change in the liver of $9 \%$ females relative to the control group. A decreased incidence of periportal fatty change was observed in the liver of $9 \%$ males relative to the control group as well, but this decrease was not significant, and it was the same as that observed in $1 \%$ males. The appearance of periportal fatty change was similar in both males and females and in both exposed and control groups.

Under the conditions of the 6-month feed study of chitosan, male and female rats fed $3 \%$ and $9 \%$ chitosan in the diet had significantly decreased levels of serum vitamin A and serum and hepatic vitamin $E$ and increased levels of serum 1,25 $(\mathrm{OH})_{2}$ vitamin D. Consumption of high levels of chitosan decreased percentage fat digestion and increased fecal weight and moisture, as well as reduced levels of phosphorous, cholesterol, and triglycerides. Female rats exposed to 9\% chitosan also had significant liver weight and histologic changes. Based on the above results, the lowest-observed-effect level for chitosan exposure was 1\% (approximately equivalent to $450 \mathrm{mg} / \mathrm{kg}$ ) in male and 9\% (approximately equivalent to $6,000 \mathrm{mg} / \mathrm{kg}$ ) in female rats.

Synonyms: 2-Amino-2-deoxy-beta-D-glucosamine; deacetylated chitin; poliglusam; poly (D-glucosamine)

Trade names: Celox, Chicol, Chitopearl, CTFA 04299, Flonac N, Kytex H, Sea Cure F

Summary of Findings Considered to be Toxicologically Relevant in Sprague Dawley Rats Exposed to Chitosan in Feed for Six Months

\begin{tabular}{|c|c|c|}
\hline & Male Rats & Female Rats \\
\hline Concentrations in feed & $0 \%, 1 \%, 3 \%, 9 \%$ & $0 \%, 1 \%, 3 \%, 9 \%$ \\
\hline Survival rates & $\begin{array}{l}\text { Group A: 10/10, 10/10, 10/10, 10/10 } \\
\text { Group B: } 9 / 10,10 / 10,10 / 10,8 / 10 \\
\text { Group C: } 10 / 10,10 / 10,10 / 10,10 / 10\end{array}$ & $\begin{array}{l}\text { Group A: } 10 / 10,10 / 10,10 / 10,10 / 10 \\
\text { Group B: 10/10, 10/10, 9/10, 10/10 } \\
\text { Group C: 10/10, 9/10, 10/10, 10/10 }\end{array}$ \\
\hline Body weights & Exposed groups similar to the control group & Exposed groups similar to the control group \\
\hline Clinical findings & None & None \\
\hline Clinical pathology & $\begin{array}{l}\downarrow \text { Phosphorus } \\
\downarrow \text { Cholesterol } \\
\downarrow \text { Triglycerides }\end{array}$ & $\begin{array}{l}\downarrow \text { Phosphorus } \\
\downarrow \text { Cholesterol } \\
\downarrow \text { Triglycerides }\end{array}$ \\
\hline $\begin{array}{l}\text { Vitamin } \\
\text { concentrations }\end{array}$ & $\begin{array}{l}\downarrow \text { Serum vitamin } \mathrm{A} \\
\uparrow \text { Serum } 1,25(\mathrm{OH})_{2} \text { vitamin } \mathrm{D} \\
\downarrow \text { Serum vitamin } \mathrm{E} \\
\downarrow \text { Hepatic vitamin } \mathrm{E}\end{array}$ & $\begin{array}{l}\downarrow \text { Serum vitamin } \mathrm{A} \\
\uparrow \text { Serum } 1,25(\mathrm{OH})_{2} \text { vitamin D } \\
\downarrow \text { Serum vitamin E } \\
\downarrow \text { Hepatic vitamin E }\end{array}$ \\
\hline Digestive parameters & $\begin{array}{l}\downarrow \text { Percent fat digested } \\
\uparrow \text { Fecal weight } \\
\uparrow \text { Fecal moisture }\end{array}$ & $\begin{array}{l}\downarrow \text { Percent fat digested } \\
\uparrow \text { Fecal weight } \\
\uparrow \text { Fecal moisture } \\
\uparrow \text { Calcium absorbed }\end{array}$ \\
\hline Bone parameters & None & None \\
\hline Reproductive toxicity & None & Not determined \\
\hline Organ weights & $\begin{array}{l}\downarrow \text { Absolute and relative liver weights } \\
\downarrow \text { Absolute and relative thymus weights }\end{array}$ & $\begin{array}{l}\downarrow \text { Absolute and relative liver weights } \\
\downarrow \text { Absolute and relative thymus weights }\end{array}$ \\
\hline Nonneoplastic effects & None & $\begin{array}{l}\text { Liver: periportal, fatty change }(7 / 10,4 / 10 \\
4 / 10,0 / 10)\end{array}$ \\
\hline
\end{tabular}




\section{Introduction}

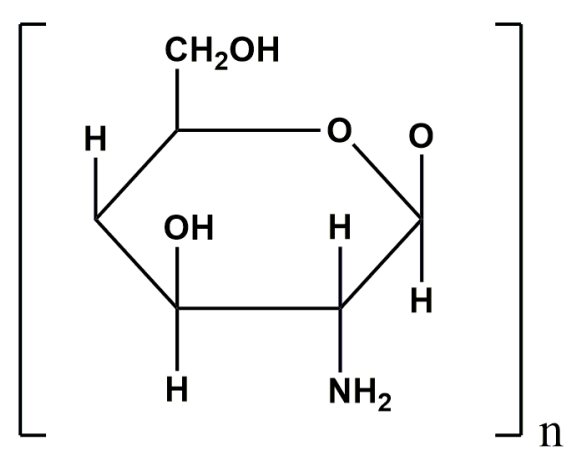

Figure 1. Chitosan (CASRN 9012-76-4; Chemical Formula: $\left.\left[\mathrm{C}_{6} \mathrm{H}_{11} \mathrm{NO}_{4}\right]_{\mathbf{n}}\right)$

Synonyms: 2-Amino-2-deoxy-beta-D-glucosamine; deacetylated chitin; poliglusam; poly. (D-glucosamine). Trade names: Celox, Chicol, Chitopearl, CTFA 04299, Flonac N, Kytex H, Sea Cure F.

\section{Chemical and Physical Properties}

Chitosan is a cationic carbohydrate polymer that is commercially derived from the deacetylation of chitin. The primary unit of the chitosan polymer is D-glucosamine. Chitosan exists in multiple forms that can differ in molecular weight [3 to 3,600 kilodaltons $(\mathrm{kDa})$ ] and in the degree of deacetylation $(40 \% \text { to } 100 \%)^{1}$. Chitosan is defined as chitin that is sufficiently deacetylated to form soluble amine salts. Solubility in aqueous, acidic media occurs when deacetylation of chitin reaches approximately $50 \%{ }^{2}$. In addition to the degree of deacetylation, chitosan solubility is also dependent on the molecular weight and the distribution of the remaining acetyl groups on the polymer ${ }^{3}$. Chitosan is insoluble in alkaline solutions at $\mathrm{pH}$ levels above 6.5. Chitosan products are highly viscous, resembling natural gums ${ }^{4}$.

\section{Production, Use, and Human Exposure}

Chitin, from which chitosan is derived, is a naturally occurring carbohydrate polymer second only to cellulose in abundance. Chitin is a structural component found in the exoskeleton of arthropods and in the cell walls of fungi and yeast ${ }^{2}$. The primary unit of chitin, $N$-acetyl-Dglucosamine, forms the polymeric structure via $1 \rightarrow 4$ glycosidic bonds. Discarded crab and shrimp shells from the seafood industry are the primary source material of chitin for the commercial production of chitosan ${ }^{5}$. For chitosan production, seafood shells are deproteinized by treatment with an aqueous $3 \%$ to $5 \%$ sodium hydroxide $(\mathrm{NaOH})$ solution. The resulting product is neutralized and calcium is removed by treatment with an aqueous $3 \%$ to $5 \%$ hydrochloric acid $(\mathrm{HCl})$ solution at room temperature resulting in a white or slightly pink precipitate of chitin. The $\mathrm{N}$-deacetylation of chitin is done by treatment with an aqueous $40 \%$ to $45 \% \mathrm{NaOH}$ solution, and the precipitate is washed with water. The precipitate is then dissolved in aqueous $2 \%$ acetic acid and the insoluble material is removed. The resulting clear supernatant solution is neutralized with aqueous $\mathrm{NaOH}$ solution producing chitosan as a white precipitate.

Chitosan is used in a wide range of products including use as a flocculating agent for water and waste treatment and as a chelating agent for removal of traces of heavy metals from aqueous 
solutions ${ }^{4}$. In agriculture, chitosan is used as a plant growth regulator through foliar application and as an antimicrobial agent and a time-release reservoir for fertilizers in soil amendments.

Chitosan has several current or proposed biomedical applications. Chitosan is considered to be hemostatic due to its cationic nature. As such, wound dressings manufactured from chitosan are available for clinical use ${ }^{6}$. Several drug delivery systems based on chitosan nanoparticles are currently being investigated. Chitosan nanoparticles are capable of permeating the blood brain barrier, and the mucoadhesive properties of chitosan have been shown to enhance drug absorption $^{2 ; 7}$. Chitosan has also been evaluated for the manufacture of ocular bandage lenses and biodegradable surgical and dental implants ${ }^{8}$.

In cosmetics, chitosan is used in a variety of hair and skin products, including hair and body washes, coloring shampoos, and agents for skin cleaning and protection ${ }^{9}$. Chitosan has also been evaluated for use as an additive to toothpaste for prevention of enamel erosion ${ }^{10}$.

As a dietary supplement, chitosan is marketed and sold in weight-loss products, but the mechanism behind chitosan-induced inhibition of fat digestion is not well understood. It has been proposed that chitosan acts as a weak anion exchanger and decreases intestinal cholesterol absorption while also increasing the excretion of bile acids ${ }^{11-13}$. Another possible mechanism is that chitosan traps fat in the intestines by increasing the viscosity of the intestinal contents and preventing the hydrolysis of triglycerides ${ }^{13-15}$. The manufacturer-recommended consumption of chitosan as a weight-loss product in humans typically averages 1,000 $\mathrm{mg}$ per day, or approximately $14.3 \mathrm{mg} / \mathrm{kg}$ per day (based on a $70 \mathrm{~kg}$ adult ${ }^{16 ; 17}$. There are no available dose or prevalence data for human consumption of chitosan as a dietary supplement.

\section{Absorption, Distribution, Metabolism, Excretion, and Toxicokinetics}

The systemic absorption and distribution of chitosan following oral exposure are likely influenced by the molecular weight of the polymer. The effect of molecular weight on chitosan absorption has been evaluated in male Sprague Dawley rats. Oral gavage administration of chitosan with molecular weights of $3.8,7.5,13,22$, or $230 \mathrm{kDa}$ resulted in maximum plasma chitosan concentrations $\left(C_{\max }\right)$ of $20.23,9.30,5.86,4.32$, or less than $0.5 \mu \mathrm{g} / \mathrm{mL}$, respectively ${ }^{18}$. The results of this study suggest that the absorption of chitosan from the gastrointestinal tract following oral exposure is inversely related to chitosan molecular weight, as there is likely low bioavalability associated with the higher molecular weight chitosan polymers.

The biodegradation of chitosan influences absorption and distribution because both are dependent on molecular weight. The biodegradation of chitosan in vivo is dependent on the degree of deacetylation ${ }^{19}$. Enzymatic degradation of chitosan depends on the ability to hydrolyze glucosamine-glucosamine, glucosamine- $N$-acetyl-glucosamine and $N$-acetyl-glucosamine- $N$ acetyl-glucosamine linkages ${ }^{1}$. Degradation of chitosan in vertebrates is thought to occur predominantly by lysozymes and bacterial enzymes in the colon ${ }^{1}$. While eight human chitinases have been identified with three showing enzymatic activity, their capacity to degrade chitosan has not been investigated ${ }^{1 ; 20}$. 


\section{Toxicity}

\section{Experimental Animals}

The acute toxicities of chitosan and chitosan oligomers prepared by enzymatic depolymerization of chitosan have been evaluated. Hirano ${ }^{5}$ reported the oral $\mathrm{LD}_{50}$ for chitosan as $16 \mathrm{~g} / \mathrm{kg}$ body weight in mice. No clinical signs of toxicity were observed following a single oral administration of chitosan oligomers up to $10 \mathrm{~g} / \mathrm{kg}$ in male and female Kunming strain mice ${ }^{21}$.

No significant differences in weight gain were observed between exposed male Charles River albino rats and the controls in a 4 -week study with $1 \%$ or $5 \%$ dietary chitosan ${ }^{22}$. In male Wistar rats, no significant differences in growth, feed intake, liver weight, or dried fecal weight were observed between control and chitosan-fed ( $2 \%$ or $5 \%$ ) animals after 21 days $^{23}$. In male Sprague Dawley rats fed chitosan in the diet for 8 weeks, no toxicity was observed in animals at concentrations up to $5 \%$, progressive growth reductions and clinical pathology disturbances occurred at $10 \%$ and $15 \%$, and enlargement of the liver and kidneys was observed at $15 \%{ }^{24}$.

In female BALB/c mice fed a 5\% (4.4 $\pm 0.7 \mathrm{~g} /$ day per animal) chitosan diet for 4 weeks, body weight reduction correlated with significantly decreased feed consumption and alterations in normal gut flora ${ }^{25}$.

In a study to evaluate mineral and fat-soluble vitamin status in male Charles River Japan Sprague Dawley rats, exposure to a diet containing 5\% chitosan for 2 weeks caused a decrease in mineral absorption and bone mineral content ${ }^{26}$. Decreased serum vitamin E was observed in rats fed $5 \%$ chitosan with ascorbic acid supplementation in the diet. Serum vitamin E depletion was not observed in rats given glucosamine instead of chitosan.

Depletion of fat-soluble vitamins has been associated with a variety of neurologic and metabolic disorders. Male C57BL/6 mice fed a vitamin E-deficient diet showed signs of cognitive decline after 3 months of exposure and had increased lipid peroxidation products in brain tissue after 6 months of exposure ${ }^{27}$. Male rats fed a vitamin A-deficient diet for 3 months had lower levels of serum cholesterol, HDL-cholesterol, and triacylglycerol, as well as decreased synthesis of liver fatty $\operatorname{acids}^{28}$.

The toxicity of glucosamine oligomers has been evaluated in male and female Charles River Japan F344 rats fed 0\%, 0.04\%, 0.2\%, or 1\% oligoglucosamine in the diet for 90 days ${ }^{29}$. Glucosamine oligomers are prepared by hydrolysis of chitosan and, similar to the chitosan utilized in this 6-month study, are considered low molecular weight chitosan. In the $1 \%$ $(653.1 \mathrm{mg} / \mathrm{kg}$ per day in males, $719.8 \mathrm{mg} / \mathrm{kg}$ per day in females) group, erythema and edema in the snout and on the forelimbs and loss of fur on the forelimbs were observed in both male and female rats. Neutrophilic infiltration in the nasal cavity was also observed in both sexes in the $1 \%$ group. These findings were considered to be caused by topical exposure to glucosamine oligomers during feeding and grooming. Decreased feed consumption and body weight gain were also observed in animals in the $1 \%$ group in this study and were thought to be the result of feeding difficulty due to the snout and forelimb lesions described above. Rats receiving $1 \%$ oligoglucosamine also displayed lower weights of the uterus, ovary, seminal vesicles, and testes (with fewer germ cells). 
The intravenous administration of chitosan has been investigated due to the development of chitosan formulations for drug delivery. No adverse effects were reported in rabbits up to 60 days following intravenous administration of chitosan oligosaccharides (prepared by oxidative depolymerization of chitosan) at doses up to $8.6 \mathrm{mg} / \mathrm{kg}$ daily for 5 consecutive days ${ }^{30}$. In this study, increased lysozyme activity was observed in rabbit serum collected the day after the last intravenous injection. Chemical modifications and nanoparticle suspensions of chitosan are currently being investigated for drug delivery ${ }^{1}$. As such, modifications made to chitosan could alter the toxicity of the unmodified chitosan polymer.

No adverse effects of chitosan were reported in eye or skin irritation tests in rabbits or guinea pigs, respectively ${ }^{31}$.

\section{Humans}

Studies designed to evaluate the effectiveness of chitosan as a weight-loss supplement suggest that chitosan is well tolerated in humans. No adverse effects were reported in male ( $4.5 \mathrm{~g}$ chitosan per day) or female ( $2.5 \mathrm{~g}$ per day) volunteers following oral chitosan administration for 12 days $^{32 ; 33}$. Additionally, no adverse effects were reported following oral administration of chitosan at up to $6.75 \mathrm{~g}$ per day for 8 weeks in male and female volunteers ${ }^{34}$.

\section{Carcinogenicity}

No 2-year carcinogenicity studies of chitosan were identified in the available literature.

Carcinogenicity and chronic toxicity have been evaluated for $N$-acetyl-D-glucosamine, a monomeric constituent of chitosan. F344 rats administered $N$-acetyl-D-glucosamine at concentrations up to $5 \%$ in the diet $(1,935 \mathrm{mg} / \mathrm{kg}$ per day in males and $2,244 \mathrm{mg} / \mathrm{kg}$ per day in females) for 104 weeks had no associated increases in tumor response ${ }^{35}$. In a second study in F344 rats, administration of $N$-acetyl-D-glucosamine in feed at concentrations up to $5 \%$ in the diet $(2,323 \mathrm{mg} / \mathrm{kg}$ per day in males and $2,545 \mathrm{mg} / \mathrm{kg}$ per day in females) for 52 weeks did not induce an increase in tumor response ${ }^{35}$.

\section{Developmental and Reproductive Toxicity}

A limited number of developmental and reproductive toxicity studies were identified in the literature.

In a multigenerational prenatal and postnatal assessment of high molecular weight chitosan (HMWCS), $F_{0}$ time-mated ICR mice were administered $0,125,500$, or 2,000 mg/kg HMWCS via a single intraperitoneal injection on gestational day 6 (GD 6) and subjected to a laparotomy or allowed to litter ${ }^{36}$. $F_{1}$ offspring (1 mouse/sex per litter) from the same exposure group were mated and females similarly subjected to either a laparotomy or allowed to litter to produce an $\mathrm{F}_{2}$ generation. $\mathrm{F}_{0}$ dams in the $2,000 \mathrm{mg} / \mathrm{kg}$ group exhibited signs of maternal toxicity (mortality and diarrhea). $F_{0}$ dams in the 500 and $2,000 \mathrm{mg} / \mathrm{kg}$ groups displayed dose-dependent increases in vaginal bleeding, postimplantation loss, and lower spleen weights. Fetal weights for both generations were lower in the $2,000 \mathrm{mg} / \mathrm{kg}$ group. There were no external, visceral, or skeletal malformations attributed to chitosan administration. $\mathrm{F}_{0}$ dams allowed to litter displayed a doserelated reduction in litter size. $\mathrm{F}_{1}$ mice exposed in utero to 2,000 $\mathrm{mg} / \mathrm{kg}$ HMWCS and examined on postnatal day 21 (PND 21) exhibited higher uterus, ovary, and thymus weights. Female $\mathrm{F}_{1}$ 
mice exposed in utero to $2,000 \mathrm{mg} / \mathrm{kg}$ HMWCS displayed lower thymus weights on PND 56. $\mathrm{F}_{2}$ mice exposed in utero to $2,000 \mathrm{mg} / \mathrm{kg}$ HMWCS displayed lower testis and ovary weights on PNDs 21 and 56.

Chitosan oligomers did not induce morphologic sperm abnormalities in male mice following oral gavage daily for 5 days with up to $5,000 \mathrm{mg} / \mathrm{kg}^{21}$.

The effects of chitosan nanoparticles (spherical; $200 \pm 6 \mathrm{~nm}$ or $340 \pm 10 \mathrm{~nm}$ diameter) have been examined in zebrafish (Danio rerio) embryos. Embryos exposed 4 to 5 hours after fertilization to $0,5,10,20,30$, or $40 \mu \mathrm{g} / \mathrm{mL}$ (200 nm particles) or $0,10,20$, or $40 \mu \mathrm{g} / \mathrm{mL}$ (340 nm particles) displayed concentration-dependent decreases in hatching rates and increases in mortality 96 hours after exposure ${ }^{37}$. Increased rates of cell death and reactive oxygen species production were observed in all exposure groups. Exposure to $200 \mathrm{~nm}$, but not $340 \mathrm{~nm}$, chitosan nanoparticles induced developmental malformations in embryos, including bent spines, pericardial edema, and opaque yolks.

\section{Genetic Toxicity}

No in vitro or in vivo studies evaluating chitosan for mutagenic effects were identified in the available literature.

Chitosan oligomers were negative at concentrations up to 5,000 $\mu \mathrm{g} /$ plate in Salmonella typhimurium strains TA97, TA98, TA100, and TA102 with and without rat liver S9 metabolic activation enzymes, and they were negative for micronucleus induction in mouse bone marrow following oral gavage for 2 days at up to $5,000 \mathrm{mg} / \mathrm{kg}^{21}$.

\section{Study Rationale}

Chitosan was nominated for study by the National Cancer Institute due to widespread human exposure, especially through use as a dietary supplement for body weight reduction, and for concerns regarding potential vitamin $\mathrm{E}$ and bone mineral depletion following ingestion. NTP conducted a 6-month study evaluated the effects of dietary chitosan on the development of osteopenia/osteoporosis, fat and calcium absorption, fat-soluble vitamin depletion, and general toxicity effects in Charles River Sprague Dawley rats. 


\section{Materials and Methods}

\section{Procurement and Characterization of Chitosan}

Chitosan was obtained from Vanson HaloSource, Inc. (Redmond, WA), in one lot (02-ASSF0715), which was used in the 6-month study. Identity, purity, and stability analyses were conducted by the analytical chemistry laboratory at Midwest Research Institute (MRI) (Kansas City, MO) and by the study laboratory at Battelle Columbus Operations (Columbus, $\mathrm{OH}$ ) (Appendix F). Reports on analyses performed in support of the chitosan studies are on file at the National Institute of Environmental Health Sciences.

The test article, an off-white powder, was identified using infrared and proton nuclear magnetic resonance (NMR) spectroscopy. The percentage of deacetylation of the test article, determined by proton NMR, ranged from $85.97 \%$ to $87.17 \%$, with an average of $86.5 \%$. All spectra were consistent with the literature spectra ${ }^{38 ; 39}$, and with the Sadtler spectral database.

The moisture content for lot 02-ASSF-0715 was determined using weight loss on drying, the inorganic content was determined on the dried test article by ashing, viscosity was determined using a Brookfield viscometer, and the most abundant molecular weight was determined using gel permeation chromatography (GPC) with refractive index (RI) detection.

Moisture content was $4.50 \%$ water, the average inorganic content was $2.13 \%$, and viscosity was 81.3 centipoise. GPC/RI indicated one major peak and the determined molecular weight of the bulk chemical ranged from 62,755 to 87,343 daltons (Da). This resulted in an average molecular weight of $81,644 \mathrm{~g} / \mathrm{mol}$, or approximately $82 \mathrm{kDa}$, classifying the test article as a low molecular weight chitosan (LMWCS). A sample of lot 02-ASSF-0715 was submitted to Covance Laboratories, Inc. (Madison, WI), for nutritional and contaminant testing using standard methods. Levels of organochlorine and organophosphorous pesticides, nitrosamines, and aflatoxins were below the detection limits of the analytical methods. The purity of lot 02-ASSF-0715 was estimated to be approximately $94 \%$ based on the analysis of moisture and inorganic content. Taken together, these data indicated that the test article was chitosan.

To ensure stability, the test article was stored in sealed amber glass vials at room temperature. Reanalysis of the test article was performed during the study using GPC/RI and no degradation of the test article was detected.

\section{Preparation and Analysis of Dose Formulations}

The dose formulations were prepared approximately monthly by mixing chitosan with feed. Dose formulations were stored in lined plastic buckets sealed with lids and stored at $-30^{\circ} \mathrm{C}$ to $-15^{\circ} \mathrm{C}$ for up to 42 days.

Homogeneity studies of approximately $0.5 \%$ and $9 \%$ formulations $(5,046$ and 90,049 $\mu \mathrm{g} / \mathrm{g}$, respectively) and stability studies of an approximately $0.5 \%(5,046 \mu \mathrm{g} / \mathrm{g})$ formulation were performed by the analytical chemistry laboratory using GPC/RI. Two peaks were attributed to chitosan with retention times of approximately 6.9 minutes and 12.1 minutes, respectively. Chitosan quantitation was based on the larger polymeric components of the first peak only because vehicle components co-eluted with the later oligomeric peak. Homogeneity studies of 
$1 \%$ and $9 \%$ (10 and $90 \mathrm{mg} / \mathrm{g}$ in feed, respectively) dose formulations were performed by the study laboratory using GPC/RI. Homogeneity was confirmed, and stability was confirmed for at least 42 days for dose formulations stored in lined plastic buckets sealed with lids at temperatures up to room temperature and for at least 7 days under simulated animal room conditions.

Periodic analyses of the dose formulations of chitosan were performed by the study laboratory using GPC/RI. Of the dose formulations analyzed, all nine were within 10\% of the target concentrations (Table F-3). Animal room samples were also analyzed; all three were within 10\% of the target concentrations.

\section{Animal Source}

Male and female Sprague Dawley [Crl:CD(SD)] rats were obtained from Charles River Laboratories (Portage, MI) for use in the 6-month study.

\section{Animal Welfare}

Animal care and use are in accordance with the Public Health Service Policy on Humane Care and Use of Animals. All animal studies were conducted in an animal facility accredited by the Association for the Assessment and Accreditation of Laboratory Animal Care International. Studies were approved by the Battelle Columbus Operations Animal Care and Use Committee and conducted in accordance with all relevant NIH and NTP animal care and use policies and applicable federal, state, and local regulations and guidelines.

\section{Six-month Study}

The rats were 5 to 6 weeks old upon receipt. Rats were quarantined for 12 to 15 days and were 7 to 9 weeks old on the first day of the study. Before the study began, five male and five female rats were randomly selected for parasite evaluation and gross observation for evidence of disease. The health of the animals was monitored during the study according to the protocols of the NTP Sentinel Animal Program (Appendix I). A positive test result for parvovirus occurred in one animal at the 4-week timepoint. Additional testing of serum from this animal and other sentinel animals via other testing methodologies deemed the original positive result to be a false positive. All other test results were negative for rodent pathogens.

The animals in this study were split into three groups, the core group, Group A, and two special study groups, Groups B (vitamin and bone analysis) and C (fat digestion, hematology, clinical chemistry, and urinalysis). Different parameters were evaluated in each group, which allowed for the collection of extensive endpoints (Table 1). Groups of 10 male and 10 female rats were examined per endpoint and there was no crossover of analyses between any of the groups. Group A rats were fed diets containing $0 \%, 1 \%, 3 \%$, or $9 \%$ chitosan for 25 weeks. Groups B and $\mathrm{C}$ rats were fed diets containing the same concentrations for up to 26 weeks. Feed and water were available ad libitum. The AIN-93M diet was used for this study instead of the NTP-2000 diet because of the high levels of fat-soluble vitamins and higher total fat content found in the NTP-2000 diet. The NTP-2000 feed contains almost double the amount of required fat-soluble vitamins and has a higher fat content (7\% to 8\%) than the AIN-93M feed $(4 \%)^{40-42}$. One of the primary rationales for this chitosan study was the potential for decreases in fat-soluble vitamin 
concentrations, and therefore, utilizing a diet with lower levels of preexisting vitamins and a lower fat content was ideal to avoid confounding potential results. Rats were housed individually. Feed consumption was recorded weekly for core study rats. Core study rats were weighed and clinical findings were recorded initially, on day 8 , weekly thereafter, and at the end of the study. Details of the study design and animal maintenance are summarized in Table 2.

Table 1. Distribution of Evaluated Parameters

\begin{tabular}{llcl}
\hline & & Group & C \\
\hline Parameter & A & B & - \\
\hline Feed consumption & X & - & - \\
Body weights & X & - & - \\
Clinical findings & X & - & - \\
SMVCE & X & - & - \\
Bone histomorphometry & X & - & - \\
Gross lesions and histopathology & $X$ & - & - \\
Vitamin A (serum and liver) & - & $X$ & - \\
Vitamin E (serum and liver) & - & $X$ & - \\
$1,25(O H)_{2}$ Vitamin D (serum) & - & $X$ & $X$ \\
Bone calcium, ash, and moisture & - & $X$ & $X$ \\
Hematology & - & - & $X$ \\
Clinical chemistry & - & - & $X$ \\
Vitamin K 1 (plasma and liver) & - & - & $X$ \\
Feed and fecal analysis & - & - & \\
Urinalysis & - & - & X \\
\hline
\end{tabular}

On the first day of weeks 7, 13, 19, and 26, blood was collected from all Group B rats via the retroorbital plexus under $\mathrm{CO}_{2} / \mathrm{O}_{2}$ anesthesia for determination of vitamins $\mathrm{A}, \mathrm{E}$, and $1,25(\mathrm{OH})_{2}$ vitamin D concentrations. Blood was collected into tubes, allowed to clot, and centrifuged. Sera were stored at approximately $-70^{\circ} \mathrm{C}$ until analysis. Blood samples for vitamin $\mathrm{K}_{1}$ concentrations in Group $\mathrm{C}$ rats, collected into tubes containing EDTA at the same time as hematology collections, were centrifuged; the plasma was harvested, snap frozen, and stored at $-70^{\circ} \mathrm{C}$ protected from light. At study termination (week 26), liver samples were collected from surviving Group B and $\mathrm{C}$ rats, processed, and stored frozen for determination of vitamins $\mathrm{A}$ and $\mathrm{E}$ (Group B) or vitamin $\mathrm{K}_{1}$ (Group C) concentrations. Blood and liver samples were analyzed by high performance liquid chromatography for vitamins A and $\mathrm{E}$ (Covance Laboratories, Inc.), by competitive enzyme immunoassay for $1,25(\mathrm{OH})_{2}$ vitamin $\mathrm{D}$ (Antech Diagnostics, Morrisville, NC), or by gas chromatography/mass spectrometry for vitamin $\mathrm{K}_{1}$ (Analytics, Inc., Gaithersburg, MD). Because most values for vitamin $\mathrm{K}_{1}$ were below the limit of quantitation, the results are not presented in this Toxicity Study Report. 
For 8 days beginning during weeks 6, 12, 18, and 24, Group C rats were placed in metabolism cages (Nalgene Company, Rochester, NY) for fecal and urine collection. During collection periods, rats were allowed control or dosed feed and water ad libitum, and feed samples were collected. Feces were collected for a period of 8 days, with each day's collection being combined with previous days' collection and stored at approximately $-20^{\circ} \mathrm{C}$. Feces were stored at $-70^{\circ} \mathrm{C}$ after each collection period until shipping to Covance Laboratories, Inc., on dry ice for analyses of calcium, fat, and moisture; the feed samples were also sent for analysis. Fat content in feed and feces was determined gravimetrically by Soxhlet extraction. Feed consumption, fat intake [(total feed consumed per interval $) \times(\%$ fat in feed/100)], and fat excretion [fecal weight $\times(\%$ fecal fat/100)], were calculated to estimate fat digestion: $\{[($ fat intake - fat excreted in feces $) /$ fat intake $] \times 100\}$. Calcium concentrations in feed and feces were determined using inductively coupled plasma emission spectrometry. Moisture was determined by weight loss upon drying. Urine was collected on ice for each Group $\mathrm{C}$ rat over a 24-hour period during the last day in the metabolism cage and coincided with the last day of fecal collection. Total urine collected was transferred to centrifuge tubes and the volume was recorded. Urine creatinine was measured using a Hitachi $911^{\mathrm{TM}}$ chemistry analyzer (Roche Diagnostics, Indianapolis, IN), and deoxypyridinoline was measured using a Metra Total DPD Enzyme Immunoassay Kit (Quidel, San Diego, CA).

On the last day in the metabolism cage, at the beginning of weeks 7, 13, 19, and 25, blood was collected from all Group $\mathrm{C}$ rats via the retroorbital plexus under $\mathrm{CO}_{2} / \mathrm{O}_{2}$ anesthesia for hematology (week 25 only) and clinical chemistry. Blood samples for hematology were collected in tubes containing EDTA as an anticoagulant. Hematology parameters were determined using an Advia 120 hematology analyzer (Bayer Diagnostics Division, Tarrytown, NY). Blood for clinical chemistry determinations was collected in tubes without anticoagulant, allowed to clot, and centrifuged and then the serum was harvested. Except as noted, clinical chemistry parameters were determined using a Hitachi $911^{\mathrm{TM}}$ chemistry analyzer (Roche Diagnostics). For osteocalcin and parathyroid hormone, serum was stored frozen at $-20^{\circ} \mathrm{C}$ until analysis. Serum osteocalcin was measured using a Rat-MID ${ }^{\mathrm{TM}}$ Osteocalcin ELISA (Nordic Bioscience Diagnostics, Herlev, Denmark). Serum parathyroid hormone was measured using an Intact PTH Enzyme Immunoassay Kit (ALPCO Diagnostics, Salem, NH).

At study termination (week 26), right and left femurs were collected from the Group B rats for determination of calcium, ash, and moisture. Covance Laboratories, Inc., determined bone moisture by measuring weight loss upon drying, calcium by inductively coupled plasma emission spectrometry, and ash gravimetrically.

At the end of the study (week 25), samples were collected for sperm motility and vaginal cytology evaluations on Group A rats. The parameters evaluated are listed in Table 2. Due to inconsistent sample collection and slide staining, an assessment of estrous cyclicity could not be made. Male animals were evaluated for sperm count and motility. The left testis and left epididymis were isolated and weighed. The tail of the epididymis (cauda epididymis) was then removed from the epididymal body (corpus epididymis) and weighed. Test yolk was applied to slides and a small incision was made at the distal border of the cauda epididymis. The sperm effluxing from the incision were dispersed in the buffer on the slides, and the numbers of motile and nonmotile spermatozoa were counted for five fields per slide by two observers. Following completion of sperm motility estimates, each left cauda epididymis was placed in buffered saline solution. Caudae were finely minced, and the tissue was incubated in the saline solution and then 
heat fixed at $65^{\circ} \mathrm{C}$. Sperm density was then determined microscopically with the aid of a hemacytometer. To quantify spermatogenesis, the testicular spermatid head count was determined by removing the tunica albuginea and homogenizing the left testis in phosphatebuffered saline containing 10\% dimethyl sulfoxide. Homogenization-resistant spermatid nuclei were counted with a hemacytometer.

Necropsies were performed on all Group A animals at study termination (week 25). The heart, right kidney, liver, lung, right ovary, parathyroid gland, right testis, thymus, thyroid gland and parathyroid gland together, and uterus were weighed. Both tibias and both femurs were collected; the lengths of both tibias and the left femur were measured. The right tibia and femur were dehydrated in ethanol (70\% to 100\%) and infiltrated with glycol methacrylate. Tissues for microscopic examination were fixed and preserved in 10\% neutral buffered formalin (except eyes were first fixed in Davidson's solution), processed and trimmed, embedded in paraffin, sectioned to a thickness of 4 to $6 \mu \mathrm{m}$, and stained with hematoxylin and eosin. Complete histopathologic examinations were performed by the study laboratory pathologist on $0 \%$ and $9 \%$ rats. The kidney and liver of males and females and the parathyroid gland and prostate gland of males were examined in all exposure groups. Table 2 lists the tissues and organs routinely examined.

After a review of the laboratory reports and selected histopathology slides by a quality assessment (QA) pathologist, the findings and reviewed slides were submitted to an NTP Pathology Peer Review (PPR) coordinator for a second independent review. Any inconsistencies in the diagnoses made by the study laboratory and QA pathologists were resolved by the NTP pathology peer review process. Final diagnoses for reviewed lesions represent a consensus of the PPR or a consensus between the study laboratory pathologist, NTP pathologist, QA pathologist(s), and the PPR coordinator. Details of these review procedures have been described, in part, by Maronpot and Boorman ${ }^{43}$ and Boorman et al. ${ }^{44}$. 
Table 2. Experimental Design and Materials and Methods in the Six-month Feed Study of Chitosan Six-month Studies

Study Laboratory

Battelle Columbus Operations (Columbus, $\mathrm{OH}$ )

Strain and Species

Charles River Sprague Dawley $[\mathrm{Crl}: \mathrm{CD}(\mathrm{SD})]$ rats

Animal Source

Charles River Laboratories (Portage, MI)

Time Held Before Study

Group A (core study): 14 (males) or 15 (females) days

Groups B and C (special studies): 12 (males) or 13 (females) days

Average Age When Study Began

7 to 8 weeks (Group A males and Groups B and C males and females)

8 to 9 weeks (Group A females)

Date of First Exposure

Group A: August 31 (males) or September 1 (females), 2006

Groups B and C: August 29 (males) or 30 (females), 2006

Duration of Exposure

Group A: 25 weeks

Groups B and C: 26 weeks

Date of Last Exposure

Group A: February 15 (males) or 16 (females), 2007

Groups B and C: February 20 (males) or 21 (females), 2007

\section{Necropsy Dates}

Group A: February 15 (males) or 16 (females), 2007

Groups B and C: February 20 (males) or 21 (females), 2007

\section{Average Age at Necropsy}

32 to 33 weeks (Group A females and Groups B and C males and females)

31 to 32 weeks (Group A males)

\section{Size of Study Groups}

10 males and 10 females

\section{Method of Distribution}

Animals were distributed randomly into groups of approximately equal initial mean body weights.

Animals per Cage

1

\section{Method of Animal Identification}

Tail tattoo

Diet

AIN-93M maintenance purified meal diet (Purina TestDiet, Richmond, IN), available ad libitum, changed twice weekly

Water 


\section{Six-month Studies}

Tap water (Columbus, OH municipal supply) via automatic watering system (Edstrom Industries, Inc. Waterford, WI), available ad libitum

\section{Cages}

Polycarbonate solid-bottom (Lab Products, Inc., Seaford, DE), changed weekly, rotated in rack every 2 weeks

\section{Bedding}

Irradiated hardwood bedding chips (P.J. Murphy Forest Products Corporation, Montville, NJ), changed weekly

\section{Rack Filters}

Spun-bonded polyester (Snow Filtration Company, Cincinnati, OH), changed every 2 weeks

\section{Racks}

Stainless steel (Lab Products, Inc), changed and rotated every 2 weeks

\section{Animal Room Environment}

Temperature: $72^{\circ} \pm 3^{\circ} \mathrm{F}$

Relative humidity: $50 \% \pm 15 \%$

Room fluorescent light: 12 hours/day

Room air changes: 10/hour

\section{Exposure Concentrations}

$0 \%, 1 \%, 3 \%$, and $9 \%$ in feed, available ad libitum

\section{Type and Frequency of Observation}

Observed twice daily; Group A rats were weighed and clinical findings were recorded initially, on day 8, weekly thereafter, and at the end of the study. Feed consumption was recorded weekly for Group A rats and during fecal collection periods for Group C rats.

\section{Method of Euthanasia}

$100 \%$ Carbon dioxide

\section{Necropsy}

Necropsies were performed on all Group A rats at the end of the study (week 25). Organs weighed were heart, right kidney, liver, lung, right ovary, parathyroid gland, right testis, thymus, thyroid gland and parathyroid gland together, and uterus. Lengths of both tibias and the left femur were measured.

\section{Clinical Pathology}

Blood was collected via the retroorbital plexus from all Group C rats on the first day of weeks 7, 13, 19, and 25 for hematology (week 25 only) and clinical chemistry. Urine was collected from Group C rats for 24 hours beginning the last day of weeks $6,12,18$, and 24 .

Hematology: hematocrit (auto and manual); hemoglobin concentration; erythrocyte, reticulocyte, and platelet counts; mean cell volume; mean cell hemoglobin; mean cell hemoglobin concentration; and leukocyte count and differentials Clinical chemistry: urea nitrogen, creatinine, calcium, phosphorous, total protein, albumin, cholesterol, triglycerides, alanine aminotransferase, alkaline phosphatase, creatine kinase, sorbitol dehydrogenase, bile acids, total osteocalcin, and parathyroid hormone

Urinalysis: creatinine, volume, and deoxypyridinoline

\section{Histopathology}




\section{Six-month Studies}

Histopathology was performed on $0 \%$ and $9 \%$ Group A rats. In addition to gross lesions and tissue masses, the following tissues were examined: adrenal gland, bone (left femur and tibia) with marrow, brain, clitoral gland, esophagus, eye, Harderian gland, heart and aorta, large intestine (cecum, colon, rectum), small intestine (duodenum, jejunum, ileum), kidney, liver, lung (with mainstem bronchus), lymph nodes (mandibular and mesenteric), mammary gland, nose, ovary, pancreas, parathyroid gland, pituitary gland, preputial gland, prostate gland, salivary gland, seminal vesicle, skin, spleen, stomach (forestomach and glandular), testis (with epididymis), thymus, thyroid gland, trachea, urinary bladder, and uterus. The kidney and liver of males and females and the parathyroid gland and prostate gland of males were also examined in the $1 \%$ and $3 \%$ groups.

\section{Sperm Motility}

At the end of the study, sperm samples were collected from male Group A rats for sperm count and motility evaluations. The following parameters were evaluated: spermatid heads per gram testis and per testis, spermatid heads per gram cauda and per cauda, and epididymal spermatozoal motility. The left cauda, left epididymis, and left testis were weighed.

\section{Digestion Studies}

Feces were collected from Group C rats for 8 days beginning weeks 6, 12, 18, and 24 and analyzed for calcium, fat, and moisture. Fecal calcium and fat content were compared to that in feed samples collected during the same time period to produce values for fat digested and calcium absorbed.

\section{Serum and Hepatic Vitamins}

Blood was collected from the retroorbital plexus of Groups B and C rats on the first day of weeks 7, 13, 19, and 25 (Group C), and 26 (Group B). At study termination (week 26), liver samples were collected from Groups B and C rats. Blood and liver samples were analyzed for vitamins $\mathrm{A}, \mathrm{E}, 1,25(\mathrm{OH})_{2} \mathrm{D}$, and/or $\mathrm{K}_{1}$.

\section{Bone Analysis}

At study termination (week 26), right and left femurs were collected from Group B rats, and calcium, ash, and moisture levels were measured.

\section{Statistical Methods}

\section{Calculation and Analysis of Lesion Incidences}

The incidences of lesions are presented in Appendix A as the numbers of animals bearing such lesions at a specific anatomic site and the numbers of animals with that site examined microscopically. The Fisher exact test ${ }^{45}$, a procedure based on the overall proportion of affected animals, was used to determine significance.

\section{Analysis of Continuous Variables}

Two approaches were employed to assess the significance of pairwise comparisons between dosed and control groups in the analysis of continuous variables. Organ and body weight data, which historically have approximately normal distributions, were analyzed with the parametric multiple comparison procedures of Dunnet ${ }^{46}$ and Williams ${ }^{47 ; 48}$. Hematology, clinical chemistry, urinalysis, serum and liver vitamin concentrations, digestive and bone parameters, spermatid, and epididymal spermatozoal data, which have typically skewed distributions, were analyzed using the nonparametric multiple comparison methods of Shirley ${ }^{49}$ (as modified by Williams ${ }^{50}$ ) and Dunn ${ }^{51}$. Jonckheere's test ${ }^{52}$ was used to assess the significance of the dose-related trends and to determine whether a trend-sensitive test (Williams' or Shirley's test) was more appropriate for pairwise comparisons than a test that does not assume a monotonic dose-related trend (Dunnett's or Dunn's test). Prior to statistical analysis, extreme values identified by the outlier test of Dixon 
and Massey ${ }^{53}$ were examined by NTP personnel, and implausible values were eliminated from the analysis.

\section{Quality Assurance Methods}

The 6-month study was conducted in compliance with Food and Drug Administration Good Laboratory Practice Regulations ${ }^{54}$. In addition, as records from the 6-month study were submitted to the NTP Archives, this study was audited retrospectively by an independent QA contractor. Separate audits covered completeness and accuracy of the pathology data, pathology specimens, final pathology tables, and a draft of this NTP Toxicity Study Report. Audit procedures and findings are presented in the reports and are on file at NIEHS. The audit findings were reviewed and assessed by NTP staff, and all comments were resolved or otherwise addressed during the preparation of this Toxicity Study Report. 


\section{Results}

\section{Six-month Study}

All male and female Group A rats survived to the end of the study (Table 3); however, five rats from Groups B and C died, often after seizures that occurred near the time of blood collection, with the cause of death undetermined. There were no treatment-related clinical findings in Group A animals, although 13 animals from Groups B and C (10 from the 9\% group, one from the $3 \%$ group, and two from the $1 \%$ group) were observed with seizures either during or after the 18 -week blood collections. Seizures were not noted at any other time point. Body weights and feed consumption were measured in Group A rats, and mean body weights of exposed males and females were not significantly different from those of the control groups (Table 3 and Figure 2). Feed consumption by 3\% and 9\% Group A males was greater than that by the controls, but the increase may not be accurate due to observed food spillage possibly due to poor palatability resulting in feed being wasted (Table G-1). Dietary concentrations of $1 \%, 3 \%$, and $9 \%$ resulted in average daily doses of approximately 450, 1,500, and 5,200 $\mathrm{mg}$ chitosan/kg body weight per day to males and $650,1,800$, and $6,000 \mathrm{mg} / \mathrm{kg}$ per day to females, respectively.

Table 3. Survival, Body Weights, and Feed Consumption of Group A Rats in the Six-month Feed Study of Chitosan ${ }^{\mathrm{a}}$

\begin{tabular}{|c|c|c|c|c|c|c|c|}
\hline Concentration & Survival $^{\text {b }}$ & $\begin{array}{c}\text { Initial } \\
\text { Body } \\
\text { Weight (g) }\end{array}$ & $\begin{array}{l}\text { Final Body } \\
\text { Weight (g) }\end{array}$ & $\begin{array}{c}\text { Change in } \\
\text { Body } \\
\text { Weight } \\
\text { (g) }\end{array}$ & $\begin{array}{l}\text { Final Weight } \\
\text { Relative to } \\
\text { Controls (\%) }\end{array}$ & $\begin{array}{c}\text { Feed } \\
\text { Consumption } \\
\text { Week } 1\end{array}$ & $\begin{array}{c}\text { Feed } \\
\text { Consumption } \\
\text { Week 25 }\end{array}$ \\
\hline
\end{tabular}

\begin{tabular}{cccccccc}
\hline Male & & & & & & \\
$0 \%$ & $10 / 10$ & $238 \pm 5$ & $669 \pm 20$ & $432 \pm 18$ & & 22.2 & 21.2 \\
$1 \%$ & $10 / 10$ & $243 \pm 6$ & $702 \pm 21$ & $459 \pm 17$ & 105 & 23.8 & 20.4 \\
$3 \%$ & $10 / 10$ & $242 \pm 6$ & $687 \pm 23$ & $445 \pm 21$ & 103 & 23.6 & 24.7 \\
$9 \%$ & $10 / 10$ & $243 \pm 6$ & $612 \pm 17$ & $369 \pm 17$ & 91 & 21.4 & 27.3 \\
\hline Female & & & & & & \\
$0 \%$ & $10 / 10$ & $175 \pm 3$ & $338 \pm 11$ & $162 \pm 12$ & & 17.7 & 16.4 \\
$1 \%$ & $10 / 10$ & $173 \pm 2$ & $335 \pm 13$ & $162 \pm 12$ & 99 & 22.3 & 20.3 \\
$3 \%$ & $10 / 10$ & $177 \pm 4$ & $328 \pm 11$ & $151 \pm 9$ & 97 & 17.3 & 17.1 \\
$9 \%$ & $10 / 10$ & $177 \pm 2$ & $301 \pm 13$ & $124 \pm 12$ & 89 & 16.9 & 18.8 \\
\hline
\end{tabular}

${ }^{a}$ Weights and weight changes are given as mean \pm standard error. Feed consumption is expressed as grams per animal per day. Differences in weights and weight changes from the control group are not significant by Dunnett's test.

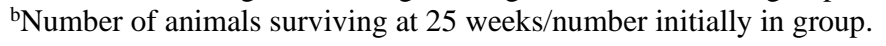



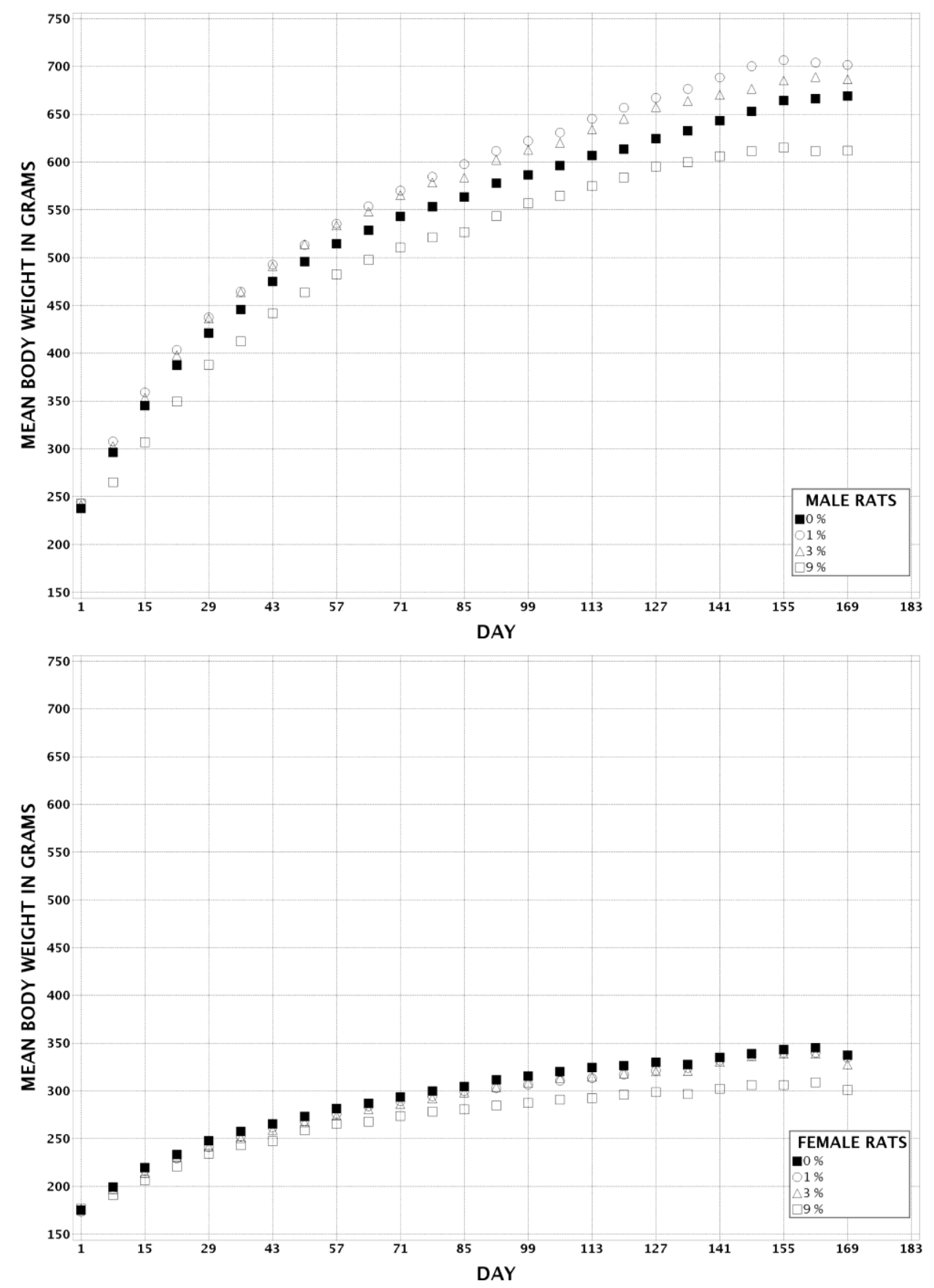

Figure 2. Growth Curves for Group A Rats Exposed to Chitosan in Feed for Six Months

Hematology data for Group C rats are listed in Table B-1. Compared to the control group, mild significant increases (4\% to $6 \%$ ) in automated hematocrit, hemoglobin concentration, mean cell volume, and mean cell hemoglobin were observed in $9 \%$ males; manual hematocrit and erythrocyte count were similar to those of the controls. These changes may be due to biological variability and are likely not toxicologically relevant. All other differences from control values in the male and female hematology data were mild or sporadic and not considered toxicologically significant. 
Clinical chemistry data for Group C rats are listed in Table 4 and Table B-1. Both the 9\% male and female rats had significantly decreased cholesterol values (26\% to 48\%), compared to the controls, at all time points. Triglycerides values were also significantly decreased in the $9 \%$ male $(47 \%$ to $57 \%)$ and female $(30 \%)$ rats, but not at every time point. Phosphorus levels were significantly decreased in the $9 \%$ male rats at weeks 13,19 , and 25 (12\% to $18 \%)$; a decrease also occurred in the 3\% males at week 13 (14\%). Similarly, phosphorus levels were significantly decreased in the 3\% and 9\% females at weeks 13 (20\% and 16\%, respectively) and 25 (9\% and $19 \%$, respectively). A mild, but statistically significant, decrease (4\%) in calcium concentration was observed in $9 \%$ males at weeks 19 and 25. Alanine aminotransferase (ALT) activity, a marker of hepatocellular injury, was mildly but significantly elevated at week 25 in the $9 \%$ male rats $(104 \%)$ and in the $3 \%$ and $9 \%$ female rats (28\% and $88 \%$, respectively). However, sorbitol dehydrogenase (another marker of hepatocellular injury) was not significantly increased relative to the controls, and hepatocellular changes associated with increases in ALT were not observed microscopically. Thus, the toxicologic significance of the increases in ALT is uncertain. Urea nitrogen was mildly increased in the $9 \%$ males $(23 \%)$ and females $(15 \%)$ at week 25 . Minimal to mild significant alterations were also observed in several other parameters. These alterations were inconsistent or within the range of biological variability.

Total osteocalcin (a marker of bone turnover) and parathyroid hormone levels were analyzed in Group $\mathrm{C}$ rats and were occasionally elevated throughout the study. Total osteocalcin was significantly elevated in the $9 \%$ males (38\%) at week 25 , while parathyroid hormone levels were significantly elevated in $9 \%$ males (96\%) at Week 19 and in 9\% females (56\%) at week 25 (Table 4 and Table B-1).

Urine deoxypyridinoline/creatinine ratios were calculated at weeks $7,13,19$, and 25 for both males and females in Group C and were mostly unchanged (Table 4 and Table B-1). A significant increase, compared to the control group, occurred at week 25 in the $9 \%$ males (28\%). In females, minimal increases and decreases occurred inconsistently across all time points with a significant increase at week 7 in the $9 \%$ group (42\%) and significant decreases at weeks 13 $(26 \%)$ and $19(20 \%)$ in the $1 \%$ group compared to controls.

To calculate the deoxypyridinoline/creatinine ratios, urine volume, urine creatinine concentrations, and urine deoxypyridinoline concentrations were measured at weeks 7, 13, 19, and 25. Urine volume was significantly decreased in various male and female exposure groups throughout the study, but most consistently in the $9 \%$ chitosan group (approximately $40 \%$ to $60 \%$ ). Increases in urine creatinine concentration tended to parallel the decreases in urine volume indicating proper kidney function. 
Table 4. Selected Clinical Chemistry and Urinalysis Data for Group C Rats in the Six-month Feed Study of Chitosan ${ }^{\text {a }}$

\begin{tabular}{|c|c|c|c|c|}
\hline & $0 \%$ & $1 \%$ & $3 \%$ & $9 \%$ \\
\hline \multicolumn{5}{|l|}{ Male } \\
\hline \multicolumn{5}{|c|}{ Clinical Chemistry } \\
\hline $\mathbf{n}$ & 10 & 10 & 10 & 10 \\
\hline \multicolumn{5}{|c|}{ Calcium (mg/dL) } \\
\hline Week 13 & $12.6 \pm 0.1$ & $12.5 \pm 0.1$ & $12.3 \pm 0.2$ & $12.4 \pm 0.2$ \\
\hline Week 19 & $12.5 \pm 0.1$ & $12.3 \pm 0.2$ & $12.3 \pm 0.1$ & $12.0 \pm 0.1^{*}$ \\
\hline Week 25 & $12.1 \pm 0.1$ & $12.1 \pm 0.2$ & $12.0 \pm 0.1$ & $11.6 \pm 0.1^{*}$ \\
\hline \multicolumn{5}{|c|}{ Phosphorus (mg/dL) } \\
\hline Week 13 & $8.4 \pm 0.3$ & $8.1 \pm 0.3$ & $7.2 \pm 0.3 * *$ & $7.4 \pm 0.4^{*}$ \\
\hline Week 19 & $8.2 \pm 0.4$ & $7.7 \pm 0.2$ & $7.4 \pm 0.3$ & $6.7 \pm 0.2 * *$ \\
\hline Week 25 & $6.9 \pm 0.3$ & $6.8 \pm 0.2$ & $6.7 \pm 0.1$ & $5.8 \pm 0.3 * *$ \\
\hline \multicolumn{5}{|c|}{ Cholesterol (mg/dL) } \\
\hline Week 7 & $82 \pm 5$ & $75 \pm 8$ & $80 \pm 6$ & $53 \pm 3 * *$ \\
\hline Week 13 & $95 \pm 7$ & $84 \pm 8$ & $90 \pm 7$ & $53 \pm 2 * *$ \\
\hline Week 19 & $101 \pm 6$ & $87 \pm 10$ & $94 \pm 8$ & $59 \pm 4^{* *}$ \\
\hline Week 25 & $95 \pm 6$ & $81 \pm 8$ & $90 \pm 6$ & $49 \pm 4^{* *}$ \\
\hline \multicolumn{5}{|c|}{ Triglycerides (mg/dL) } \\
\hline Week 7 & $202 \pm 28$ & $234 \pm 43$ & $226 \pm 30$ & $88 \pm 15^{*}$ \\
\hline Week 13 & $198 \pm 33$ & $202 \pm 38$ & $195 \pm 24$ & $86 \pm 8 * *$ \\
\hline Week 19 & $180 \pm 26$ & $218 \pm 43$ & $210 \pm 29$ & $95 \pm 13^{*}$ \\
\hline Week 25 & $173 \pm 18$ & $207 \pm 30$ & $218 \pm 24$ & $109 \pm 13$ \\
\hline \multicolumn{5}{|c|}{ Alanine aminotransferase (IU/L) } \\
\hline Week 25 & $28 \pm 3$ & $29 \pm 2$ & $29 \pm 1$ & $57 \pm 2 * *$ \\
\hline \multicolumn{5}{|c|}{ Sorbitol dehydrogenase (IU/L) } \\
\hline Week 25 & $17 \pm 3$ & $17 \pm 2$ & $15 \pm 1$ & $14 \pm 1$ \\
\hline \multicolumn{5}{|c|}{ Total osteocalcin (ng/mL) } \\
\hline Week 7 & $445.7 \pm 17.2$ & $439.8 \pm 15.8$ & $441.8 \pm 18.2$ & $520.4 \pm 22.6$ \\
\hline Week 13 & $306.2 \pm 13.0$ & $289.7 \pm 28.6$ & $245.4 \pm 37.9$ & $372.6 \pm 23.4$ \\
\hline Week 19 & $239.4 \pm 12.4$ & $225.7 \pm 10.6$ & $181.6 \pm 26.8$ & $269.2 \pm 20.9$ \\
\hline Week 25 & $158.3 \pm 10.0$ & $168.1 \pm 11.6$ & $145.9 \pm 22.7$ & $218.3 \pm 14.6^{*}$ \\
\hline \multicolumn{5}{|c|}{ Parathyroid hormone (ng/mL) } \\
\hline Week 7 & $1.882 \pm 0.137$ & $1.643 \pm 0.449$ & $1.838 \pm 0.348$ & $1.521 \pm 0.368$ \\
\hline Week 13 & $2.343 \pm 0.350$ & $2.763 \pm 0.479$ & $3.215 \pm 0.537$ & $2.433 \pm 0.222$ \\
\hline Week 19 & $1.879 \pm 0.186$ & $3.101 \pm 0.475$ & $2.710 \pm 0.365$ & $3.679 \pm 0.361 * *$ \\
\hline Week 25 & $2.668 \pm 0.475$ & $2.924 \pm 0.276$ & $3.981 \pm 0.349$ & $2.848 \pm 0.506$ \\
\hline
\end{tabular}




\section{Chitosan, NTP TOX 93}

\begin{tabular}{|c|c|c|c|c|}
\hline & $\mathbf{0 \%}$ & $1 \%$ & $3 \%$ & $9 \%$ \\
\hline \multicolumn{5}{|l|}{ Urinalysis } \\
\hline \multicolumn{5}{|l|}{$\mathbf{n}$} \\
\hline Week 7 & 10 & 9 & 10 & 10 \\
\hline Week 13 & 10 & 10 & 10 & 10 \\
\hline Week 19 & 10 & 10 & 10 & 10 \\
\hline Week 25 & 10 & 10 & 10 & 10 \\
\hline \multicolumn{5}{|c|}{ Volume (mL) } \\
\hline Week 7 & $8.3 \pm 0.8$ & $7.5 \pm 1.5$ & $6.4 \pm 0.8$ & $5.0 \pm 1.1 *$ \\
\hline Week 13 & $7.9 \pm 1.0$ & $4.6 \pm 0.3 * *$ & $5.1 \pm 0.4^{*}$ & $4.5 \pm 0.5 * *$ \\
\hline Week 19 & $10.7 \pm 1.6$ & $4.0 \pm 0.4^{* *}$ & $5.3 \pm 0.7 *$ & $5.6 \pm 0.6$ \\
\hline Week 25 & $8.6 \pm 1.2$ & $5.4 \pm 0.6^{*}$ & $6.1 \pm 0.8^{*}$ & $5.1 \pm 0.6^{* *}$ \\
\hline \multicolumn{5}{|c|}{ Deoxypyridinoline/creatinine (nmol/mg) } \\
\hline Week 7 & $1.810 \pm 0.135$ & $1.889 \pm 0.148$ & $1.810 \pm 0.159$ & $1.920 \pm 0.160$ \\
\hline Week 13 & $0.910 \pm 0.035$ & $0.890 \pm 0.031$ & $0.930 \pm 0.040$ & $0.960 \pm 0.078$ \\
\hline Week 19 & $0.530 \pm 0.050$ & $0.550 \pm 0.034$ & $0.570 \pm 0.042$ & $0.660 \pm 0.048$ \\
\hline Week 25 & $0.430 \pm 0.030$ & $0.470 \pm 0.030$ & $0.480 \pm 0.020$ & $0.550 \pm 0.027 * *$ \\
\hline \multicolumn{5}{|l|}{ Female } \\
\hline \multicolumn{5}{|c|}{ Clinical Chemistry } \\
\hline \multicolumn{5}{|l|}{$\mathbf{n}$} \\
\hline Week 7 & 10 & 10 & 10 & 10 \\
\hline Week 13 & 10 & 10 & 10 & 10 \\
\hline Week 19 & 10 & 10 & 10 & 10 \\
\hline Week 25 & 10 & 9 & 10 & 10 \\
\hline \multicolumn{5}{|c|}{ Calcium (mg/dL) } \\
\hline Week 13 & $12.9 \pm 0.2$ & $13.1 \pm 0.1$ & $12.7 \pm 0.2$ & $12.5 \pm 0.2$ \\
\hline Week 19 & $12.9 \pm 0.1$ & $13.1 \pm 0.2$ & $12.8 \pm 0.1$ & $12.5 \pm 0.1$ \\
\hline Week 25 & $12.7 \pm 0.3$ & $12.8 \pm 0.1$ & $12.7 \pm 0.2$ & $12.3 \pm 0.2$ \\
\hline \multicolumn{5}{|c|}{ Phosphorus (mg/dL) } \\
\hline Week 13 & $8.1 \pm 0.5$ & $7.4 \pm 0.4$ & $6.5 \pm 0.4 * *$ & $6.8 \pm 0.3^{*}$ \\
\hline Week 19 & $8.4 \pm 0.4$ & $8.2 \pm 0.5$ & $8.1 \pm 0.3$ & $7.4 \pm 0.5$ \\
\hline Week 25 & $6.8 \pm 0.2$ & $6.4 \pm 0.2$ & $6.2 \pm 0.3 *$ & $5.5 \pm 0.3 * *$ \\
\hline \multicolumn{5}{|c|}{ Cholesterol (mg/dL) } \\
\hline Week 7 & $80 \pm 6$ & $81 \pm 8$ & $67 \pm 4$ & $59 \pm 4 * *$ \\
\hline Week 13 & $92 \pm 8$ & $86 \pm 7$ & $73 \pm 5$ & $58 \pm 4 * *$ \\
\hline Week 19 & $107 \pm 7$ & $105 \pm 9$ & $91 \pm 8$ & $67 \pm 5^{* *}$ \\
\hline Week 25 & $94 \pm 7$ & $108 \pm 5$ & $96 \pm 8$ & $63 \pm 4 * *$ \\
\hline
\end{tabular}




\section{Chitosan, NTP TOX 93}

\begin{tabular}{|c|c|c|c|c|}
\hline & $0 \%$ & $1 \%$ & $3 \%$ & $9 \%$ \\
\hline \multicolumn{5}{|c|}{ Triglycerides (mg/dL) } \\
\hline Week 7 & $88 \pm 12$ & $130 \pm 48$ & $81 \pm 8$ & $86 \pm 14$ \\
\hline Week 13 & $125 \pm 10$ & $163 \pm 30$ & $140 \pm 23$ & $88 \pm 23^{*}$ \\
\hline Week 19 & $143 \pm 15$ & $181 \pm 32$ & $137 \pm 18$ & $90 \pm 13$ \\
\hline Week 25 & $188 \pm 31$ & $231 \pm 44$ & $245 \pm 31$ & $158 \pm 35$ \\
\hline \multicolumn{5}{|c|}{ Alanine aminotransferase (IU/L) } \\
\hline Week 25 & $25 \pm 3$ & $28 \pm 3$ & $32 \pm 2 * *$ & $47 \pm 4 * *$ \\
\hline \multicolumn{5}{|c|}{ Sorbitol dehydrogenase (IU/L) } \\
\hline Week 25 & $17 \pm 3$ & $17 \pm 2$ & $19 \pm 2$ & $16 \pm 1$ \\
\hline \multicolumn{5}{|c|}{ Total osteocalcin (ng/mL) } \\
\hline Week 7 & $293.6 \pm 19.4$ & $287.5 \pm 21.2$ & $282.1 \pm 34.7$ & $316.7 \pm 23.5$ \\
\hline Week 13 & $197.9 \pm 22.6$ & $202.3 \pm 15.4$ & $184.4 \pm 19.4$ & $234.2 \pm 14.5$ \\
\hline Week 19 & $158.1 \pm 18.3$ & $184.8 \pm 13.2$ & $166.7 \pm 24.7$ & $210.1 \pm 16.0$ \\
\hline Week 25 & $107.9 \pm 18.6$ & $97.1 \pm 7.1$ & $96.0 \pm 16.2$ & $148.8 \pm 15.1$ \\
\hline \multicolumn{5}{|c|}{ Parathyroid hormone (ng/mL) } \\
\hline Week 7 & $0.995 \pm 0.150^{\mathrm{b}}$ & $1.156 \pm 0.176$ & $1.092 \pm 0.182$ & $1.023 \pm 0.146$ \\
\hline Week 13 & $1.506 \pm 0.203$ & $1.734 \pm 0.194$ & $1.925 \pm 0.306$ & $1.767 \pm 0.212$ \\
\hline Week 19 & $1.406 \pm 0.232$ & $1.994 \pm 0.353$ & $1.845 \pm 0.418$ & $1.673 \pm 0.223$ \\
\hline Week 25 & $1.471 \pm 0.189^{b}$ & $1.628 \pm 0.220$ & $1.818 \pm 0.224$ & $2.301 \pm 0.212 *$ \\
\hline
\end{tabular}

\section{Urinalysis}

n

\begin{tabular}{lcccc} 
Week 7 & 10 & 10 & 10 & 10 \\
Week 13 & 10 & 10 & 10 & 10 \\
Week 19 & 10 & 10 & 10 & 10 \\
Week 25 & 10 & 9 & 10 & 9 \\
\hline
\end{tabular}

Volume (mL)

Week 7

Week 13

$8.2 \pm 1.2$

$8.5 \pm 1.0$

$5.4 \pm 0.8$

$3.4 \pm 0.3^{* *}$

Week 19

$6.4 \pm 0.7$

$6.5 \pm 0.6$

$4.1 \pm 0.8 *$

$2.9 \pm 0.5^{* *}$

Week 25

$7.7 \pm 1.2$

$8.1 \pm 1.4$

$5.0 \pm 0.8$

$3.4 \pm 0.5^{* *}$

Deoxypyridinoline/creatinine $(\mathrm{nmol} / \mathrm{mg})$

$\begin{array}{lcccc}\text { Week } 7 & 1.620 \pm 0.128 & 1.240 \pm 0.129 & 1.940 \pm 0.229 & 2.300 \pm 0.182^{*} \\ \text { Week 13 } & 0.580 \pm 0.039 & 0.430 \pm 0.037^{* *} & 0.540 \pm 0.034 & 0.570 \pm 0.042 \\ \text { Week 19 } & 0.450 \pm 0.017 & 0.360 \pm 0.016^{*} & 0.440 \pm 0.016 & 0.520 \pm 0.020 \\ \text { Week 25 } & 0.340 \pm 0.043 & 0.222 \pm 0.022 & 0.340 \pm 0.027 & 0.411 \pm 0.026\end{array}$

*Significantly different $(\mathrm{P} \leq 0.05)$ from the control group by Dunn's or Shirley's test.

$* * \mathrm{P} \leq 0.01$.

aData are presented as mean \pm standard error. Statistical tests were performed on unrounded data. $\mathrm{b}_{\mathrm{n}}=9$. 
Serum and hepatic vitamin concentrations were measured in Group B rats (Table 5 and Table C-1). Exposure concentration-dependent decreases were observed in serum vitamin A concentrations starting at week 13 in the male rats. The decreases reached statistical significance at weeks $13(27 \%), 19(26 \%)$, and $26(29 \%)$ in 9\% males and at weeks $13(15 \%)$ and $26(16 \%)$ in $3 \%$ males. Females were less affected with significant decreases observed in the $9 \%$ group at weeks 19 (18\%) and $26(21 \%)$. Exposure concentration-dependent decreases were also observed in serum vitamin E concentrations in male rats at all time points. The decreases were statistically significant at all time points in $3 \%$ (33\% to $42 \%)$ and $9 \%$ males (79\% to $82 \%)$ and in $1 \%$ males at week $13(17 \%)$, with the $9 \%$ group measuring between $18 \%$ to $21 \%$ that of control values throughout the study. Females were less affected with significant decreases in serum vitamin $\mathrm{E}$ levels observed in the 9\% group (approximately 60\%) only (all time points). Hepatic vitamin E concentrations were significantly decreased at week 26 in $3 \%$ and $9 \%$ males $(48 \%$ and $87 \%$, respectively) and $9 \%$ females $(80 \%)$. In the $9 \%$ group, levels of hepatic vitamin E measured only $13 \%$ and $20 \%$ of control values in the males and females, respectively. Serum concentrations of $1,25(\mathrm{OH})_{2}$ vitamin D were significantly increased in $9 \%$ males (105\% to $\left.142 \%\right)$ and females (100\% to $180 \%$ ) at weeks 7, 19, and 26 compared to the control groups. Results of plasma hepatic vitamin $\mathrm{K}$ concentrations in Group $\mathrm{C}$ rats are not discussed or presented, as many samples were below the level of quantification.

Table 5. Serum and Hepatic Vitamin Concentration Data for Group B Rats in the Six-month Feed Study of Chitosan ${ }^{\text {a }}$

\begin{tabular}{lcccc}
\hline & $\mathbf{0 \%}$ & $\mathbf{1 \%}$ & $\mathbf{3 \%}$ & $\mathbf{9 \%}$ \\
\hline Male & & & & \\
$\mathbf{n}$ & & & & \\
Week 7 & 9 & 10 & 10 & 10 \\
Week 13 & 9 & 10 & 10 & 10 \\
Week 19 & 9 & 10 & 10 & 8 \\
Week 26 & 9 & 10 & & \\
\hline Serum vitamin A $(\mu \mathrm{g} / \mathrm{mL})$ & & & $0.513 \pm 0.026$ & $0.453 \pm 0.018$ \\
Week 7 & $0.532 \pm 0.021$ & $0.506 \pm 0.033$ & $0.476 \pm 0.022^{*}$ & $0.410 \pm 0.009^{* *}$ \\
Week 13 & $0.561 \pm 0.024$ & $0.499 \pm 0.019$ & $0.475 \pm 0.019$ & $0.392 \pm 0.014^{* *}$ \\
Week 19 & $0.533 \pm 0.028$ & $0.506 \pm 0.031$ & $0.398 \pm 0.017 * *$ & $0.336 \pm 0.026^{* *}$ \\
Week 26 & $0.476 \pm 0.019$ & $0.444 \pm 0.024$ & & \\
Serum 1,25 $(\mathrm{OH})_{2}$ vitamin D $(\mathrm{pg} / \mathrm{mL})$ & & & & \\
Week 7 & $124.4 \pm 19.6$ & $163.3 \pm 21.7$ & $183.2 \pm 26.9$ & $297.4 \pm 41.0^{* *}$ \\
Week 13 & $70.1 \pm 7.3$ & $57.4 \pm 5.3$ & $77.3 \pm 4.4$ & $86.1 \pm 8.5$ \\
Week 19 & $20.6 \pm 2.8$ & $21.7 \pm 6.1$ & $22.9 \pm 2.2$ & $42.3 \pm 3.1^{* * \mathrm{~b}}$ \\
Week 26 & $27.7 \pm 3.4^{\mathrm{c}}$ & $28.0 \pm 4.3$ & $36.1 \pm 4.6^{\mathrm{b}}$ & $66.9 \pm 11.9^{* *}$ \\
Serum vitamin E $(\mu \mathrm{gg} / \mathrm{mL})$ & & & & \\
Week 7 & $19.33 \pm 1.43$ & $15.38 \pm 1.29$ & $12.92 \pm 0.48^{* *}$ & $4.14 \pm 0.23^{* *}$ \\
Week 13 & $21.08 \pm 1.61$ & $17.45 \pm 1.06^{*}$ & $12.27 \pm 0.86^{* *}$ & $4.33 \pm 0.27^{* *}$ \\
\hline
\end{tabular}




\begin{tabular}{ccccc}
\hline & $\mathbf{0 \%}$ & $\mathbf{1 \%}$ & $\mathbf{3 \%}$ & $\mathbf{9 \%}$ \\
\hline Week 19 & $20.59 \pm 1.61$ & $16.19 \pm 0.96$ & $12.86 \pm 0.42 * *$ & $4.07 \pm 0.32^{* *}$ \\
Week 26 & $19.66 \pm 1.66$ & $17.35 \pm 1.37$ & $12.35 \pm 0.61^{* *}$ & $3.59 \pm 0.65 * *$ \\
Liver vitamin E $(\mu \mathrm{g} / \mathrm{g})$ & & & \\
Week 26 & $66.8 \pm 16.2$ & $55.0 \pm 6.8$ & $34.6 \pm 2.2^{* *}$ & $8.5 \pm 0.8 * *$ \\
\hline
\end{tabular}

\section{Female}

n

\begin{tabular}{lcccc} 
Week 7 & 10 & 10 & 10 & 10 \\
Week 13 & 10 & 10 & 10 & 10 \\
Week 19 & 10 & 10 & 10 & 10 \\
Week 26 & 10 & 10 & 9 & 10 \\
\hline
\end{tabular}

Serum vitamin $\mathrm{A}(\mu \mathrm{g} / \mathrm{mL})$

$\begin{array}{lllll}\text { Week } 7 & 0.272 \pm 0.011 & 0.253 \pm 0.007 & 0.260 \pm 0.012 & 0.266 \pm 0.012 \\ \text { Week 13 } & 0.308 \pm 0.020 & 0.295 \pm 0.011 & 0.309 \pm 0.019 & 0.281 \pm 0.018 \\ \text { Week 19 } & 0.283 \pm 0.014 & 0.271 \pm 0.015 & 0.291 \pm 0.012 & 0.231 \pm 0.010^{*} \\ \text { Week 26 } & 0.316 \pm 0.015 & 0.302 \pm 0.014 & 0.294 \pm 0.018 & 0.249 \pm 0.010^{* *}\end{array}$

Serum 1,25 $(\mathrm{OH})_{2}$ vitamin $\mathrm{D}(\mathrm{pg} / \mathrm{mL})$

$\begin{array}{lcccc}\text { Week } 7 & 104.0 \pm 15.1 & 96.7 \pm 10.9 & 111.0 \pm 8.7 & 208.1 \pm 18.2^{* *} \\ \text { Week } 13 & 60.6 \pm 7.5 & 60.7 \pm 7.9 & 69.3 \pm 11.0 & 110.1 \pm 16.9 \\ \text { Week } 19 & 11.6 \pm 1.6 & 12.6 \pm 1.7 & 15.8 \pm 1.4 & 31.4 \pm 3.2^{* *} \\ \text { Week } 26 & 19.2 \pm 2.2 & 20.7 \pm 4.2 & 28.6 \pm 6.5 & 53.7 \pm 5.8^{* *}\end{array}$

Serum vitamin E $(\mu \mathrm{g} / \mathrm{mL})$

$\begin{array}{lllll}\text { Week } 7 & 18.65 \pm 0.71 & 20.08 \pm 0.87 & 18.38 \pm 0.85 & 6.99 \pm 0.58^{* *} \\ \text { Week 13 } & 19.81 \pm 1.41 & 20.85 \pm 1.06 & 20.19 \pm 1.20 & 7.48 \pm 0.38^{* *} \\ \text { Week 19 } & 21.02 \pm 1.76 & 19.74 \pm 1.75 & 19.86 \pm 1.08 & 7.37 \pm 0.57 * * \\ \text { Week 26 } & 20.94 \pm 1.56 & 23.43 \pm 1.66 & 22.23 \pm 1.75 & 7.28 \pm 0.64 * *\end{array}$

Liver vitamin $\mathrm{E}(\mu \mathrm{g} / \mathrm{g})$

Week 26

$84.5 \pm 8.9$

$97.1 \pm 10.1$

$82.0 \pm 11.8$

$17.2 \pm 3.2^{* *}$

*Significantly different $(\mathrm{P} \leq 0.05)$ from the control group by Dunn's or Shirley's test.

**Significantly different $(\mathrm{P} \leq 0.01)$ from the control group by Shirley's test.

${ }^{\text {a } D a t a}$ are presented as mean \pm standard error. Statistical tests were performed on unrounded data.

$\mathrm{b}_{\mathrm{n}}=9$.

${ }^{c} \mathrm{n}=7$.

Digestive parameters were calculated for Group $\mathrm{C}$ rats and are listed in Table 6. Compared to the control groups, percent fat digested was significantly decreased at week 6 in $9 \%$ males (28\%) and females (14\%), during week 12 in $3 \%$ and $9 \%$ males ( $8 \%$ and $33 \%$, respectively), during week 18 in $9 \%$ males (20\%) and females (10\%), and during week 24 in all exposed groups of males and females (up to 32\%). Calcium absorption was significantly increased in $9 \%$ females during weeks $12(55 \%)$ and 24 (154\%). Fecal weight was significantly increased in 3\% and 9\% males (up to 170\%) and females (up to 126\%) during each collection period and in $1 \%$ females 
during weeks 12,18 , and 24 (18\% to $29 \%$ ). Fecal moisture was significantly increased in $9 \%$ males and females at all time points $(10 \%$ to $15 \%)$, in $3 \%$ males $(4 \%)$ at week 6 , and in $3 \%$ females $(7 \%)$ at weeks 12 and 18.

Male rats did not display any changes in testis or epididymis weights or sperm parameters, indicating that chitosan did not exhibit the potential to be a reproductive toxicant in male rats (Table E-1).

Table 6. Digestive Data for Group C Rats in the Six-month Feed Study of Chitosan ${ }^{\text {a }}$

\begin{tabular}{|c|c|c|c|c|}
\hline & $0 \%$ & $1 \%$ & $3 \%$ & $9 \%$ \\
\hline \multicolumn{5}{|l|}{ Male } \\
\hline \multicolumn{5}{|l|}{$\mathbf{n}$} \\
\hline Weeks 6-7 & 10 & 10 & 10 & 10 \\
\hline Weeks 12-13 & 10 & 10 & 10 & 10 \\
\hline Weeks 18-19 & 10 & 10 & 10 & 9 \\
\hline Weeks 24-25 & 10 & 10 & 10 & 10 \\
\hline \multicolumn{5}{|l|}{ Fat digested (\%) } \\
\hline Weeks 6-7 & $97.04 \pm 0.40$ & $97.55 \pm 0.22$ & $94.37 \pm 0.84$ & $69.55 \pm 3.01 * *$ \\
\hline Weeks 12-13 & $94.79 \pm 0.46$ & $93.36 \pm 0.83$ & $87.08 \pm 0.68 * *$ & $63.50 \pm 2.40 * *$ \\
\hline Weeks 18-19 & $97.56 \pm 0.58$ & $98.48 \pm 0.19$ & $95.87 \pm 0.70$ & $77.59 \pm 1.83^{* *}$ \\
\hline Weeks 24-25 & $97.01 \pm 0.19$ & $95.61 \pm 0.32 * *$ & $92.14 \pm 0.87^{* *}$ & $66.18 \pm 3.24 * *$ \\
\hline \multicolumn{5}{|c|}{ Calcium absorbed (\%) } \\
\hline Weeks 6-7 & $31.69 \pm 1.84$ & $34.57 \pm 4.05$ & $27.54 \pm 1.83$ & $33.01 \pm 1.59$ \\
\hline Weeks 12-13 & $19.81 \pm 3.36$ & $14.73 \pm 0.76$ & $18.42 \pm 3.25$ & $28.01 \pm 2.69$ \\
\hline Weeks 18-19 & $13.33 \pm 4.33$ & $18.42 \pm 5.43$ & $3.64 \pm 2.62$ & $11.11 \pm 1.35$ \\
\hline Weeks 24-25 & $2.93 \pm 1.54$ & $5.14 \pm 1.08$ & $0.70 \pm 1.57$ & $9.46 \pm 1.88$ \\
\hline \multicolumn{5}{|l|}{ Fecal weight (g) } \\
\hline Weeks 6-7 & $21.42 \pm 0.68$ & $21.01 \pm 1.93$ & $31.33 \pm 0.90^{* *}$ & $52.39 \pm 2.85^{* *}$ \\
\hline Weeks 12-13 & $24.32 \pm 1.68$ & $27.70 \pm 1.37$ & $32.84 \pm 1.73^{* *}$ & $47.59 \pm 4.30 * *$ \\
\hline Weeks 18-19 & $23.11 \pm 1.25$ & $22.67 \pm 1.85$ & $33.30 \pm 1.72 * *$ & $62.38 \pm 3.67 * * \mathrm{~b}$ \\
\hline Weeks 24-25 & $26.43 \pm 1.12$ & $25.75 \pm 0.73$ & $37.17 \pm 1.11^{* *}$ & $56.35 \pm 3.45^{* *}$ \\
\hline \multicolumn{5}{|c|}{ Fecal moisture (\%) } \\
\hline Weeks 6-7 & $45.0 \pm 0.5$ & $42.0 \pm 1.6$ & $46.8 \pm 0.4^{*}$ & $51.0 \pm 0.8^{* *}$ \\
\hline Weeks 12-13 & $46.8 \pm 2.0$ & $49.0 \pm 0.8$ & $48.8 \pm 0.6$ & $53.6 \pm 0.8^{* *}$ \\
\hline Weeks 18-19 & $47.7 \pm 1.1$ & $45.3 \pm 1.8$ & $49.1 \pm 0.7$ & $54.8 \pm 1.5^{* * \mathrm{~b}}$ \\
\hline Weeks 24-25 & $47.2 \pm 0.6$ & $45.7 \pm 0.5$ & $49.3 \pm 0.7$ & $53.1 \pm 0.8^{* *}$ \\
\hline
\end{tabular}




\begin{tabular}{|c|c|c|c|c|}
\hline & $0 \%$ & $1 \%$ & $3 \%$ & $9 \%$ \\
\hline \multicolumn{5}{|l|}{ Female } \\
\hline \multicolumn{5}{|l|}{$\mathbf{n}$} \\
\hline Weeks 6-7 & 10 & 10 & 10 & 9 \\
\hline Weeks 12-13 & 10 & 10 & 10 & 10 \\
\hline Weeks 18-19 & 10 & 10 & 10 & 10 \\
\hline Weeks 24-25 & 8 & 9 & 10 & 10 \\
\hline \multicolumn{5}{|l|}{ Fat digested $(\%)$} \\
\hline Weeks 6-7 & $96.47 \pm 0.49$ & $95.53 \pm 1.30$ & $95.46 \pm 0.66$ & $83.23 \pm 2.69 * *$ \\
\hline Weeks $12-13$ & $97.12 \pm 1.58$ & $98.54 \pm 0.99$ & $97.27 \pm 1.16$ & $91.95 \pm 2.70$ \\
\hline Weeks 18-19 & $99.17 \pm 0.18$ & $97.52 \pm 0.50$ & $97.15 \pm 1.24$ & $89.61 \pm 2.53 * *$ \\
\hline Weeks 24-25 & $98.66 \pm 0.08$ & $97.68 \pm 0.39 * *$ & $96.79 \pm 0.49 * *$ & $86.73 \pm 1.55^{* *}$ \\
\hline \multicolumn{5}{|c|}{ Calcium absorbed (\%) } \\
\hline Weeks 6-7 & $31.44 \pm 2.35$ & $24.42 \pm 2.54$ & $24.36 \pm 2.50$ & $32.29 \pm 1.69$ \\
\hline Weeks 12-13 & $14.84 \pm 1.76$ & $17.03 \pm 3.11$ & $17.96 \pm 1.22$ & $23.02 \pm 2.39 *$ \\
\hline Weeks 18-19 & $8.96 \pm 3.00$ & $9.78 \pm 1.98$ & $0.47 \pm 3.37$ & $13.07 \pm 1.65$ \\
\hline Weeks 24-25 & $5.65 \pm 2.84$ & $9.23 \pm 2.74$ & $8.25 \pm 1.59$ & $14.50 \pm 1.40^{*}$ \\
\hline \multicolumn{5}{|l|}{ Fecal weight (g) } \\
\hline Weeks 6-7 & $14.37 \pm 0.91$ & $15.76 \pm 0.60$ & $19.85 \pm 1.64 * *$ & $32.61 \pm 1.67 * * \mathrm{~b}$ \\
\hline Weeks $12-13$ & $15.37 \pm 0.60$ & $18.41 \pm 1.28 *$ & $21.11 \pm 1.07 * *$ & $30.83 \pm 2.78 * *$ \\
\hline Weeks 18-19 & $16.30 \pm 0.86$ & $19.23 \pm 0.97 *$ & $25.21 \pm 1.42 * *$ & $36.58 \pm 2.41 * *$ \\
\hline Weeks 24-25 & $16.01 \pm 0.92^{\mathrm{b}}$ & $20.66 \pm 1.14^{* *}$ & $24.85 \pm 1.19 * *$ & $35.78 \pm 2.27 * *$ \\
\hline \multicolumn{5}{|c|}{ Fecal moisture $(\%)$} \\
\hline Weeks 6-7 & $45.3 \pm 1.1$ & $45.3 \pm 0.4$ & $47.3 \pm 0.8$ & $50.0 \pm 0.9 * * \mathrm{~b}$ \\
\hline Weeks $12-13$ & $45.9 \pm 0.7$ & $47.5 \pm 1.0$ & $49.3 \pm 0.5^{* *}$ & $52.7 \pm 1.0 * *$ \\
\hline Weeks 18-19 & $46.1 \pm 1.1$ & $47.2 \pm 0.4$ & $49.5 \pm 0.9 * *$ & $53.0 \pm 0.7 * *$ \\
\hline Weeks 24-25 & $47.2 \pm 0.6^{\mathrm{b}}$ & $48.4 \pm 1.4$ & $49.2 \pm 0.6$ & $52.6 \pm 0.9^{* *}$ \\
\hline
\end{tabular}

*Significantly different $(\mathrm{P} \leq 0.05)$ from the control group by Shirley's test.

$* * \mathrm{P} \leq 0.01$.

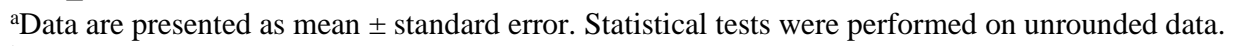

${ }^{\mathrm{b}} \mathrm{n}=10$.

Bone parameters in Groups A and B rats were generally unaffected by chitosan exposure (Table C-2). Bone moisture was significantly increased, relative to the control group, in 9\% females $(7 \%)$.

The absolute and relative liver weights of Group A 9\% males and females were significantly less (22\% and $21 \%$ lower, respectively) than those of the respective control groups (Table 7 and Table D-1). The absolute and relative thymus weights of Group A 3\% and 9\% males and 9\% females were significantly less than those of the controls (Table D-1). 
There was a significant decrease in the incidence of periportal fatty change of the liver in Group A female rats in the 9\% group compared to the control group and decreases in $1 \%$ and $3 \%$ females that resulted in a negative trend (Table 7 and Table A-2). In male rats, there were decreases in the incidences of periportal fatty change in the $1 \%$ and $9 \%$ groups, and the severities were decreased in the 3\% and $9 \%$ groups (Table 7 and Table A-1). Fatty change was characterized by hepatocytes with clear vacuoles (lipid), mostly located within the periportal region of the liver (zone 1) (Figure 3).

Table 7. Liver Parameter Data for Group A Rats in the Six-month Feed Study of Chitosan

\begin{tabular}{|c|c|c|c|c|}
\hline & $0 \%$ & $1 \%$ & $3 \%$ & $9 \%$ \\
\hline \multicolumn{5}{|l|}{ Male } \\
\hline $\mathbf{n}^{\mathrm{a}}$ & 10 & 10 & 10 & 10 \\
\hline Necropsy body wt & $669 \pm 20$ & $702 \pm 21$ & $687 \pm 23$ & $612 \pm 17$ \\
\hline \multicolumn{5}{|l|}{ Liver weight ${ }^{\mathrm{b}}$} \\
\hline Absolute & $25.19 \pm 0.87$ & $24.87 \pm 1.35$ & $23.74 \pm 1.51$ & $19.53 \pm 0.71^{\# \#}$ \\
\hline Relative & $37.662 \pm 0.731$ & $35.321 \pm 1.179$ & $34.345 \pm 1.411^{\#}$ & $31.933 \pm 0.817^{\# \#}$ \\
\hline Periportal, Fatty Change ${ }^{c}$ & $6(1.7)^{\mathrm{d}}$ & $3(1.7)$ & $6(1.3)$ & $3(1.0)$ \\
\hline
\end{tabular}

Female

\begin{tabular}{lcccc}
$\mathbf{n}$ & 10 & 10 & 10 & 10 \\
\hline Necropsy body wt & $338 \pm 11$ & $335 \pm 13$ & $328 \pm 11$ & $301 \pm 13$ \\
Liver weight & & & & \\
$\quad$ Absolute & $12.54 \pm 0.82$ & $12.47 \pm 0.39$ & $11.85 \pm 0.29$ & $9.85 \pm 0.20^{\# \#}$ \\
$\quad$ Relative & $36.900 \pm 1.502$ & $37.341 \pm 0.444$ & $36.346 \pm 0.904$ & $33.036 \pm 0.910^{\#}$ \\
Periportal, Fatty Change & $7(1.1)$ & $4(1.0)$ & $4(1.0)$ & $0^{* *}$ \\
\hline
\end{tabular}

"Significantly different $(\mathrm{P} \leq 0.05)$ from the control group by Williams' or Dunnett's test.

\#\#Significantly different $(\mathrm{P} \leq 0.01)$ from the control group by Williams' test.

**Significantly different $(\mathrm{P} \leq 0.01)$ from the control group by the Fisher exact test.

${ }^{a}$ Number of animals with liver weighed and with liver examined microscopically.

${ }^{b}$ Liver weights (absolute weights) and body weights are given in grams; Liver-weight-to-body-weight ratios (relative weights) are given as $\mathrm{mg}$ liver weight/g body weight (mean \pm standard error).

cNumber of animals with lesion.

${ }^{\mathrm{d}}$ Average severity grade of lesions in affected animals: $1=$ minimal, $2=$ mild, $3=$ moderate, $4=$ marked.

Hepatocytes contained large, well-defined, single round vacuoles (macrovesicular) within each cell that displaced the nuclei and cytoplasm to the cell periphery (Figure 4) and can be compared with a liver lacking fatty change (Figure 5). 


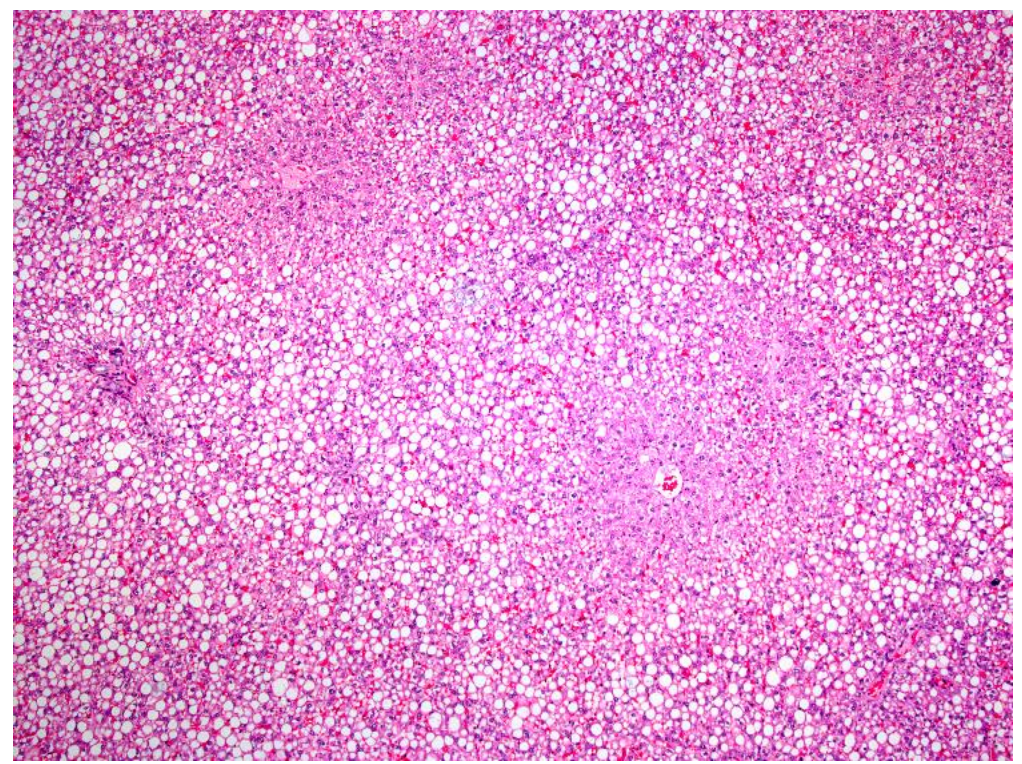

Figure 3. Section of the Liver from a Control Male Sprague Dawley Rat from the Six-month Feed Study of Chitosan with a Moderate Degree of Fatty Change (H\&E)

There is a predominant periportal distribution of affected hepatocytes.

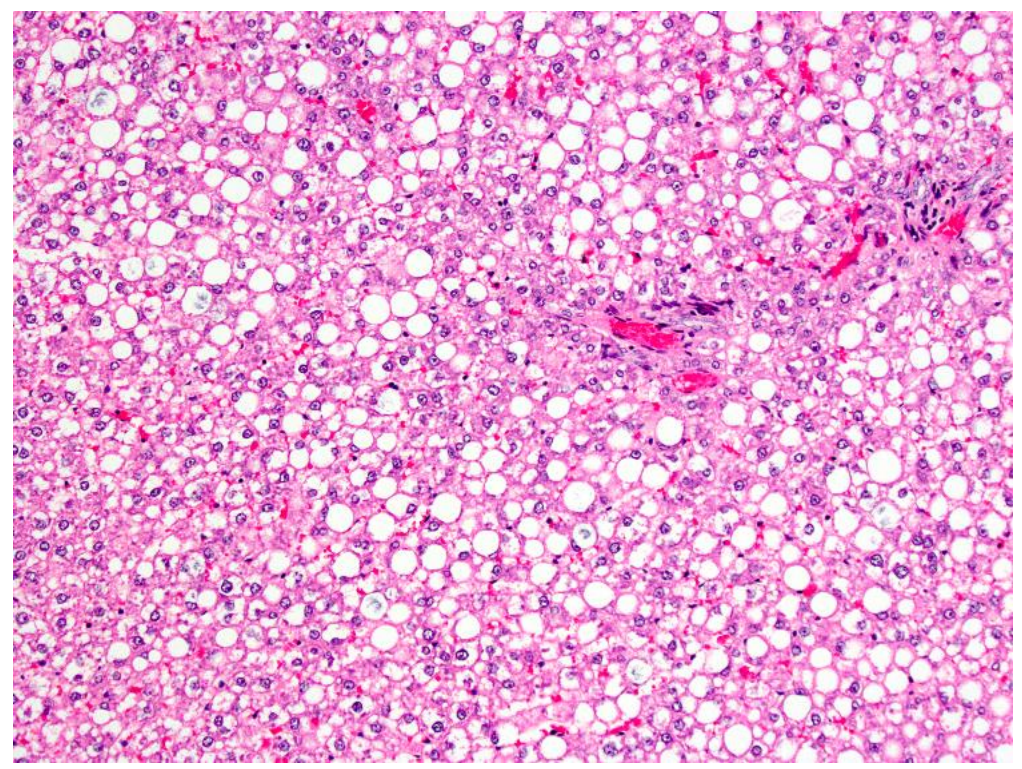

Figure 4. Higher Magnification of Figure $3(\mathrm{H} \& \mathrm{E})$

The fatty change is characterized by round, discrete vacuoles within hepatocytes that displace the nuclei and cytoplasm to the periphery. 


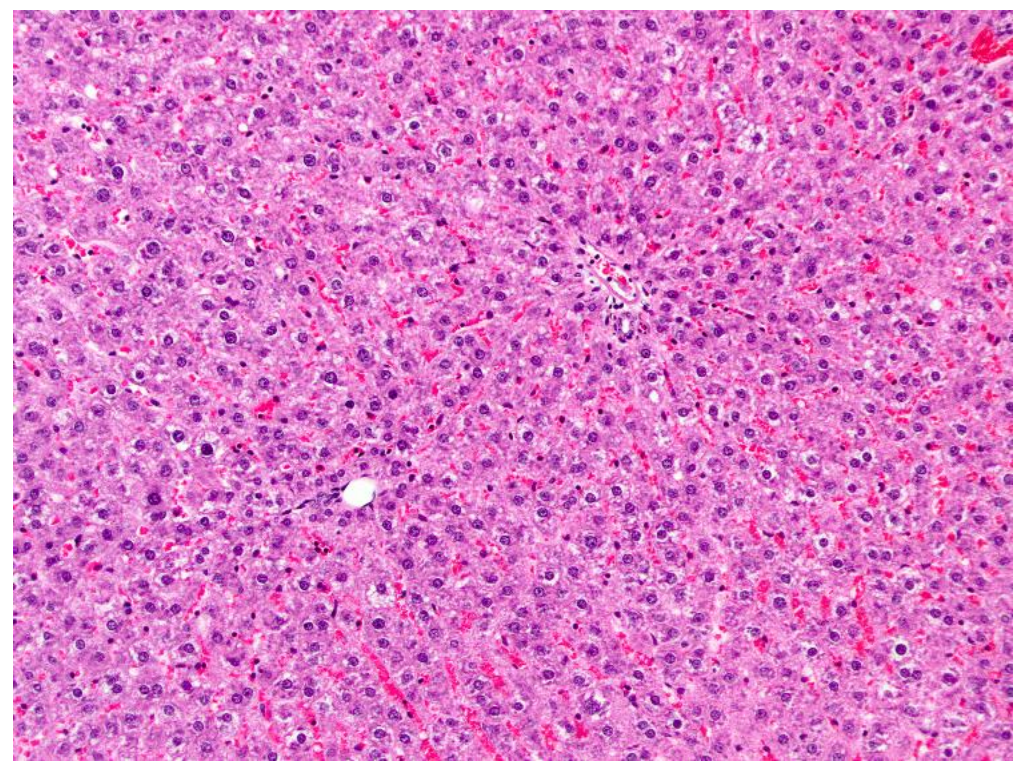

Figure 5. Section of the Liver with a Lack of Fatty Change from a Male Sprague Dawley Rat Exposed to 9\% Chitosan in Feed for Six Months (H\&E)

There is some minimal vacuolization within many hepatocytes. The vacuoles lack distinct round borders and the nuclei are centrally located, consistent with glycogen accumulation. 


\section{Discussion}

Human exposure to chitosan occurs primarily through consumption of dietary supplements, as chitosan is marketed as a fiber-like supplement to increase satiation and promote weight loss through inhibition of fat absorption ${ }^{16}$. The acute toxicity of chitosan has previously been examined in human studies (12 days or up to 8 weeks) evaluating the effectiveness of chitosan as a weight-loss supplement, and the results from these studies demonstrated no observable toxicity following oral administration of chitosan ${ }^{32-34}$. However, there is indication of serum vitamin and bone mineral depletion following consumption of chitosan in rats ${ }^{26}$. Therefore, NTP conducted 6-month feed studies to evaluate the effects of dietary chitosan on bone metabolism, fat-soluble vitamin levels, and dietary fat and calcium absorption, as well as general toxicity in Charles River Sprague Dawley rats.

Feed concentrations of $1 \%, 3 \%$, and $9 \%$ chitosan, which resulted in average daily doses of approximately $450,1,500$, and 5,200 $\mathrm{mg}$ chitosan/kg body weight per day to males and 650 , 1,800 , and $6,000 \mathrm{mg} / \mathrm{kg}$ per day to females, were selected based on existing data from animal studies $^{24 ; 26}$. The 9\% concentration is higher than the typical 5\% NTP concentration limit, but the $9 \%$ diet was considered to be nutritionally adequate. The AIN-93M feed was selected for this study over the NTP-2000 feed based on the high levels of fat-soluble vitamins and higher total fat content found in the NTP-2000 feed. The NTP-2000 feed contains almost double the amount of required fat-soluble vitamins and has a higher fat content $(7 \%$ to $8 \%)$ than the AIN-93M feed $(4 \%)^{41 ; 42}$. One of the primary rationales for this chitosan study was the potential for decreases in fat-soluble vitamin concentrations, and therefore utilizing a diet with lower levels of preexisting vitamins and a lower fat content was ideal to avoid confounding potential results.

The animals used in this study were split into three groups, the core group, Group A, and two special study groups, Groups B and C. Different parameters were evaluated in each group, which, while allowing for the collection of extensive endpoints, meant that only 10 animals were examined per endpoint instead of 30, as there was no crossover of analyses between the groups.

Multiple endpoints were evaluated at multiple time points $(6,12,18$, and 24 weeks) in Group C rats to determine effects on fat absorption. Treatment-related decreases in percentage fat digestion of $20 \%$ to $33 \%$ in males and $5 \%$ to $14 \%$ in females relative to control, were consistently observed in the $9 \%$ group with effects also noted in males in the $3 \%$ group (decreases of $2 \%$ to $8 \%$ ). Stronger responses were observed in males relative to females. Additionally, fecal weight was significantly increased in 1\% females at weeks 12, 18, and 24 $(19 \%, 18 \%$, and $29 \%$, respectively), and in 3\% (35\% to 56\%) and $9 \%$ (96\% to $170 \%)$ males and females relative to controls at all time points. These data suggest that consumption of chitosan reduced the absorption of fat in the feed, resulting in increased fecal weight due to fat being excreted. Similar results have been observed in other studies. Deuchi et al. ${ }^{55}$ reported that rats fed deacetylated chitosan had decreased fat digestion; as the degree of deacetylation increased, fat digestibility decreased. The chitosan used by Deuchi et al. ${ }^{55}$ was $70 \%$ to $90 \%$ deacetylated, which is a level very similar to the chitosan ( $86.5 \%$ deacetylated) used in the current study. Gallaher et al. ${ }^{12}$ demonstrated that male Wistar rats exposed to $10 \%$ chitosan in AIN-93 feed had increased fecal fat excretion and dry fecal weight and decreased cholesterol absorption relative to control rats, similar to what was observed in the current study. 
Due to the high percentage of chitosan in the feed of the $9 \%$ group, it is possible that the observed decreases in percentage fat digested were due to bulk chitosan in the feces confounding the amount of fat actually being excreted. Misrepresented fecal weights would alter the calculated amount of fat excreted in the feces, which would subsequently affect the calculation of percentage fat digested. The observed increases in fecal weight could also be attributed to an increase in the percentage fecal moisture, which was significantly increased in both males and females in the 3\% and 9\% groups. In Group A, there were decreases, albeit not significant, in mean body weights of $9 \%$ males and females (decreases of $9 \%$ and $11 \%$, respectively), but overall there were no significant changes in the body weights of rats exposed to chitosan; the mean body weights of exposed animals were similar to those of control animals. Considering the large decrease in percent fat digested, combined with the significant increase in fecal weight observed in $9 \%$ males and females, it would be expected that mean body weights would significantly decrease due to more fat being excreted than digested. The slight mean body weight decrease observed in this study could be due in part to excretion of bulk chitosan, but regardless, the magnitude of increase in fecal fat excretion as well as the decrease in hepatic periportal fatty change still indicates a treatment-related response.

Consistent significant decreases in cholesterol levels were observed in $9 \%$ male and female rats; triglycerides levels were also affected but not as consistently as cholesterol. Decreases in cholesterol were consistent with many other studies and not an unexpected finding, as chitosan is well known to have a cholesterol lowering effect in rats ${ }^{14 ; 56-59}$. The mechanism by which chitosan lowers cholesterol is still controversial, but recent studies indicate that chitosan, acting as a weak anion exchange resin, reduces cholesterol by causing a decrease in its absorption in the small intestine and by inducing increases in bile acid excretion ${ }^{11-13}$. With bile acid excretion, plasma or liver cholesterol is utilized to maintain the bile acid pool ${ }^{12}$. Alternatively, the cholesterol lowering effects of chitosan may be related to an increase in viscosity of intestinal contents, which entrap fat and prevent lipolysis, or this mechanism may be in addition to chitosan's ability to bind bile acids ${ }^{13-15}$.

Along with an inhibition in dietary fat absorption and decreases in serum lipids there were also treatment-related decreases in the levels of fat-soluble vitamins A and E. Serum and liver vitamin E levels were substantially affected, being $62 \%$ to $87 \%$ lower in the $9 \%$ males and females. These findings are similar to those of Deuchi et al. ${ }^{26}$ where decreases in serum and liver vitamin E levels were observed after 14 days of consuming a 5\% chitosan feed. In this same study, liver vitamin A levels were decreased, but vitamin A serum levels were unchanged. Bile and lipids are needed for the absorption of dietary vitamins A and E, as both must be incorporated into intestinal micelles for their absorption ${ }^{60}$. Thus, it is highly plausible that the decrease in dietary fat absorption, including cholesterol, led to the decreases in serum and liver concentrations of these vitamins. It is also possible that, by some unknown mechanism, chitosan may enhance vitamin $\mathrm{A}$ or $\mathrm{E}$ requirements in the peripheral tissues.

There were no histologic changes associated with the observed decreases in vitamin levels; however, the decreases were significant enough to suggest nutritional inadequacies. The longterm effects of vitamin $A$ and vitamin E deficiencies are well-known ${ }^{60-63}$, and it is unknown what deficiency-related effects would have been observed had these decreased levels been maintained for a longer period of time. When circulating levels of vitamin E, specifically $\alpha$-tocopherol, are depleted, tissue damage can occur. Vitamin E depletion in humans has subsequently been correlated with anemia, disruption of normal growth, decreased responses to infection, and 
pregnancy concerns ${ }^{62}$. Vitamin $\mathrm{A}$ is essential in numerous biological processes and pathways, including growth, vision development, immune function, and metabolism. Severe vitamin A deficiency (VAD) results in disruption of normal tissue function and is associated with childhood blindness, anemia, and depressed responses to infection; VAD during a severe infection may result in death ${ }^{61-63}$. While the long-term effects of vitamin deficiency in rodents are not as well understood, the available literature on human deficiencies suggests that the decreases in vitamin $\mathrm{A}$ and $\mathrm{E}$ observed in this study may be detrimental over time.

In contrast to decreases in vitamins $\mathrm{A}$ and $\mathrm{E}, 1,25(\mathrm{OH})_{2}$ vitamin $\mathrm{D}$ (bioactive vitamin $\mathrm{D}$ ) levels were significantly elevated in $9 \%$ male and female rats. Vitamin D's main function is to help maintain normal calcium and phosphorus levels by regulating the intestinal absorption of these minerals from the diet. In addition to the increased 1,25 $(\mathrm{OH})_{2}$ vitamin D levels, significant decreases in serum phosphorus were also seen in male and female rats. Although intestinal absorption of phosphorus was not measured in this study, chitosan has been observed by others to cause a significant reduction in intestinal phosphorus absorption ${ }^{64}$. Low phosphorus concentrations stimulate 1,25 $(\mathrm{OH})_{2}$ vitamin D production by the kidney, therefore the increased levels of $1,25(\mathrm{OH})_{2}$ vitamin $\mathrm{D}$ observed in this study may be the result of the low phosphorus levels. Increased levels of 1,25 $(\mathrm{OH})_{2}$ vitamin D can cause an increase in intestinal absorption of calcium regardless of serum calcium levels. Significant elevation in intestinal absorption of calcium was observed sporadically in the female rats, but serum calcium levels were relatively stable. This effect is most likely due to a loss of calcium through the urine, which has been observed in other chitosan feed studies ${ }^{64 ; 65}$ and is known to occur in cases of hypophosphatemiainduced elevations in $1,25(\mathrm{OH})_{2}$ vitamin D due to Fanconi's syndrome ${ }^{66}$. The reported urinary calcium loss in chitosan feed studies may be compensatory or directly induced by the chitosan.

Significant decreases in urine volume were observed in various male and female groups, but most consistently in the $9 \%$ group where decreases of $40 \%$ to $58 \%$ of the control group volume were observed. As the urine volumes decreased, urine creatinine concentrations were seen to increase significantly. This is consistent with proper renal function. The most likely cause of the decrease in urine volume is decreased consumption of water, although water consumption was not measured, so this cannot be certain. However, the mild increases in urea nitrogen in the 9\% male and female rats at 25 weeks (the only time point measured) supports decreased water consumption (i.e., mild dehydration). Water retention in the intestine may have contributed to the decreases in urine volume, as fecal moisture was mildly increased in some of the treatment groups, although it is highly unlikely this would be the primary cause and no diarrhea was observed.

There was a significant decrease in the occurrence of periportal fatty change, or lipid accumulation, in the livers of $9 \%$ females relative to the controls, and this negative trend was maintained in both $1 \%$ and $3 \%$ females, although not significantly. In male rats, the incidences of periportal fatty change were decreased in both $1 \%$ and $9 \%$ groups and the severities were decreased in both the 3\% and 9\% groups. The decrease in lipid accumulation was inconsistent between male and female rats in the $9 \%$ exposure groups, as a more severe decrease was observed in the $9 \%$ female rats (100\% lower) compared to the $9 \%$ male rats (50\% lower) relative to the respective controls. The morphologic features observed during this study (periportal hepatocytes with large, single, well-defined intracytoplasmic vacuoles displacing the nucleus), were consistent with the intracytoplasmic lipid accumulation that is associated with fatty change ${ }^{67}$. During normal function, fatty acids circulate between the liver and adipose tissue, 
which maintains a balance of triglycerides between the two locations. When this balance becomes skewed, hepatic fatty acids can accumulate as small vacuoles in the hepatocytes and progress over time into larger globules ${ }^{67 ; 68}$.

Lipid accumulation in the liver can occur via multiple mechanisms, including 1) increased synthesis of fatty acids, 2) increased uptake of fatty acids from adipose tissue and/or the diet, 3) improper removal of fatty acids from the liver, or 4 ) decreased oxidation of fatty acids ${ }^{69}$. Diet and nutritional status can also influence lipid accumulation ${ }^{68 ; 70}$. Singh et al. ${ }^{71}$ demonstrated that albino rats administered vitamin A orally for 2 days had increased hepatic lipid accumulation. In the present study, there were treatment-related decreases in hepatic vitamin A and $\mathrm{E}$ in both male and female rats, which could have contributed to the loss of periportal lipid accumulation observed in the animals fed 9\% chitosan. Lipid accumulation in the liver can also occur due to imbalanced uptake of lipids from the blood and secretion of lipoproteins from the hepatocytes ${ }^{72}$. In this chitosan study, the fatty change (lipid accumulation) observed was periportal, or in Zone 1 . Zone 1 is closest to the incoming vasculature and receives the majority of oxygenated blood, and Zone 1 hepatocytes are generally resistant to the effects of nutritional deficiencies ${ }^{73}$. Therefore, the decrease in fatty change observed in rats fed $9 \%$ chitosan could be an adaptive response to the vitamin and mineral depletion noted in this study.

The incidences and severities of fatty change in both male and female control animals was particularly high (6/10, males; 7/10, females; average severity 1.7 and 1.1, respectively), suggesting that the Charles River Sprague Dawley rats used in this study may have a normally high level of hepatic periportal lipid accumulation. Figure 3, Figure 4, and Figure 5, included in this report, are well representative of the observations made in this study, as the increased severity of periportal fatty change in control animals was a strong response.

Absolute and relative liver weights of male and female rats were significantly decreased in animals fed 9\% chitosan relative to control animals. As described above, there were decreases in the incidence of periportal fatty change in all exposed animals, particularly in the female rats fed 9\% chitosan. The decrease in liver weights observed in the 9\% animals could be due to the loss of fat accumulation in the livers, which would alter the weight of the organs.

The absolute and relative thymus weights of 3\% and 9\% males and 9\% females were also significantly decreased relative to those of control groups. The thymus is extremely sensitive to toxic compounds and similar stressors, and alterations in thymus weight can be an indicator of apoptosis and organ atrophy in response to a toxic insult. Nutritional status can cause a decrease in thymus weight, in particular vitamin, mineral, and fatty acid deficiencies ${ }^{74}$. In the current study, male and female rats fed $9 \%$ chitosan had depleted levels of serum vitamin A and E, liver vitamin $\mathrm{E}$, and serum cholesterol and triglycerides, indicating nutritional inadequacies. The observations from this chitosan study, combined with what is known about the thymus, suggest that exposure to chitosan may have induced reductions in thymus weight secondary to nutritional deficiencies.

Results of this study did not support chitosan as a cause of bone resorption. Significant elevation of parathyroid hormone levels occurred occasionally and inconsistently, while calcium levels were relatively stable. Calcium was mildly, but significantly, decreased at only two time points in male groups by no more than $4 \%$. Additionally, serum total osteocalcin and urinary deoxypyridinoline level, both biomarkers of bone turnover, while occasionally significantly 
elevated, lacked any consistent increases over time or between sexes. In fact, deoxypyridinoline was significantly decreased at some time points. Lastly, bone calcium, bone length, and the histology findings of this study did not support calcium loss from the bone.

Although bone parameters were unaffected by chitosan exposure, a limitation of this study may be that the time frame of the study was not extensive enough to adequately evaluate bone loss. Rats are generally not considered skeletally mature until 10 months of age, and the long bones in rats can continue to grow until 30 months of age, making it difficult to observe any loss of bone before that point ${ }^{75}$. In a study of female Charles River Sprague Dawley rats, Wronski et al. ${ }^{76}$ observed closed growth plates in the tibias of 15-month-old animals. In a separate study, Fukuda and Iida ${ }^{77}$ noted that natural decreases in bone mineral density did not begin until 15 months of age in female Wistar rats. Also, standard osteoporosis studies using rat models commonly utilize ovariectomized animals, which mimics the conditions of menopause and generally increases rates of bone remodeling and bone loss. Ovariectomized SHRSP rats fed 10\% chitosan alongside a low calcium diet exhibited decreased bone mineral density and increased femur stiffness ${ }^{64}$. Following ovariectomy, bone loss in the femurs, specifically the femoral neck, is still not observed until a minimum of 30 days postprocedure ${ }^{75}$. Therefore, given the time frame of the study there was reduced likelihood of observing any osteologic changes possibly induced by chitosan exposure.

There were no treatment-related clinical findings in the core, Group A animals, but there were instances of seizures in Groups B and C animals. Thirteen animals from Groups B and C (two $1 \%$, one $3 \%$, and ten $9 \%$ ) were observed with seizures either during or after the 18 -week blood collection. Seizures were not noted at any other time point. Similarly, there was no treatmentrelated mortality in the Group A animals, but five animals from Groups B and C died, often after seizures, near the time of blood collection. Cause of death was undetermined for these animals. While there was no clear connection between chitosan treatment and the incidence of seizures, there was an exposure concentration-related increase in the occurrence of seizures. Therefore, it is possible that chitosan exposure may have induced the increased rate of seizures observed in this study.

Under the conditions of the 6-month feed study of chitosan, male and female rats fed 3\% and 9\% chitosan in the diet had significantly decreased levels of serum vitamin A and serum and hepatic vitamin $E$ and increased levels of serum 1,25 $(\mathrm{OH})_{2}$ vitamin D. Consumption of high levels of chitosan decreased percentage fat digestion and increased fecal weight and moisture, as well as reduced levels of phosphorous, cholesterol, and triglycerides. Female rats exposed to 9\% chitosan also had significant liver weight and histologic changes. Based on the above results, the lowest-observed-effect level for chitosan exposure was 1\% (approximately equivalent to $450 \mathrm{mg} / \mathrm{kg}$ ) in male and $9 \%$ (approximately equivalent to $6,000 \mathrm{mg} / \mathrm{kg}$ ) in female rats. 


\section{References}

1. Kean T, Thanou M. Biodegradation, biodistribution and toxicity of chitosan. Adv Drug Del Rev. 2010; 62(1):3-11. http://dx.doi.org/10.1016/j.addr.2009.09.004

2. Rinaudo M. Chitin and chitosan: Properties and applications. Prog Polym Sci. 2006;

31(7):603-632. http://dx.doi.org/10.1016/j.progpolymsci.2006.06.001

3. Kubota N, Eguchi Y. Facile preparation of water-soluble N-acetylated chitosan and molecular weight dependence of its water-solubility. Polym J. 1997; 29(2):123.

http://dx.doi.org/10.1295/polymj.29.123

4. Peniston Q, Johnson E, inventors. Process for the manufacture of chitosan. United States patent $4,195,175 ; 1980$.

5. Hirano S. Chitin biotechnology applications. Biotechnol Annu Rev. 1996; 2:237-258. http://dx.doi.org/10.1016/S1387-2656(08)70012-7

6. Wedmore I, McManus JG, Pusateri AE, Holcomb JB. A special report on the chitosan-based hemostatic dressing: Experience in current combat operations. J Trauma Acute Care Surg. 2006; 60(3):655-658. http://dx.doi.org/10.1097/01.ta.0000199392.91772.44

7. Songjiang Z, Lixiang W. Amyloid-beta associated with chitosan nano-carrier has favorable immunogenicity and permeates the BBB. AAPS PharmSciTech. 2009; 10(3):900. http://dx.doi.org/10.1208/s12249-009-9279-1

8. Felt O, Buri P, Gurny R. Chitosan: A unique polysaccharide for drug delivery. Drug Dev Ind Pharm. 1998; 24(11):979-993. http://dx.doi.org/10.3109/03639049809089942

9. Lang G, Wendel H, Konrad E, inventors. Cosmetics composition based upon chitosan derivatives, new chitosan derivatives as well as processes for production thereof. United States patent $4,528,283 ; 1985$.

10. Carvalho T, Lussi A. Combined effect of a fluoride-, stannous-and chitosan-containing toothpaste and stannous-containing rinse on the prevention of initial enamel erosion-abrasion. $\mathbf{J}$ Dent. 2014; 42(4):450-459. http://dx.doi.org/10.1016/j.jdent.2014.01.004

11. Ebihara K, Schneeman BO. Interaction of bile acids, phospholipids, cholesterol and triglyceride with dietary fibers in the small intestine of rats. J Nutr. 1989; 119(8):1100-1106. http://dx.doi.org/10.1093/jn/119.8.1100

12. Gallaher CM, Munion J, Hesslink Jr R, Wise J, Gallaher DD. Cholesterol reduction by glucomannan and chitosan is mediated by changes in cholesterol absorption and bile acid and fat excretion in rats. J Nutr. 2000; 130(11):2753-2759. http://dx.doi.org/10.1093/jn/130.11.2753

13. Liu J, Zhang J, Xia W. Hypocholesterolaemic effects of different chitosan samples in vitro and in vivo. Food Chem. 2008; 107(1):419-425.

http://dx.doi.org/10.1016/j.foodchem.2007.08.044 
14. Ikeda I, Sugano M, Yoshida K, Sasaki E, Iwamoto Y, Hatano K. Effects of chitosan hydrolyzates on lipid absorption and on serum and liver lipid concentration in rats. J Agric Food Chem. 1993; 41(3):431-435. http://dx.doi.org/10.1021/jf00027a016

15. Kanauchi O, Deuchi K, Imasato Y, Shizukuishi M, Kobayashi E. Mechanism for the inhibition of fat digestion by chitosan and for the synergistic effect of ascorbate. Biosci Biotechnol Biochem. 1995; 59(5):786-790. http://dx.doi.org/10.1271/bbb.59.786

16. General Nutrition Centers Inc. GNC Total LeanTM chitosan with glucomannan. 2015. http://www.gnc.com/GNC-Total-Lean-Chitosan-withGlucomannan/product.jsp?productId=2459379 [Accessed: June, 2016]

17. Vitamin World Inc. Chitosan 500 mg. 2015. http://www.vitaminworld.com/fiber/chitosan500mg-0070004945.html [Accessed: June, 2016]

18. Chae SY, Jang M-K, Nah J-W. Influence of molecular weight on oral absorption of water soluble chitosans. J Control Release. 2005; 102(2):383-394.

http://dx.doi.org/10.1016/j.jconrel.2004.10.012

19. Yang Y, Hu W, Wang X, Gu X. The controlling biodegradation of chitosan fibers by Nacetylation in vitro and in vivo. J Mater Sci Mater Med. 2007; 18(11):2117-2121. http://dx.doi.org/10.1007/s10856-007-3013-x

20. Funkhouser JD, Aronson NN. Chitinase family GH18: Evolutionary insights from the genomic history of a diverse protein family. BMC Evol Biol. 2007; 7(1):96. http://dx.doi.org/10.1186/1471-2148-7-96

21. Qin C, Gao J, Wang L, Zeng L, Liu Y. Safety evaluation of short-term exposure to chitooligomers from enzymic preparation. Food Chem Toxicol. 2006; 44(6):855-861. http://dx.doi.org/10.1016/i.fct.2005.11.009

22. Vahouny GV, Satchithanandam S, Cassidy MM, Lightfoot FB, Furda I. Comparative effects of chitosan and cholestyramine on lymphatic absorption of lipids in the rat. Am J Clin Nutr. 1983; 38(2):278-284. http://dx.doi.org/10.1093/ajcn/38.2.278

23. Fukada Y, Kimura K, Ayaki Y. Effect of chitosan feeding on intestinal bile acid metabolism in rats. Lipids. 1991; 26(5):395-399.

24. Landes D, Bough W. Effects of chitosan - a coagulating agent for food processing wastesin the diets of rats on growth and liver and blood composition. Bull Environ Contam Toxicol. 1976; 15(5):555-563. http://dx.doi.org/10.1007/BF01685704

25. Tanaka Y, Tanioka S-i, Tanaka M, Tanigawa T, Kitamura Y, Minami S, Okamoto Y, Miyashita M, Nanno M. Effects of chitin and chitosan particles on BALB/c mice by oral and parenteral administration. Biomaterials. 1997; 18(8):591-595. http://dx.doi.org/10.1016/S0142$\underline{9612(96) 00182-2}$

26. Deuchi K, Kanauchi O, Shizukuishi M, Kobayashi E. Continuous and massive intake of chitosan affects mineral and fat-soluble vitamin status in rats fed on a high-fat diet. Biosci Biotechnol Biochem. 1995; 59(7):1211-1216. http://dx.doi.org/10.1271/bbb.59.1211 
27. Fukui K, Nakamura K, Shirai M, Hirano A, Takatsu H, Urano S. Long-term vitamin Edeficient mice exhibit cognitive dysfunction via elevation of brain oxidation. J Nutr Sci Vitaminol (Tokyo). 2015; 61(5):362-368. http://dx.doi.org/10.3177/jnsv.61.362

28. Oliveros LB, Domeniconi MA, Vega VA, Gatica LV, Brigada AM, Gimenez MS. Vitamin A deficiency modifies lipid metabolism in rat liver. Br J Nutr. 2007; 97(2):263-272. http://dx.doi.org/10.1017/S0007114507182659

29. Naito Y, Tago K, Nagata T, Furuya M, Seki T, Kato H, Morimura T, Ohara N. A 90-day ad libitum administration toxicity study of oligoglucosamine in F344 rats. Food Chem Toxicol. 2007; 45(9):1575-1587. http://dx.doi.org/10.1016/j.fct.2007.02.018

30. Hirano S, Iwata M, Yamanaka K, Tanaka H, Toda T, Inui H. Enhancement of serum lysozyme activity by injecting a mixture of chitosan oligosaccharides intravenously in rabbits. Agric Biol Chem. 1991; 55(10):2623-2625. https://doi.org/10.1080/00021369.1991.10871007

31. Rao SB, Sharma CP. Use of chitosan as a biomaterial: Studies on its safety and hemostatic potential. J Biomed Mater Res. 1997; 34(1):21-28. http://dx.doi.org/10.1002/(SICI)10974636(199701)34:1<21::AID-JBM4>3.0.CO;2-P

32. Gades MD, Stern JS. Chitosan supplementation and fecal fat excretion in men. Obes Res. 2003; 11(5):683-688. http://dx.doi.org/10.1038/oby.2003.97

33. Gades MD, Stern JS. Chitosan supplementation and fat absorption in men and women. J Am Diet Assoc. 2005; 105(1):72-77. http://dx.doi.org/10.1016/j.jada.2004.10.004

34. Tapola NS, Lyyra ML, Kolehmainen RM, Sarkkinen ES, Schauss AG. Safety aspects and cholesterol-lowering efficacy of chitosan tablets. J Am Coll Nutr. 2008; 27(1):22-30. http://dx.doi.org/10.1080/07315724.2008.10719671

35. Takahashi M, Inoue K, Yoshida M, Morikawa T, Shibutani M, Nishikawa A. Lack of chronic toxicity or carcinogenicity of dietary $\mathrm{N}$-acetylglucosamine in F344 rats. Food Chem Toxicol. 2009; 47(2):462-471. http://dx.doi.org/10.1016/j.fct.2008.12.002

36. Cheng Q, Zhang J, Xia W. Prenatal and developmental effect of high molecular weight chitosan (HMWCS) to mice. Regul Toxicol Pharmacol. 2013; 65(3):294-303. http://dx.doi.org/10.1016/j.yrtph.2013.01.003

37. Hu Y-L, Qi W, Han F, Shao J-Z, Gao J-Q. Toxicity evaluation of biodegradable chitosan nanoparticles using a zebrafish embryo model. Int J Nanomed. 2011; 6:3351.

38. Domard A, Rinaudo M. Preparation and characterization of fully deacetylated chitosan. Int J Biol Macromol. 1983; 5(1):49-52. http://dx.doi.org/10.1016/0141-8130(83)90078-8

39. Hirai A, Odani H, Nakajima A. Determination of degree of deacetylation of chitosan by $1 \mathrm{H}$ NMR spectroscopy. Polym Bull. 1991; 26(1):87-94. http://dx.doi.org/10.1007/BF00299352

40. Reeves PG, Nielsen FH, Fahey Jr GC. AIN-93 purified diets for laboratory rodents: Final report of the American Institute of Nutrition ad hoc writing committee on the reformulation of the AIN-76A rodent diet. J Nutr. 1993; 123:1939-1951. http://dx.doi.org/10.1093/jn/123.11.1939 
41. Rao GN. New nonpurified diet (NTP-2000) for rodents in the National Toxicology Program's toxicology and carcinogenesis studies. J Nutr. 1997; 127(5):842S-846S.

http://dx.doi.org/10.1093/jn/127.5.842S

42. Reeves PG. Components of the AIN-93 diets as improvements in the AIN-76A diet. J Nutr. 1997; 127(5):838S-841S. http://dx.doi.org/10.1093/jn/127.5.838S

43. Maronpot R, Boorman G. Interpretation of rodent hepatocellular proliferative alterations and hepatocellular tumors in chemical safety assessment. Toxicol Pathol. 1982; 10(2):71-78. http://dx.doi.org/10.1177/019262338201000210

44. Boorman GA, Montgomery CA, Jr., Eustis SL, Wolfe MJ, McConnell EE, Hardisty JF. Quality assurance in pathology for rodent carcinogenicity studies. In: Milman HA, Weisburger EK, editors. Handbook of Carcinogen Testing. Park Ridge, NJ: Noyes Publications; 1985. p. 345-357.

45. Gart JJ, Chu KC, Tarone RE. Statistical issues in interpretation of chronic bioassay tests for carcinogenicity. J Natl Cancer Inst. 1979; 62(4):957-974.

46. Dunnett CW. A multiple comparison procedure for comparing several treatments with a control. J American Stat Assoc. 1955; 50(272):1096-1121.

http://dx.doi.org/10.1080/01621459.1955.10501294

47. Williams D. A test for differences between treatment means when several dose levels are compared with a zero dose control. Biometrics. 1971; 27(1):103-117.

http://dx.doi.org/10.2307/2528930

48. Williams D. The comparison of several dose levels with a zero dose control. Biometrics. 1972; 28(2):519-531. http://dx.doi.org/10.2307/2556164

49. Shirley E. A non-parametric equivalent of Williams' test for contrasting increasing dose levels of a treatment. Biometrics. 1977; 33(2):386-389. http://dx.doi.org/10.2307/2529789

50. Williams D. A note on Shirley's nonparametric test for comparing several dose levels with a zero-dose control. Biometrics. 1986; 42(1):183-186. http://dx.doi.org/10.2307/2531254

51. Dunn OJ. Multiple comparisons using rank sums. Technometrics. 1964; 6(3):241-252. http://dx.doi.org/10.1080/00401706.1964.10490181

52. Jonckheere A. A distribution-free k-sample test against ordered alternatives. Biometrika. 1954; 41:133-145. http://dx.doi.org/10.1093/biomet/41.1-2.133

53. Dixon W, Massey F. Introduction to statistical analysis. New York, NY: McGraw Hill Book Company Inc; 1957. http://dx.doi.org/10.2307/2332898

54. Code of Federal Regulations (CFR). 21:Part 58.

55. Deuchi K, Kanauchi O, Imasato Y, Kobayashi E. Effect of the viscosity or deacetylation degree of chitosan on fecal fat excreted from rats fed on a high-fat diet. Biosci Biotechnol Biochem. 1995; 59(5):781-785. http://dx.doi.org/10.1271/bbb.59.781 
56. Sugano M, Fujikawa T, Hiratsuji Y, Hasegawa Y. Hypocholesterolemic effects of chitosan in cholesterol-fed rats. Nutr Rep Int. 1978; 18:531-537.

57. Sugano M, Fujikawa T, Hiratsuji Y, Nakashima K, Fukuda N, Hasegawa Y. A novel use of chitosan as a hypocholesterolemic agent in rats. Am J Clin Nutr. 1980; 33(4):787-793. http://dx.doi.org/10.1093/ajen/33.4.787

58. Chiang M-T, Yao H-T, Chen H-C. Effect of dietary chitosans with different viscosity on plasma lipids and lipid peroxidation in rats fed on a diet enriched with cholesterol. Biosci Biotechnol Biochem. 2000; 64(5):965-971. http://dx.doi.org/10.1271/bbb.64.965

59. Hossain S, Rahman A, Kabir Y, Shams A, Afros F, Hashimoto M. Effects of shrimp (Macrobracium rosenbergii)-derived chitosan on plasma lipid profile and liver lipid peroxide levels in normo- and hypercholesterolaemic rats. Clin Exp Pharmacol Physiol. 2007; 34:170-176. http://dx.doi.org/10.1111/j.1440-1681.2007.04568.x

60. Rucker R, Morris J, Fascetti A. Vitamins In: Kaneko J, Harvey J, Bruss M, editors. Clinical biochemistry of domestic animals. Burlington, MA: Academic Press; 2008. p. 695-730. http://dx.doi.org/10.1016/B978-0-12-370491-7.00023-4

61. Sommer A. Vitamin A deficiency and clinical disease: An historical overview. J Nutr. 2008; 138(10):1835-1839. http://dx.doi.org/10.1093/jn/138.10.1835

62. Traber MG. Vitamin E inadequacy in humans: Causes and consequences. Adv Nutr. 2014; 5(5):503-514. http://dx.doi.org/10.3945/an.114.006254

63. Wiseman EM, Bar-El Dadon S, Reifen R. The vicious cycle of vitamin A deficiency: A review. Crit Rev Food Sci Nutr. 2017; 57(17):3703-3714. http://dx.doi.org/10.1080/10408398.2016.1160362

64. Yang C-Y, Oh T-W, Nakajima D, Maeda A, Naka T, Kim C-S, Igawa S, Ohta F. Effects of habitual chitosan intake on bone mass, bone-related metabolic markers and duodenum $\mathrm{CaBP}$ D9K mRNA in ovariectomized SHRSP rats. J Nutr Sci Vitaminol (Tokyo). 2002; 48(5):371-378. http://dx.doi.org/10.3177/jnsv.48.371

65. Wada M, Nishimura Y, Watanabe Y, Takita T, Innami S. Accelerating effect of chitosan intake on urinary calcium excretion by rats. Biosci Biotechnol Biochem. 1997; 61(7):1206-1208. http://dx.doi.org/10.1271/bbb.61.1206

66. Tieder M, Arie R, Modai D, Samuel R, Weissgarten J, Liberman UA. Elevated serum 1, 25dihydroxyvitamin D concentrations in siblings with primary Fanconi's syndrome. N Engl J Med. 1988; 319(13):845-849. http://dx.doi.org/10.1056/NEJM198809293191307

67. Thoolen B, Maronpot RR, Harada T, Nyska A, Rousseaux C, Nolte T, Malarkey DE, Kaufmann W, Küttler K, Deschl U et al. Proliferative and nonproliferative lesions of the rat and mouse hepatobiliary system. Toxicol Pathol. 2010; 38(7_suppl):5S-81S.

http://dx.doi.org/10.1177/0192623310386499

68. Hassan K, Bhalla V, El Regal ME, A-Kader HH. Nonalcoholic fatty liver disease: A comprehensive review of a growing epidemic. World J Gastroenterol. 2014; 20(34):12082. http://dx.doi.org/10.3748/wjg.v20.i34.12082 
69. Sozio MS, Liangpunsakul S, Crabb D. The role of lipid metabolism in the pathogenesis of alcoholic and nonalcoholic hepatic steatosis. Semin Liver Dis. 2010; 30(04):378-390. http://dx.doi.org/10.1055/s-0030-1267538

70. Greaves P. Liver and pancreas In: Greaves P, editor. Histopatology of Preclinical Toxicity Studies, 3rd ed. Oxford, UK: Elsevier; 2007. p. 457-569. http://dx.doi.org/10.1016/B978$\underline{044452771-4 / 50010-9}$

71. Singh VN, Singh M, Venkitasubramanian T. Early effects of feeding excess vitamin A: Mechanism of fatty liver production in rats. J Lipid Res. 1969; 10(4):395-401.

72. Kucera O, Cervinkova Z. Experimental models of non-alcoholic fatty liver disease in rats. World J Gastroenterol. 2014; 20(26):8364. http://dx.doi.org/10.3748/wjg.v20.i26.8364

73. Jungermann K, Katz N. Functional specialization of different hepatocyte populations. Physiol Rev. 1989; 69(3):708-764. http://dx.doi.org/10.1152/physrev.1989.69.3.708

74. Pearse G. Histopathology of the thymus. Toxicol Pathol. 2006; 34(5):515-547. http://dx.doi.org/10.1080/01926230600978458

75. Lelovas PP, Xanthos TT, Thoma SE, Lyritis GP, Dontas IA. The laboratory rat as an animal model for osteoporosis research. Comp Med. 2008; 58(5):424-430.

76. Wronski T, Dann L, Scott K, Cintron M. Long-term effects of ovariectomy and aging on the rat skeleton. Calcif Tissue Int. 1989; 45(6):360-366. http://dx.doi.org/10.1007/BF02556007

77. Fukuda S, Iida H. Age-related changes in bone mineral density, cross-sectional area and the strength of long bones in the hind limbs and first lumbar vertebra in female Wistar rats. J Vet Med Sci. 2004; 66:755-760. 


\section{Appendix A. Summary of Lesions in Rats in the Six-month Feed Study of Chitosan}

\section{Tables}

Table A-1. Summary of the Incidence of Nonneoplastic Lesions in Group A Male Rats in the Six-month Feed Study of Chitosan

Table A-2. Summary of the Incidence of Neoplasms and Nonneoplastic Lesions in

Group A Female Rats in the Six-month Feed Study of Chitosan ..... A-4 
Table A-1. Summary of the Incidence of Nonneoplastic Lesions in Group A Male Rats in the Sixmonth Feed Study of Chitosan ${ }^{a}$

\begin{tabular}{|c|c|c|c|c|}
\hline & $0 \%$ & $1 \%$ & $3 \%$ & $9 \%$ \\
\hline \multicolumn{5}{|l|}{ Disposition Summary } \\
\hline Animals initially in study & 10 & 10 & 10 & 10 \\
\hline \multicolumn{5}{|l|}{ Survivors } \\
\hline Terminal euthanasia & 10 & 10 & 10 & 10 \\
\hline Animals examined microscopically & 10 & 10 & 10 & 10 \\
\hline \multicolumn{5}{|l|}{ Alimentary System } \\
\hline Liver & $(10)$ & $(10)$ & $(10)$ & $(10)$ \\
\hline Degeneration, cystic & 0 & 0 & 0 & $1(10 \%)$ \\
\hline Hematopoietic cell proliferation & $2(20 \%)$ & $3(30 \%)$ & $3(30 \%)$ & $6(60 \%)$ \\
\hline Inflammation, chronic active & $10(100 \%)$ & $10(100 \%)$ & $10(100 \%)$ & $9(90 \%)$ \\
\hline Periportal, fatty change & $6(60 \%)$ & $3(30 \%)$ & $6(60 \%)$ & $3(30 \%)$ \\
\hline Pancreas & (10) & (0) & (0) & $(10)$ \\
\hline Basophilic focus & $1(10 \%)$ & - & - & 0 \\
\hline Inflammation & $2(20 \%)$ & - & - & $1(10 \%)$ \\
\hline Stomach, forestomach & $(10)$ & (0) & (0) & $(10)$ \\
\hline Epithelium, hyperplasia & $3(30 \%)$ & - & - & $1(10 \%)$ \\
\hline \multicolumn{5}{|l|}{ Cardiovascular System } \\
\hline Blood vessel & (10) & (0) & (0) & (10) \\
\hline Inflammation & 0 & - & - & $1(10 \%)$ \\
\hline Heart & $(10)$ & (0) & (0) & (10) \\
\hline Cardiomyopathy & $5(50 \%)$ & - & - & $3(30 \%)$ \\
\hline Mineralization & 0 & - & - & $1(10 \%)$ \\
\hline \multicolumn{5}{|l|}{ Endocrine System } \\
\hline Adrenal cortex & (10) & (1) & (0) & (10) \\
\hline Vacuolization cytoplasmic & 0 & 0 & - & $1(10 \%)$ \\
\hline Parathyroid gland & $(10)$ & (10) & $(10)$ & (10) \\
\hline Hyperplasia & $1(10 \%)$ & 0 & 0 & 0 \\
\hline Pituitary gland & $(10)$ & (0) & (0) & $(10)$ \\
\hline Cyst & $1(10 \%)$ & - & - & 0 \\
\hline Thyroid gland & (10) & (0) & (0) & (10) \\
\hline C-cell, hyperplasia & 0 & - & - & $1(10 \%)$ \\
\hline \multicolumn{5}{|l|}{ General Body System } \\
\hline None & - & - & - & - \\
\hline
\end{tabular}


Chitosan, NTP TOX 93

\begin{tabular}{|c|c|c|c|c|}
\hline & $\mathbf{0 \%}$ & $1 \%$ & $3 \%$ & $9 \%$ \\
\hline \multicolumn{5}{|l|}{ Genital System } \\
\hline Preputial gland & $(10)$ & $(0)$ & $(0)$ & (10) \\
\hline Inflammation & 0 & - & - & $1(10 \%)$ \\
\hline Inflammation, chronic active & 0 & - & - & $2(20 \%)$ \\
\hline Prostate & (10) & (10) & (10) & (10) \\
\hline Inflammation & $8(80 \%)$ & $9(90 \%)$ & $10(100 \%)$ & $10(100 \%)$ \\
\hline Testes & (10) & (0) & $(0)$ & $(10)$ \\
\hline Mineralization & 0 & - & - & $1(10 \%)$ \\
\hline \multicolumn{5}{|l|}{ Hematopoietic System } \\
\hline Lymph node, mandibular & (10) & $(0)$ & $(0)$ & (10) \\
\hline Infiltration cellular, plasma cell & $1(10 \%)$ & - & - & $2(20 \%)$ \\
\hline Spleen & $(10)$ & (0) & $(0)$ & (10) \\
\hline Hematopoietic cell proliferation & $5(50 \%)$ & - & - & $2(20 \%)$ \\
\hline Thymus & $(10)$ & $(0)$ & $(0)$ & $(10)$ \\
\hline Atrophy & $1(10 \%)$ & - & - & 0 \\
\hline \multicolumn{5}{|l|}{ Integumentary System } \\
\hline Skin & (10) & $(0)$ & $(0)$ & $(10)$ \\
\hline Hemorrhage & 0 & - & - & $1(10 \%)$ \\
\hline Mineralization & 0 & - & - & $1(10 \%)$ \\
\hline Ulcer & 0 & - & - & $1(10 \%)$ \\
\hline \multicolumn{5}{|l|}{ Musculoskeletal System } \\
\hline Skeletal muscle & $(0)$ & $(0)$ & $(0)$ & (1) \\
\hline Inflammation, granulomatous & - & - & - & $1(100 \%)$ \\
\hline \multicolumn{5}{|l|}{ Nervous System } \\
\hline None & - & - & - & - \\
\hline \multicolumn{5}{|l|}{ Respiratory System } \\
\hline Lung & $(10)$ & $(0)$ & $(0)$ & (10) \\
\hline Hemorrhage & $2(20 \%)$ & - & - & 0 \\
\hline Inflammation, chronic active & $2(20 \%)$ & - & - & $4(40 \%)$ \\
\hline Nose & $(10)$ & $(0)$ & $(0)$ & $(10)$ \\
\hline Inflammation & $1(10 \%)$ & - & - & 0 \\
\hline Goblet cell, hyperplasia & 0 & - & - & $1(10 \%)$ \\
\hline Special Senses System & - & - & - & \\
\hline Eye & $(10)$ & (1) & $(0)$ & $(10)$ \\
\hline Choroid, fibrosis & 0 & $1(100 \%)$ & - & 0 \\
\hline Lens, cataract & 0 & $1(100 \%)$ & - & 0 \\
\hline
\end{tabular}


Chitosan, NTP TOX 93

\begin{tabular}{lcccc}
\hline & $\mathbf{0 \%}$ & $\mathbf{1 \%}$ & $\mathbf{3 \%}$ & $\mathbf{9 \%}$ \\
\hline Harderian gland & $(10)$ & $(0)$ & $(0)$ & $(10)$ \\
Hyperplasia & 0 & - & - & $1(10 \%)$ \\
Infiltration cellular, lymphocyte & $2(20 \%)$ & - & - & $1(10 \%)$ \\
\hline Urinary System & & & $(10)$ & $(10)$ \\
Kidney & $(10)$ & $(10)$ & $1(10 \%)$ & 0 \\
Infarct & 0 & 0 & $3(30 \%)$ & $5(50 \%)$ \\
Mineralization & $2(20 \%)$ & $4(40 \%)$ & $9(90 \%)$ & $9(90 \%)$ \\
Nephropathy & $9(90 \%)$ & $9(90 \%)$ & 0 & 0 \\
Cortex, cyst & $1(10 \%)$ & 0 & $1(10 \%)$ & 0 \\
$\begin{array}{l}\text { Pelvis, dilatation } \\
\text { Pelvis, inflammation }\end{array}$ & $2(20 \%)$ & 0 & 0 & 0 \\
$\begin{array}{l}\text { Urinary bladder } \\
\text { Transitional epithelium, } \\
\text { hyperplasia }\end{array}$ & $1(10 \%)$ & 0 & $(0)$ & $(10)$ \\
\hline anumber of animals examined microscopically at the site and the number of animals with lesion. & - & $1(10 \%)$
\end{tabular}

Table A-2. Summary of the Incidence of Neoplasms and Nonneoplastic Lesions in Group A Female Rats in the Six-month Feed Study of Chitosan ${ }^{a}$

\begin{tabular}{|c|c|c|c|c|}
\hline & $\mathbf{0 \%}$ & $1 \%$ & $3 \%$ & $9 \%$ \\
\hline \multicolumn{5}{|l|}{ Disposition Summary } \\
\hline Animals initially in study & 10 & 10 & 10 & 10 \\
\hline \multicolumn{5}{|l|}{ Survivors } \\
\hline Terminal euthanasia & 10 & 10 & 10 & 10 \\
\hline Animals examined microscopically & 10 & 10 & 10 & 10 \\
\hline \multicolumn{5}{|l|}{ Alimentary System } \\
\hline Liver & (10) & (10) & (10) & (10) \\
\hline Hematopoietic cell proliferation & $1(10 \%)$ & $1(10 \%)$ & $2(20 \%)$ & $1(10 \%)$ \\
\hline Inflammation, chronic active & $9(90 \%)$ & $9(90 \%)$ & $9(90 \%)$ & $10(100 \%)$ \\
\hline Periportal, fatty change & $7(70 \%)$ & $4(40 \%)$ & $4(40 \%)$ & 0 \\
\hline Pancreas & $(10)$ & (0) & $(0)$ & (10) \\
\hline Atrophy & 0 & - & - & $1(10 \%)$ \\
\hline Inflammation & $1(10 \%)$ & - & - & 0 \\
\hline Inflammation, chronic active & 0 & - & - & $1(10 \%)$ \\
\hline \multicolumn{5}{|l|}{ Cardiovascular System } \\
\hline Heart & (10) & (0) & (0) & (10) \\
\hline Cardiomyopathy & $1(10 \%)$ & - & - & 0 \\
\hline \multicolumn{5}{|l|}{ Endocrine System } \\
\hline Pituitary gland & (10) & (0) & (0) & (10) \\
\hline
\end{tabular}




\section{Chitosan, NTP TOX 93}

\begin{tabular}{|c|c|c|c|c|}
\hline & $0 \%$ & $1 \%$ & $3 \%$ & $9 \%$ \\
\hline Rathke's cleft, hyperplasia & $1(10 \%)$ & - & - & 0 \\
\hline \multicolumn{5}{|l|}{ General Body System } \\
\hline None & - & - & - & - \\
\hline \multicolumn{5}{|l|}{ Genital System } \\
\hline Clitoral gland & $(10)$ & $(0)$ & $(0)$ & $(10)$ \\
\hline Inflammation, chronic active & $2(20 \%)$ & - & - & 0 \\
\hline \multicolumn{5}{|l|}{ Hematopoietic System } \\
\hline Spleen & $(10)$ & $(0)$ & $(0)$ & $(10)$ \\
\hline Hematopoietic cell proliferation & $1(10 \%)$ & - & - & 0 \\
\hline Thymus & $(10)$ & $(0)$ & $(0)$ & $(10)$ \\
\hline Atrophy & $1(10 \%)$ & - & - & 0 \\
\hline \multicolumn{5}{|l|}{ Integumentary System } \\
\hline Mammary gland & $(10)$ & $(0)$ & $(0)$ & (10) \\
\hline Adenoma & 0 & - & - & $1(10 \%)$ \\
\hline \multicolumn{5}{|l|}{ Musculoskeletal System } \\
\hline None & - & - & - & - \\
\hline \multicolumn{5}{|l|}{ Nervous System } \\
\hline Brain & (10) & $(0)$ & $(0)$ & (10) \\
\hline Developmental malformation & $1(10 \%)$ & - & - & 0 \\
\hline \multicolumn{5}{|l|}{ Respiratory System } \\
\hline Lung & $(10)$ & $(0)$ & $(0)$ & (10) \\
\hline Mineralization & 0 & - & - & $1(10 \%)$ \\
\hline Alveolar epithelium, hyperplasia & 0 & - & - & $1(10 \%)$ \\
\hline $\begin{array}{l}\text { Alveolus, infiltration cellular, } \\
\text { histiocyte }\end{array}$ & $2(20 \%)$ & - & - & 0 \\
\hline Artery, mineralization & $1(10 \%)$ & - & - & $1(10 \%)$ \\
\hline Nose & $(10)$ & $(0)$ & (0) & (10) \\
\hline Goblet cell, hyperplasia & $1(10 \%)$ & - & - & 0 \\
\hline \multicolumn{5}{|l|}{ Special Senses System } \\
\hline Harderian gland & $(10)$ & $(0)$ & $(0)$ & $(10)$ \\
\hline Infiltration cellular, lymphocyte & $1(10 \%)$ & - & - & $1(10 \%)$ \\
\hline \multicolumn{5}{|l|}{ Urinary System } \\
\hline Kidney & $(10)$ & $(10)$ & $(10)$ & $(10)$ \\
\hline Mineralization & $8(80 \%)$ & $8(80 \%)$ & $5(50 \%)$ & $6(60 \%)$ \\
\hline Nephropathy & $5(50 \%)$ & $6(60 \%)$ & $5(50 \%)$ & 0 \\
\hline
\end{tabular}

${ }^{\mathrm{a} N u m b e r}$ of animals examined microscopically at the site and the number of animals with lesion. 
Chitosan, NTP TOX 93

\section{Appendix B. Clinical Pathology Results}

\section{Tables}

Table B-1. Hematology, Clinical Chemistry, and Urinalysis Data for Group C Rats in the Six-month Feed Study of Chitosan................................................................. 
Table B-1. Hematology, Clinical Chemistry, and Urinalysis Data for Group C Rats in the Sixmonth Feed Study of Chitosan ${ }^{a}$

\begin{tabular}{|c|c|c|c|c|}
\hline & $0 \%$ & $1 \%$ & $3 \%$ & $9 \%$ \\
\hline \multicolumn{5}{|l|}{ Male } \\
\hline \multicolumn{5}{|c|}{ Hematology } \\
\hline $\mathbf{n}$ & 10 & 10 & 10 & 10 \\
\hline \multicolumn{5}{|c|}{ Hematocrit (auto) (\%) } \\
\hline Week 25 & $45.5 \pm 0.4$ & $47.1 \pm 0.5$ & $46.3 \pm 0.4$ & $47.4 \pm 0.6^{*}$ \\
\hline \multicolumn{5}{|c|}{ Hematocrit (manual) (\%) } \\
\hline Week 25 & $47.2 \pm 0.5^{\mathrm{b}}$ & $48.2 \pm 0.5$ & $47.6 \pm 0.5$ & $48.9 \pm 0.6$ \\
\hline \multicolumn{5}{|c|}{ Hemoglobin (g/dL) } \\
\hline Week 25 & $14.9 \pm 0.2$ & $15.4 \pm 0.2$ & $15.2 \pm 0.1$ & $15.7 \pm 0.2^{* *}$ \\
\hline \multicolumn{5}{|c|}{ Erythrocytes $\left(10^{6} / \mu \mathrm{L}\right)$} \\
\hline Week 25 & $8.44 \pm 0.08$ & $8.59 \pm 0.12$ & $8.43 \pm 0.08$ & $8.45 \pm 0.12$ \\
\hline \multicolumn{5}{|c|}{ Reticulocytes $\left(10^{3} / \mu \mathrm{L}\right)$} \\
\hline Week 25 & $186.0 \pm 14.3$ & $138.4 \pm 6.3^{* *}$ & $157.7 \pm 7.2$ & $139.3 \pm 9.1 * *$ \\
\hline \multicolumn{5}{|c|}{ Mean cell volume (fL) } \\
\hline Week 25 & $53.9 \pm 0.4$ & $54.9 \pm 0.6$ & $54.9 \pm 0.2$ & $56.1 \pm 0.6^{*}$ \\
\hline \multicolumn{5}{|c|}{ Mean cell hemoglobin (pg) } \\
\hline Week 25 & $17.6 \pm 0.2$ & $18.0 \pm 0.2$ & $18.0 \pm 0.1$ & $18.6 \pm 0.2 * *$ \\
\hline \multicolumn{5}{|c|}{ Mean cell hemoglobin concentration $(\mathrm{g} / \mathrm{dL})$} \\
\hline Week 25 & $32.7 \pm 0.2$ & $32.7 \pm 0.1$ & $32.9 \pm 0.2$ & $33.2 \pm 0.2$ \\
\hline \multicolumn{5}{|c|}{ Platelets $\left(10^{3} / \mu \mathrm{L}\right)$} \\
\hline Week 25 & $916 \pm 52$ & $824 \pm 26$ & $921 \pm 19$ & $973 \pm 36$ \\
\hline \multicolumn{5}{|c|}{ Leukocytes $\left(10^{3} / \mu \mathrm{L}\right)$} \\
\hline Week 25 & $10.62 \pm 0.98$ & $9.39 \pm 0.94$ & $7.38 \pm 0.69$ & $9.54 \pm 0.91$ \\
\hline \multicolumn{5}{|c|}{ Segmented neutrophils $\left(10^{3} / \mu \mathrm{L}\right)$} \\
\hline Week 25 & $2.04 \pm 0.38$ & $1.48 \pm 0.24$ & $1.06 \pm 0.12$ & $1.76 \pm 0.39$ \\
\hline \multicolumn{5}{|c|}{ Lymphocytes $\left(10^{3} / \mu \mathrm{L}\right)$} \\
\hline Week 25 & $8.02 \pm 0.64$ & $7.42 \pm 0.74$ & $6.01 \pm 0.62$ & $7.44 \pm 0.65$ \\
\hline \multicolumn{5}{|c|}{ Monocytes $\left(10^{3} / \mu \mathrm{L}\right)$} \\
\hline Week 25 & $0.31 \pm 0.05$ & $0.32 \pm 0.05$ & $0.20 \pm 0.02$ & $0.19 \pm 0.03$ \\
\hline \multicolumn{5}{|c|}{ Basophils $\left(10^{3} / \mu \mathrm{L}\right)$} \\
\hline Week 25 & $0.04 \pm 0.01$ & $0.04 \pm 0.01$ & $0.02 \pm 0.00$ & $0.03 \pm 0.01$ \\
\hline \multicolumn{5}{|c|}{ Eosinophils $\left(10^{3} / \mu \mathrm{L}\right)$} \\
\hline Week 25 & $0.21 \pm 0.05$ & $0.15 \pm 0.03$ & $0.09 \pm 0.01 *$ & $0.11 \pm 0.03$ \\
\hline
\end{tabular}




\begin{tabular}{lllll}
\hline & $0 \%$ & $1 \%$ & $3 \%$ & $9 \%$ \\
\hline
\end{tabular}

\section{Clinical Chemistry}

n

10

10

10

10

Urea nitrogen $(\mathrm{mg} / \mathrm{dL})$

Week 25

$12.4 \pm 0.6$

$12.1 \pm 0.5$

$12.7 \pm 0.5$

$15.3 \pm 0.9^{* *}$

Creatinine (mg/dL)

Week 25

$0.62 \pm 0.01$

$0.64 \pm 0.02$

$0.62 \pm 0.01$

$0.64 \pm 0.02$

Calcium (mg/dL)

Week 13

$12.6 \pm 0.1$

$12.5 \pm 0.1$

$12.3 \pm 0.2$

$12.4 \pm 0.2$

Week 19

$12.5 \pm 0.1$

$12.3 \pm 0.2$

$12.3 \pm 0.1$

$12.0 \pm 0.1 *$

Week 25

$12.1 \pm 0.1$

$12.1 \pm 0.2$

$12.0 \pm 0.1$

$11.6 \pm 0.1^{*}$

Phosphorus (mg/dL)

Week 13

Week 19

$8.4 \pm 0.3$

$8.1 \pm 0.3$

$7.2 \pm 0.3^{* *}$

$7.4 \pm 0.4^{*}$

$8.2 \pm 0.4$

$7.7 \pm 0.2$

$7.4 \pm 0.3$

$6.7 \pm 0.2 * *$

Week 25

$6.9 \pm 0.3$

$6.8 \pm 0.2$

$6.7 \pm 0.1$

$5.8 \pm 0.3^{* *}$

Total protein $(\mathrm{g} / \mathrm{dL})$

Week 25

$7.4 \pm 0.1$

$7.2 \pm 0.1$

$7.3 \pm 0.1$

$6.9 \pm 0.1^{*}$

Albumin (g/dL)

Week 19

$4.8 \pm 0.1$

$4.6 \pm 0.1$

$4.7 \pm 0.1$

$4.5 \pm 0.0^{*}$

Week 25

$4.8 \pm 0.1$

$4.7 \pm 0.1$

$4.8 \pm 0.1$

$4.6 \pm 0.0$

Cholesterol (mg/dL)

Week 7

$82 \pm 5$

$75 \pm 8$

$80 \pm 6$

$53 \pm 3^{* *}$

Week 13

$95 \pm 7$

$84 \pm 8$

$90 \pm 7$

$53 \pm 2 * *$

Week 19

$101 \pm 6$

$87 \pm 10$

$94 \pm 8$

$59 \pm 4 * *$

Week 25

$95 \pm 6$

$81 \pm 8$

$90 \pm 6$

$49 \pm 4 * *$

Triglycerides (mg/dL)

Week 7

Week 13

Week 19

Week 25

Alanine aminotransferase (IU/L)

Week 25

Alkaline phosphatase (IU/L)

Week 7

Week 13

Week 19

Week 25
$202 \pm 28$

$198 \pm 33$

$180 \pm 26$

$173 \pm 18$

$28 \pm 3$

$134 \pm 7$

$100 \pm 6$

$91 \pm 11$

$85 \pm 7$
$234 \pm 43$

$202 \pm 38$

$218 \pm 43$

$207 \pm 30$

$29 \pm 2$

$134 \pm 7$

$95 \pm 6$

$87 \pm 7$

$83 \pm 7$
$226 \pm 30$

$195 \pm 24$

$210 \pm 29$

$218 \pm 24$

$29 \pm 1$

$138 \pm 8$

$102 \pm 6$

$84 \pm 4$

$82 \pm 5$
$88 \pm 15^{*}$

$86 \pm 8 * *$

$95 \pm 13^{*}$

$109 \pm 13$ 


\section{Chitosan, NTP TOX 93}

\begin{tabular}{lcccc}
\hline & $\mathbf{0 \%}$ & $\mathbf{1 \%}$ & $\mathbf{3 \%}$ & $\mathbf{9 \%}$ \\
\hline $\begin{array}{l}\text { Creatine kinase (IU/L) } \\
\text { Week 25 }\end{array}$ & $192 \pm 29$ & $205 \pm 27$ & $233 \pm 23$ & $245 \pm 20$ \\
$\begin{array}{l}\text { Sorbitol dehydrogenase (IU/L) } \\
\text { Week 25 }\end{array}$ & $17 \pm 3$ & $17 \pm 2$ & $15 \pm 1$ & $14 \pm 1$ \\
Bile acids ( $\mu$ mol/L) & & & & \\
Week 25 & $9.6 \pm 2.3$ & $6.4 \pm 2.7$ & $2.4 \pm 0.2^{* * *}$ & $4.3 \pm 0.8$ \\
Total osteocalcin (ng/mL) & & & & \\
Week 7 & $445.7 \pm 17.2$ & $439.8 \pm 15.8$ & $441.8 \pm 18.2$ & $520.4 \pm 22.6$ \\
Week 13 & $306.2 \pm 13.0$ & $289.7 \pm 28.6$ & $245.4 \pm 37.9$ & $372.6 \pm 23.4$ \\
Week 19 & $239.4 \pm 12.4$ & $225.7 \pm 10.6$ & $181.6 \pm 26.8$ & $269.2 \pm 20.9$ \\
Week 25 & $158.3 \pm 10.0$ & $168.1 \pm 11.6$ & $145.9 \pm 22.7$ & $218.3 \pm 14.6 *$ \\
Parathyroid hormone (ng/mL) & & & & \\
Week 7 & $1.882 \pm 0.137$ & $1.643 \pm 0.449$ & $1.838 \pm 0.348$ & $1.521 \pm 0.368$ \\
Week 13 & $2.343 \pm 0.350$ & $2.763 \pm 0.479$ & $3.215 \pm 0.537$ & $2.433 \pm 0.222$ \\
Week 19 & $1.879 \pm 0.186$ & $3.101 \pm 0.475$ & $2.710 \pm 0.365$ & $3.679 \pm 0.361 * *$ \\
Week 25 & $2.668 \pm 0.475$ & $2.924 \pm 0.276$ & $3.981 \pm 0.349$ & $2.848 \pm 0.506$ \\
\hline
\end{tabular}

\section{Urinalysis}

n

\begin{tabular}{lcccc} 
Week 7 & 10 & 9 & 10 & 10 \\
Week 13 & 10 & 10 & 10 & 10 \\
Week 19 & 10 & 10 & 10 & 10 \\
Week 25 & 10 & 10 & 10 & 10 \\
\hline
\end{tabular}

Creatinine (mg/dL)

\begin{tabular}{lcccc} 
Week 7 & $192.5 \pm 15.1$ & $227.2 \pm 30.7$ & $269.4 \pm 33.6$ & $254.9 \pm 37.2$ \\
Week 13 & $249.4 \pm 25.1$ & $360.7 \pm 19.5^{*}$ & $350.3 \pm 22.5^{*}$ & $334.0 \pm 35.8$ \\
Week 19 & $204.3 \pm 20.4$ & $394.2 \pm 32.5^{* *}$ & $345.1 \pm 26.0^{* *}$ & $302.5 \pm 26.6$ \\
Week 25 & $254.1 \pm 27.4$ & $374.8 \pm 25.6^{*}$ & $345.9 \pm 27.1$ & $325.4 \pm 36.0$ \\
Volume (mL) & & & \\
Week 7 & $8.3 \pm 0.8$ & $7.5 \pm 1.5$ & $6.4 \pm 0.8$ & $5.0 \pm 1.1^{*}$ \\
Week 13 & $7.9 \pm 1.0$ & $4.6 \pm 0.3^{* *}$ & $5.1 \pm 0.4^{*}$ & $4.5 \pm 0.5^{* *}$ \\
Week 19 & $10.7 \pm 1.6$ & $4.0 \pm 0.4^{* *}$ & $5.3 \pm 0.7^{*}$ & $5.6 \pm 0.6$ \\
Week 25 & $8.6 \pm 1.2$ & $5.4 \pm 0.6^{*}$ & $6.1 \pm 0.8^{*}$ & $5.1 \pm 0.6^{* *}$ \\
Deoxypyridinoline (nmol/L) & & & & \\
Week 7 & $3,396.0 \pm 268.0$ & $4,210.0 \pm 643.0$ & $4,917.0 \pm 826.0$ & $4,754.0 \pm 761.0$ \\
Week 13 & $2,185.1 \pm 188.9$ & $3,197.3 \pm 148.3^{*}$ & $3,233.8 \pm 218.0^{*}$ & $3,129.1 \pm 296.5^{*}$ \\
Week 19 & $1,084.9 \pm 158.9$ & $2,209.6 \pm 246.3^{* *}$ & $1,963.0 \pm 200.5^{*}$ & $1,994.9 \pm 214.3^{*}$ \\
\hline
\end{tabular}


Chitosan, NTP TOX 93

\begin{tabular}{lcccc}
\hline & $\mathbf{0 \%}$ & $\mathbf{1 \%}$ & $\mathbf{3 \%}$ & $\mathbf{9 \%}$ \\
\hline Week 25 & $1,083.5 \pm 145.9$ & $1,699.3 \pm 139.6^{*}$ & $1,658.3 \pm 136.7^{*}$ & $1,750.8 \pm 167.6^{*}$ \\
Deoxypyridinoline/creatinine $(\mathrm{nmol} / \mathrm{mg})$ & & & \\
Week 7 & $1.810 \pm 0.135$ & $1.889 \pm 0.148$ & $1.810 \pm 0.159$ & $1.920 \pm 0.160$ \\
Week 13 & $0.910 \pm 0.035$ & $0.890 \pm 0.031$ & $0.930 \pm 0.040$ & $0.960 \pm 0.078$ \\
Week 19 & $0.530 \pm 0.050$ & $0.550 \pm 0.034$ & $0.570 \pm 0.042$ & $0.660 \pm 0.048$ \\
Week 25 & $0.430 \pm 0.030$ & $0.470 \pm 0.030$ & $0.480 \pm 0.020$ & $0.550 \pm 0.027^{* *}$ \\
\hline
\end{tabular}

Female

\section{Hematology}

n

10

9

10

10

Hematocrit (auto) (\%)

Week 25

$45.5 \pm 1.0$

$44.9 \pm 0.9$

$44.5 \pm 0.8$

$45.2 \pm 0.9$

Hematocrit (manual) (\%)

Week 25

$47.4 \pm 1.1$

$46.9 \pm 1.0$

$46.5 \pm 0.8$

$46.6 \pm 0.9$

Hemoglobin (g/dL)

Week 25

$15.2 \pm 0.4$

$15.0 \pm 0.3$

$15.0 \pm 0.3$

$15.1 \pm 0.3$

Erythrocytes $\left(10^{6} / \mu \mathrm{L}\right)$

Week 25

$8.16 \pm 0.19$

$8.17 \pm 0.18$

$8.01 \pm 0.11$

$8.10 \pm 0.15$

Reticulocytes $\left(10^{3} / \mu \mathrm{L}\right)$

Week 25

$135.2 \pm 14.6$

$109.2 \pm 6.1$

$109.6 \pm 7.7$

$129.5 \pm 14.6$

Mean cell volume (fL)

Week 25

$55.8 \pm 0.6$

$55.0 \pm 0.3$

$55.6 \pm 0.3$

$55.8 \pm 0.8$

Mean cell hemoglobin (pg)

Week 25

$18.7 \pm 0.2$

$18.4 \pm 0.1$

$18.7 \pm 0.1$

$18.7 \pm 0.3$

Mean cell hemoglobin concentration $(\mathrm{g} / \mathrm{dL})$

Week 25

$33.5 \pm 0.1$

$33.4 \pm 0.2$

$33.6 \pm 0.2$

$33.4 \pm 0.2$

Platelets $\left(10^{3} / \mu \mathrm{L}\right)$

Week 25

$791 \pm 43$

$798 \pm 40$

$848 \pm 38$

$1,024 \pm 51 * *$

Leukocytes $\left(10^{3} / \mu \mathrm{L}\right)$

Week 25

$6.62 \pm 0.92$

$3.66 \pm 0.49^{*}$

$5.72 \pm 0.87$

$4.92 \pm 0.58$

Segmented neutrophils $\left(10^{3} / \mu \mathrm{L}\right)$

Week 25

$$
1.15 \pm 0.24
$$

$0.53 \pm 0.10^{*}$

$0.67 \pm 0.11$

$0.67 \pm 0.11$

Lymphocytes $\left(10^{3} / \mu \mathrm{L}\right)$

Week 25

$5.09 \pm 0.79$

$2.93 \pm 0.41$

$4.78 \pm 0.77$

$4.06 \pm 0.49$

Monocytes $\left(10^{3} / \mu \mathrm{L}\right)$

Week 25

$0.24 \pm 0.04$

$0.13 \pm 0.02$

$0.18 \pm 0.03$

$0.11 \pm 0.02 *$ 


\begin{tabular}{|c|c|c|c|c|}
\hline & $0 \%$ & $1 \%$ & $3 \%$ & $9 \%$ \\
\hline \multicolumn{5}{|c|}{ Basophils $\left(10^{3} / \mu \mathrm{L}\right)$} \\
\hline Week 25 & $0.02 \pm 0.00$ & $0.01 \pm 0.00 *$ & $0.02 \pm 0.01$ & $0.01 \pm 0.00$ \\
\hline \multicolumn{5}{|c|}{ Eosinophils $\left(10^{3} / \mu \mathrm{L}\right)$} \\
\hline Week 25 & $0.12 \pm 0.02$ & $0.06 \pm 0.01$ & $0.08 \pm 0.01$ & $0.07 \pm 0.02$ \\
\hline
\end{tabular}

\section{Clinical Chemistry}

n

$\begin{array}{lcccc}\text { Week 7 } & 10 & 10 & 10 & 10 \\ \text { Week } 13 & 10 & 10 & 10 & 10 \\ \text { Week } 19 & 10 & 10 & 10 & 10 \\ \text { Week } 25 & 10 & 9 & 10 & 10\end{array}$

Urea nitrogen $(\mathrm{mg} / \mathrm{dL})$

Week 25

$14.2 \pm 1.4$

$14.1 \pm 0.7$

$15.2 \pm 0.7$

$16.3 \pm 0.7^{*}$

Creatinine (mg/dL)

Week 25

$0.65 \pm 0.02$

$0.68 \pm 0.01$

$0.70 \pm 0.01$

$0.69 \pm 0.02$

Calcium (mg/dL)

Week 13

Week 19

Week 25

Phosphorus (mg/dL)

Week 13

Week 19

Week 25

Total protein $(\mathrm{g} / \mathrm{dL})$

Week 25

Albumin (g/dL)

Week 19

Week 25

Cholesterol (mg/dL)

Week 7

Week 13

Week 19

Week 25

Triglycerides (mg/dL)

Week 7

Week 13

Week 19

$\begin{array}{llll}12.9 \pm 0.2 & 13.1 \pm 0.1 & 12.7 \pm 0.2 & 12.5 \pm 0.2 \\ 12.9 \pm 0.1 & 13.1 \pm 0.2 & 12.8 \pm 0.1 & 12.5 \pm 0.1 \\ 12.7 \pm 0.3 & 12.8 \pm 0.1 & 12.7 \pm 0.2 & 12.3 \pm 0.2\end{array}$

$8.1 \pm 0.5$

$8.4 \pm 0.4$

$6.8 \pm 0.2$

$8.2 \pm 0.2$

$5.9 \pm 0.2$

$5.8 \pm 0.2$

$6.2 \pm 0.1$

$6.5 \pm 0.2^{*}$

$80 \pm 6$

$81 \pm 8$

$86 \pm 7$

$105 \pm 9$

$108 \pm 5$

$94 \pm 7$

$88 \pm 12$

$130 \pm 48$

$163 \pm 30$

$181 \pm 32$

$125 \pm 10$
$6.5 \pm 0.4 * *$

$6.8 \pm 0.3^{*}$

$8.1 \pm 0.3$

$7.4 \pm 0.5$

$6.2 \pm 0.3^{*}$

$5.5 \pm 0.3^{* *}$

$143 \pm 15$
$8.6 \pm 0.2$

$8.4 \pm 0.2$

$5.9 \pm 0.2$

$5.7 \pm 0.1$

$6.2 \pm 0.1$

$6.2 \pm 0.1$

$67 \pm 4$

$59 \pm 4 * *$

$73 \pm 5$

$58 \pm 4 * *$

$91 \pm 8$

$67 \pm 5^{* *}$

$96 \pm 8$

$63 \pm 4 * *$

$86 \pm 14$

$88 \pm 23 *$

$90 \pm 13$ 


\section{Chitosan, NTP TOX 93}

\begin{tabular}{|c|c|c|c|c|}
\hline & $0 \%$ & $1 \%$ & $3 \%$ & $9 \%$ \\
\hline Week 25 & $188 \pm 31$ & $231 \pm 44$ & $245 \pm 31$ & $158 \pm 35$ \\
\hline \multicolumn{5}{|c|}{ Alanine aminotransferase (IU/L) } \\
\hline Week 25 & $25 \pm 3$ & $28 \pm 3$ & $32 \pm 2 * *$ & $47 \pm 4 * *$ \\
\hline \multicolumn{5}{|c|}{ Alkaline phosphatase (IU/L) } \\
\hline Week 7 & $102 \pm 7$ & $99 \pm 5$ & $99 \pm 7$ & $95 \pm 10$ \\
\hline Week 13 & $57 \pm 4$ & $63 \pm 4$ & $71 \pm 7$ & $59 \pm 5$ \\
\hline Week 19 & $49 \pm 5$ & $53 \pm 3$ & $55 \pm 6$ & $46 \pm 6$ \\
\hline Week 25 & $46 \pm 4$ & $44 \pm 2$ & $51 \pm 6$ & $44 \pm 7$ \\
\hline \multicolumn{5}{|c|}{ Creatine kinase (IU/L) } \\
\hline Week 25 & $258 \pm 44$ & $193 \pm 46$ & $210 \pm 50$ & $225 \pm 26$ \\
\hline \multicolumn{5}{|c|}{ Sorbitol dehydrogenase (IU/L) } \\
\hline Week 25 & $17 \pm 3$ & $17 \pm 2$ & $19 \pm 2$ & $16 \pm 1$ \\
\hline \multicolumn{5}{|c|}{ Bile acids $(\mu \mathrm{mol} / \mathrm{L})$} \\
\hline Week 25 & $10.7 \pm 1.8$ & $8.2 \pm 1.1$ & $32.0 \pm 14.1$ & $10.8 \pm 1.1$ \\
\hline \multicolumn{5}{|c|}{ Total osteocalcin (ng/mL) } \\
\hline Week 7 & $293.6 \pm 19.4$ & $287.5 \pm 21.2$ & $282.1 \pm 34.7$ & $316.7 \pm 23.5$ \\
\hline Week 13 & $197.9 \pm 22.6$ & $202.3 \pm 15.4$ & $184.4 \pm 19.4$ & $234.2 \pm 14.5$ \\
\hline Week 19 & $158.1 \pm 18.3$ & $184.8 \pm 13.2$ & $166.7 \pm 24.7$ & $210.1 \pm 16.0$ \\
\hline Week 25 & $107.9 \pm 18.6$ & $97.1 \pm 7.1$ & $96.0 \pm 16.2$ & $148.8 \pm 15.1$ \\
\hline \multicolumn{5}{|c|}{ Parathyroid hormone (ng/mL) } \\
\hline Week 7 & $0.995 \pm 0.150^{\mathrm{b}}$ & $1.156 \pm 0.176$ & $1.092 \pm 0.182$ & $1.023 \pm 0.146$ \\
\hline Week 13 & $1.506 \pm 0.203$ & $1.734 \pm 0.194$ & $1.925 \pm 0.306$ & $1.767 \pm 0.212$ \\
\hline Week 19 & $1.406 \pm 0.232$ & $1.994 \pm 0.353$ & $1.845 \pm 0.418$ & $1.673 \pm 0.223$ \\
\hline Week 25 & $1.471 \pm 0.189^{b}$ & $1.628 \pm 0.220$ & $1.818 \pm 0.224$ & $2.301 \pm 0.212 *$ \\
\hline
\end{tabular}

\section{Urinalysis}

n

\begin{tabular}{lcccc} 
Week 7 & 10 & 10 & 10 & 10 \\
Week 13 & 10 & 10 & 10 & 10 \\
Week 19 & 10 & 10 & 10 & 10 \\
Week 25 & 10 & 9 & 10 & 9 \\
\hline Creatinine (mg/dL) & & & & \\
Week 7 & $98.2 \pm 14.7$ & $107.1 \pm 12.3$ & $206.3 \pm 55.2^{*}$ & $192.0 \pm 8.3^{* *}$ \\
Week 13 & $144.7 \pm 14.8$ & $139.5 \pm 15.9$ & $247.5 \pm 30.9^{*}$ & $241.6 \pm 29.0^{* *}$ \\
Week 19 & $142.0 \pm 19.7$ & $137.7 \pm 19.4$ & $196.3 \pm 23.6$ & $230.3 \pm 19.2^{* *}$ \\
Week 25 & $179.8 \pm 59.7$ & $120.3 \pm 24.1$ & $184.5 \pm 20.5$ & $217.9 \pm 23.4^{*}$ \\
\hline
\end{tabular}




\section{Chitosan, NTP TOX 93}

\begin{tabular}{lcccc}
\hline & $\mathbf{0 \%}$ & $\mathbf{1 \%}$ & $\mathbf{3 \%}$ & $\mathbf{9 \%}$ \\
\hline Volume (mL) & & & & \\
Week 7 & $8.2 \pm 1.2$ & $8.5 \pm 1.0$ & $5.4 \pm 0.8$ & $3.4 \pm 0.3^{* *}$ \\
Week 13 & $6.4 \pm 0.7$ & $6.5 \pm 0.6$ & $4.1 \pm 0.8^{*}$ & $2.9 \pm 0.5^{* *}$ \\
Week 19 & $7.7 \pm 1.2$ & $8.1 \pm 1.4$ & $5.0 \pm 0.8$ & $3.4 \pm 0.5^{* *}$ \\
Week 25 & $8.2 \pm 1.5$ & $9.1 \pm 1.5$ & $5.8 \pm 0.9$ & $3.7 \pm 0.5^{* *}$ \\
Deoxypyridinoline (nmol/L) & & & & \\
Week 7 & $1,622.0 \pm 328.0$ & $1,378.0 \pm 295.0$ & $4,130.0 \pm 1,109.0^{*}$ & $4,423.0 \pm 355.0^{* *}$ \\
Week 13 & $875.5 \pm 129.6$ & $587.0 \pm 68.1$ & $1,364.0 \pm 215.9$ & $1,421.6 \pm 267.0$ \\
Week 19 & $666.3 \pm 106.9$ & $487.7 \pm 68.5$ & $894.9 \pm 122.1$ & $1,212.3 \pm 107.4^{* *}$ \\
Week 25 & $565.7 \pm 178.2$ & $250.4 \pm 47.1$ & $625.1 \pm 83.7$ & $891.5 \pm 114.1^{*}$ \\
Deoxypyridinoline/creatinine (nmol/mg) & & & \\
Week 7 & $1.620 \pm 0.128$ & $1.240 \pm 0.129$ & $1.940 \pm 0.229$ & $2.300 \pm 0.182^{*}$ \\
Week 13 & $0.580 \pm 0.039$ & $0.430 \pm 0.037 * *$ & $0.540 \pm 0.034$ & $0.570 \pm 0.042$ \\
Week 19 & $0.450 \pm 0.017$ & $0.360 \pm 0.016^{*}$ & $0.440 \pm 0.016$ & $0.520 \pm 0.020$ \\
Week 25 & $0.340 \pm 0.043$ & $0.222 \pm 0.022$ & $0.340 \pm 0.027$ & $0.411 \pm 0.026$ \\
\hline
\end{tabular}

*Significantly different $(\mathrm{P} \leq 0.05)$ from the control group by Dunn's or Shirley's test.

$* * \mathrm{P} \leq 0.01$.

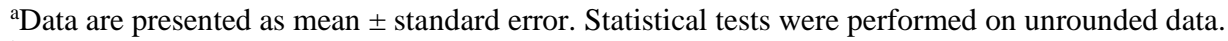
${ }^{b} \mathrm{n}=9$. 


\section{Appendix C. Vitamin Concentration and Bone Parameter Results}

\section{Tables}

Table C-1. Serum and Hepatic Vitamin Concentration Data for Group B Rats in the Sixmonth Feed Study of Chitosan

Table C-2. Bone Data for Groups A and B Rats in the Six-month Feed Study of Chitosan ........C-3 
Table C-1. Serum and Hepatic Vitamin Concentration Data for Group B Rats in the Six-month Feed Study of Chitosan ${ }^{\text {a }}$

\begin{tabular}{|c|c|c|c|c|}
\hline & $\mathbf{0 \%}$ & $1 \%$ & $3 \%$ & $9 \%$ \\
\hline \multicolumn{5}{|l|}{ Male } \\
\hline \multicolumn{5}{|l|}{$\mathbf{n}$} \\
\hline Week 7 & 9 & 10 & 10 & 10 \\
\hline Week 13 & 9 & 10 & 10 & 10 \\
\hline Week 19 & 9 & 10 & 10 & 10 \\
\hline Week 26 & 9 & 10 & 10 & 8 \\
\hline \multicolumn{5}{|c|}{ Serum vitamin $A(\mu \mathrm{g} / \mathrm{mL})$} \\
\hline Week 7 & $0.532 \pm 0.021$ & $0.506 \pm 0.033$ & $0.513 \pm 0.026$ & $0.453 \pm 0.018$ \\
\hline Week 13 & $0.561 \pm 0.024$ & $0.499 \pm 0.019$ & $0.476 \pm 0.022 *$ & $0.410 \pm 0.009 * *$ \\
\hline Week 19 & $0.533 \pm 0.028$ & $0.506 \pm 0.031$ & $0.475 \pm 0.019$ & $0.392 \pm 0.014 * *$ \\
\hline Week 26 & $0.476 \pm 0.019$ & $0.444 \pm 0.024$ & $0.398 \pm 0.017 * *$ & $0.336 \pm 0.026^{* *}$ \\
\hline \multicolumn{5}{|c|}{ Serum $1,25(\mathrm{OH})_{2}$ vitamin $\mathrm{D}(\mathrm{pg} / \mathrm{mL})$} \\
\hline Week 7 & $124.4 \pm 19.6$ & $163.3 \pm 21.7$ & $183.2 \pm 26.9$ & $297.4 \pm 41.0 * *$ \\
\hline Week 13 & $70.1 \pm 7.3$ & $57.4 \pm 5.3$ & $77.3 \pm 4.4$ & $86.1 \pm 8.5$ \\
\hline Week 19 & $20.6 \pm 2.8$ & $21.7 \pm 6.1$ & $22.9 \pm 2.2$ & $42.3 \pm 3.1 * * \mathrm{~b}$ \\
\hline Week 26 & $27.7 \pm 3.4^{\mathrm{c}}$ & $28.0 \pm 4.3$ & $36.1 \pm 4.6^{\mathrm{b}}$ & $66.9 \pm 11.9^{* *}$ \\
\hline \multicolumn{5}{|c|}{ Serum vitamin $E(\mu \mathrm{g} / \mathrm{mL})$} \\
\hline Week 7 & $19.33 \pm 1.43$ & $15.38 \pm 1.29$ & $12.92 \pm 0.48 * *$ & $4.14 \pm 0.23 * *$ \\
\hline Week 13 & $21.08 \pm 1.61$ & $17.45 \pm 1.06^{*}$ & $12.27 \pm 0.86^{* *}$ & $4.33 \pm 0.27 * *$ \\
\hline Week 19 & $20.59 \pm 1.61$ & $16.19 \pm 0.96$ & $12.86 \pm 0.42 * *$ & $4.07 \pm 0.32 * *$ \\
\hline Week 26 & $19.66 \pm 1.66$ & $17.35 \pm 1.37$ & $12.35 \pm 0.61 * *$ & $3.59 \pm 0.65^{* *}$ \\
\hline \multicolumn{5}{|c|}{ Liver vitamin $\mathrm{A}(\mu \mathrm{g} / \mathrm{g})$} \\
\hline Week 26 & $57.4 \pm 17.6$ & $29.9 \pm 2.5$ & $39.6 \pm 3.1$ & $31.4 \pm 3.7$ \\
\hline \multicolumn{5}{|c|}{ Liver vitamin $E(\mu \mathrm{g} / \mathrm{g})$} \\
\hline Week 26 & $66.8 \pm 16.2$ & $55.0 \pm 6.8$ & $34.6 \pm 2.2 * *$ & $8.5 \pm 0.8 * *$ \\
\hline
\end{tabular}

\section{Female}

$\mathbf{n}$

\begin{tabular}{lcccc} 
Week 7 & 10 & 10 & 10 & 10 \\
Week 13 & 10 & 10 & 10 & 10 \\
Week 19 & 10 & 10 & 10 & 10 \\
Week 26 & 10 & 10 & 9 & 10 \\
\hline Serum vitamin A $(\mu \mathrm{g} / \mathrm{mL})$ & & & & \\
Week 7 & $0.272 \pm 0.011$ & $0.253 \pm 0.007$ & $0.260 \pm 0.012$ & $0.266 \pm 0.012$ \\
Week 13 & $0.308 \pm 0.020$ & $0.295 \pm 0.011$ & $0.309 \pm 0.019$ & $0.281 \pm 0.018$ \\
Week 19 & $0.283 \pm 0.014$ & $0.271 \pm 0.015$ & $0.291 \pm 0.012$ & $0.231 \pm 0.010^{*}$ \\
Week 26 & $0.316 \pm 0.015$ & $0.302 \pm 0.014$ & $0.294 \pm 0.018$ & $0.249 \pm 0.010^{* *}$
\end{tabular}




\begin{tabular}{lcccc}
\hline & $\mathbf{0 \%}$ & $\mathbf{1 \%}$ & $\mathbf{3 \%}$ & $\mathbf{9 \%}$ \\
\hline Serum 1,25 $(\mathrm{OH})_{2}$ vitamin D $(\mathrm{pg} / \mathrm{mL})$ & & & \\
Week 7 & $104.0 \pm 15.1$ & $96.7 \pm 10.9$ & $111.0 \pm 8.7$ & $208.1 \pm 18.2^{* *}$ \\
Week 13 & $60.6 \pm 7.5$ & $60.7 \pm 7.9$ & $69.3 \pm 11.0$ & $110.1 \pm 16.9$ \\
Week 19 & $11.6 \pm 1.6$ & $12.6 \pm 1.7$ & $15.8 \pm 1.4$ & $31.4 \pm 3.2^{* *}$ \\
Week 26 & $19.2 \pm 2.2$ & $20.7 \pm 4.2$ & $28.6 \pm 6.5$ & $53.7 \pm 5.8^{* *}$ \\
Serum vitamin E $(\mu \mathrm{g} / \mathrm{mL})$ & $18.65 \pm 0.71$ & $20.08 \pm 0.87$ & $18.38 \pm 0.85$ & $6.99 \pm 0.58^{* *}$ \\
Week 7 & $19.81 \pm 1.41$ & $20.85 \pm 1.06$ & $20.19 \pm 1.20$ & $7.48 \pm 0.38^{* *}$ \\
Week 13 & $21.02 \pm 1.76$ & $19.74 \pm 1.75$ & $19.86 \pm 1.08$ & $7.37 \pm 0.57 * *$ \\
Week 19 & $20.94 \pm 1.56$ & $23.43 \pm 1.66$ & $22.23 \pm 1.75$ & $7.28 \pm 0.64^{* *}$ \\
Week 26 & & & \\
Liver vitamin A $(\mu \mathrm{g} / \mathrm{g})$ & $65.2 \pm 5.4$ & $58.9 \pm 5.0$ & $62.3 \pm 6.3$ & $60.3 \pm 4.8$ \\
Week 26 & & & & \\
Liver vitamin E $(\mu \mathrm{g} / \mathrm{g})$ & $84.5 \pm 8.9$ & $97.1 \pm 10.1$ & $82.0 \pm 11.8$ & $17.2 \pm 3.2^{* *}$ \\
Week 26 & & &
\end{tabular}

*Significantly different $(\mathrm{P} \leq 0.05)$ from the control group by Dunn's or Shirley's test.

**Significantly different $(\mathrm{P} \leq 0.01)$ from the control group by Shirley's test.

aData are presented as mean \pm standard error. Statistical tests were performed on unrounded data.

$\mathrm{b}_{\mathrm{n}}=9$.

${ }^{c} \mathrm{n}=7$.

Table C-2. Bone Data for Groups A and B Rats in the Six-month Feed Study of Chitosan ${ }^{\mathrm{a}}$

\begin{tabular}{lcccc}
\hline & $\mathbf{0 \%}$ & $\mathbf{1 \%}$ & $\mathbf{3 \%}$ & $\mathbf{9 \%}$ \\
\hline $\mathbf{n}$ & 10 & 10 & 10 & 10 \\
\hline Male & & & & \\
Bone calcium (\%) & $23.79 \pm 0.21^{\mathrm{b}}$ & $23.95 \pm 0.22$ & $23.92 \pm 0.30$ & $23.74 \pm 0.11^{\mathrm{c}}$ \\
Bone ash (\%) & $45.33 \pm 0.79^{\mathrm{b}}$ & $45.24 \pm 0.67$ & $45.83 \pm 0.52$ & $43.46 \pm 0.62^{\mathrm{c}}$ \\
Bone moisture (\%) & $29.90 \pm 0.49^{\mathrm{b}}$ & $30.30 \pm 0.44$ & $29.72 \pm 0.36$ & $31.79 \pm 0.62^{\mathrm{c}}$ \\
Left femur length (mm) & $43.96 \pm 0.34$ & $44.33 \pm 0.30$ & $44.10 \pm 0.30$ & $43.42 \pm 0.37$ \\
Left tibia length (mm) & $48.00 \pm 0.37$ & $48.27 \pm 0.36$ & $47.95 \pm 0.37$ & $47.57 \pm 0.41$ \\
Right tibia length (mm) & $48.06 \pm 0.32$ & $48.41 \pm 0.41$ & $47.95 \pm 0.33$ & $47.57 \pm 0.43$ \\
\hline Female & & & & \\
Bone calcium $(\%)$ & $24.65 \pm 0.17$ & $24.96 \pm 0.20$ & $24.77 \pm 0.23^{\mathrm{b}}$ & $24.84 \pm 0.12$ \\
Bone ash (\%) & $47.07 \pm 0.58$ & $47.14 \pm 0.57$ & $47.44 \pm 0.46^{\mathrm{b}}$ & $45.87 \pm 0.44$ \\
Bone moisture (\%) & $28.40 \pm 0.54$ & $28.45 \pm 0.45$ & $28.53 \pm 0.49^{\mathrm{b}}$ & $30.37 \pm 0.37^{* *}$ \\
Left femur length (mm) & $36.65 \pm 0.21$ & $36.75 \pm 0.17$ & $36.73 \pm 0.28$ & $36.37 \pm 0.26$ \\
Left tibia length (mm) & $40.56 \pm 0.28$ & $40.25 \pm 0.23$ & $40.62 \pm 0.40$ & $40.10 \pm 0.24$ \\
Right tibia length (mm) & $40.53 \pm 0.30$ & $40.42 \pm 0.24$ & $40.74 \pm 0.42$ & $40.12 \pm 0.21$ \\
\hline
\end{tabular}

**Significantly different $(\mathrm{P} \leq 0.01)$ from the control group by Shirley's test.

aData are presented as mean \pm standard error. Statistical tests were performed on unrounded data. Bone content data are from Group B rats at week 26 and bone lengths are from Group A rats at week 25.

${ }^{b} \mathrm{n}=9$.

${ }^{c} n=8$. 


\section{Appendix D. Organ Weights and Organ-Weight-to-Body- Weight Ratios}

\section{Tables}

Table D-1. Organ Weights and Organ-Weight-to-Body-Weight Ratios for Group A Rats in the Six-month Feed Study of Chitosan ...................................................... D-2 
Table D-1. Organ Weights and Organ-Weight-to-Body-Weight Ratios for Group A Rats in the Sixmonth Feed Study of Chitosan ${ }^{a}$

\begin{tabular}{|c|c|c|c|c|}
\hline & $0 \%$ & $1 \%$ & $3 \%$ & $9 \%$ \\
\hline n & 10 & 10 & 10 & 10 \\
\hline \multicolumn{5}{|l|}{ Male } \\
\hline Necropsy body wt & $669 \pm 20$ & $702 \pm 21$ & $687 \pm 23$ & $612 \pm 17$ \\
\hline \multicolumn{5}{|l|}{ Heart } \\
\hline Absolute & $1.82 \pm 0.07$ & $1.81 \pm 0.06$ & $1.86 \pm 0.08$ & $1.77 \pm 0.06$ \\
\hline Relative & $2.723 \pm 0.089$ & $2.589 \pm 0.070$ & $2.710 \pm 0.091$ & $2.904 \pm 0.085$ \\
\hline \multicolumn{5}{|l|}{ R. Kidney } \\
\hline Absolute & $2.04 \pm 0.04$ & $2.04 \pm 0.04$ & $2.11 \pm 0.06$ & $1.88 \pm 0.04 *$ \\
\hline Relative & $3.068 \pm 0.088$ & $2.920 \pm 0.047$ & $3.093 \pm 0.088$ & $3.093 \pm 0.094$ \\
\hline \multicolumn{5}{|l|}{ Liver } \\
\hline Absolute & $25.19 \pm 0.87$ & $24.87 \pm 1.35$ & $23.74 \pm 1.51$ & $19.53 \pm 0.71 * *$ \\
\hline Relative & $37.662 \pm 0.731$ & $35.321 \pm 1.179$ & $34.345 \pm 1.411^{*}$ & $31.933 \pm 0.817 * *$ \\
\hline \multicolumn{5}{|l|}{ Lung } \\
\hline Absolute & $2.49 \pm 0.11$ & $2.77 \pm 0.09$ & $2.62 \pm 0.08$ & $2.53 \pm 0.14$ \\
\hline Relative & $3.738 \pm 0.163$ & $3.949 \pm 0.095$ & $3.841 \pm 0.138$ & $4.120 \pm 0.160$ \\
\hline \multicolumn{5}{|l|}{ R. Testis } \\
\hline Absolute & $1.696 \pm 0.054$ & $1.778 \pm 0.046$ & $1.726 \pm 0.062$ & $1.750 \pm 0.028$ \\
\hline Relative & $2.555 \pm 0.108$ & $2.546 \pm 0.078$ & $2.534 \pm 0.107$ & $2.883 \pm 0.104$ \\
\hline \multicolumn{5}{|l|}{ Thymus } \\
\hline Absolute & $0.763 \pm 0.045$ & $0.727 \pm 0.065$ & $0.606 \pm 0.063 *$ & $0.489 \pm 0.032 * *$ \\
\hline Relative & $1.147 \pm 0.071$ & $1.030 \pm 0.077$ & $0.888 \pm 0.091 *$ & $0.797 \pm 0.045^{* *}$ \\
\hline \multicolumn{5}{|c|}{ Thyroid gland and parathyroid gland } \\
\hline Absolute & $0.033 \pm 0.003$ & $0.034 \pm 0.002$ & $0.034 \pm 0.002$ & $0.031 \pm 0.002$ \\
\hline Relative & $0.049 \pm 0.004$ & $0.048 \pm 0.003$ & $0.050 \pm 0.003$ & $0.051 \pm 0.003$ \\
\hline \multicolumn{5}{|l|}{ Parathyroid gland } \\
\hline Absolute & $0.0012 \pm 0.0001$ & $0.0010 \pm 0.0001$ & $0.0011 \pm 0.0001$ & $0.0011 \pm 0.0001$ \\
\hline Relative & $0.002 \pm 0.000$ & $0.001 \pm 0.000$ & $0.002 \pm 0.000$ & $0.002 \pm 0.000$ \\
\hline \multicolumn{5}{|l|}{ Female } \\
\hline Necropsy body wt & $338 \pm 11$ & $335 \pm 13$ & $328 \pm 11$ & $301 \pm 13$ \\
\hline \multicolumn{5}{|l|}{ Heart } \\
\hline Absolute & $1.14 \pm 0.03$ & $1.09 \pm 0.02$ & $1.15 \pm 0.03$ & $1.03 \pm 0.02 * *$ \\
\hline Relative & $3.393 \pm 0.121$ & $3.295 \pm 0.094$ & $3.515 \pm 0.100$ & $3.473 \pm 0.134$ \\
\hline \multicolumn{5}{|l|}{ R. Kidney } \\
\hline Absolute & $1.12 \pm 0.04$ & $1.10 \pm 0.02$ & $1.13 \pm 0.03$ & $1.01 \pm 0.03$ \\
\hline
\end{tabular}




\section{Chitosan, NTP TOX 93}

\begin{tabular}{|c|c|c|c|c|}
\hline & $\mathbf{0 \%}$ & $1 \%$ & $3 \%$ & $9 \%$ \\
\hline Relative & $3.311 \pm 0.085$ & $3.311 \pm 0.095$ & $3.465 \pm 0.108$ & $3.399 \pm 0.104$ \\
\hline \multicolumn{5}{|l|}{ Liver } \\
\hline Absolute & $12.54 \pm 0.82$ & $12.47 \pm 0.39$ & $11.85 \pm 0.29$ & $9.85 \pm 0.20 * *$ \\
\hline Relative & $36.900 \pm 1.502$ & $37.341 \pm 0.444$ & $36.346 \pm 0.904$ & $33.036 \pm 0.910^{*}$ \\
\hline \multicolumn{5}{|l|}{ Lung } \\
\hline Absolute & $1.83 \pm 0.06$ & $1.80 \pm 0.08$ & $1.81 \pm 0.05$ & $1.65 \pm 0.05$ \\
\hline Relative & $5.463 \pm 0.181$ & $5.396 \pm 0.170$ & $5.552 \pm 0.202$ & $5.557 \pm 0.281$ \\
\hline \multicolumn{5}{|l|}{ R. Ovary } \\
\hline Absolute & $0.054 \pm 0.005$ & $0.049 \pm 0.005$ & $0.057 \pm 0.005$ & $0.056 \pm 0.007$ \\
\hline Relative & $0.161 \pm 0.015$ & $0.147 \pm 0.015$ & $0.179 \pm 0.021$ & $0.190 \pm 0.026$ \\
\hline \multicolumn{5}{|l|}{ Thymus } \\
\hline Absolute & $0.436 \pm 0.033$ & $0.400 \pm 0.036$ & $0.383 \pm 0.023$ & $0.302 \pm 0.021 * *$ \\
\hline Relative & $1.284 \pm 0.081$ & $1.188 \pm 0.083$ & $1.169 \pm 0.062$ & $1.000 \pm 0.047 * *$ \\
\hline \multicolumn{5}{|c|}{ Thyroid gland and parathyroid gland } \\
\hline Absolute & $0.028 \pm 0.002$ & $0.027 \pm 0.002$ & $0.035 \pm 0.002$ & $0.031 \pm 0.002$ \\
\hline Relative & $0.084 \pm 0.005$ & $0.082 \pm 0.007$ & $0.106 \pm 0.007$ & $0.104 \pm 0.008$ \\
\hline \multicolumn{5}{|c|}{ Parathyroid gland } \\
\hline Absolute & $0.0007 \pm 0.0001$ & $0.0009 \pm 0.0001$ & $0.0008 \pm 0.0001$ & $0.0008 \pm 0.0001$ \\
\hline Relative & $0.002 \pm 0.000$ & $0.003 \pm 0.000 *$ & $0.002 \pm 0.000$ & $0.003 \pm 0.000 *$ \\
\hline \multicolumn{5}{|l|}{ Uterus } \\
\hline Absolute & $0.657 \pm 0.052$ & $0.744 \pm 0.060$ & $0.714 \pm 0.038$ & $0.789 \pm 0.096$ \\
\hline Relative & $1.980 \pm 0.186$ & $2.252 \pm 0.191$ & $2.184 \pm 0.104$ & $2.650 \pm 0.329$ \\
\hline
\end{tabular}

*Significantly different $(\mathrm{P} \leq 0.05)$ from the control group by Williams' or Dunnett's test. $* * \mathrm{P} \leq 0.01$

${ }^{a}$ Organ weights (absolute weights) and body weights are given in grams; organ-weight-to-body-weight ratios (relative weights) are given as $\mathrm{mg}$ organ weight/g body weight (mean \pm standard error). 
Chitosan, NTP TOX 93

\section{Appendix E. Reproductive Tissue Evaluations}

\section{Tables}

Table E-1. Summary of Reproductive Tissue Evaluations for Group A Male Rats in the

Six-month Feed Study of Chitosan ................................................................ 
Table E-1. Summary of Reproductive Tissue Evaluations for Group A Male Rats in the Six-month Feed Study of Chitosan ${ }^{a}$

\begin{tabular}{|c|c|c|c|c|}
\hline & $0 \%$ & $1 \%$ & $3 \%$ & $9 \%$ \\
\hline n & 10 & 10 & 10 & 10 \\
\hline \multicolumn{5}{|l|}{ Weights (g) } \\
\hline Necropsy body wt & $669 \pm 20$ & $702 \pm 21$ & $687 \pm 23$ & $612 \pm 17$ \\
\hline L. Cauda epididymis & $0.2013 \pm 0.0073$ & $0.2134 \pm 0.0079$ & $0.2281 \pm 0.0167$ & $0.2072 \pm 0.0103$ \\
\hline L. Epididymis & $0.6874 \pm 0.0184$ & $0.7047 \pm 0.0274$ & $0.7398 \pm 0.0175$ & $0.6402 \pm 0.0165$ \\
\hline L. Testis & $1.7349 \pm 0.0423$ & $1.8209 \pm 0.0478$ & $1.7922 \pm 0.0619$ & $1.7900 \pm 0.0333$ \\
\hline \multicolumn{5}{|l|}{ Spermatid measurements } \\
\hline Spermatid heads $\left(10^{6} /\right.$ testis $)$ & $207.79 \pm 18.44$ & $183.39 \pm 9.19$ & $238.70 \pm 20.45$ & $175.57 \pm 8.43$ \\
\hline Spermatid heads $\left(10^{6} / \mathrm{g}\right.$ testis $)$ & $120.38 \pm 11.23$ & $101.50 \pm 5.84$ & $135.54 \pm 14.11$ & $98.05 \pm 4.29$ \\
\hline \multicolumn{5}{|c|}{ Epididymal spermatozoal measurements } \\
\hline Sperm motility (\%) & $86.0 \pm 0.37$ & $86.1 \pm 0.46$ & $85.9 \pm 0.46$ & $85.8 \pm 0.47$ \\
\hline Sperm ( $10^{6} /$ cauda epididymis $)$ & $169.25 \pm 14.82$ & $182.38 \pm 8.81$ & $160.75 \pm 12.63$ & $157.63 \pm 12.41$ \\
\hline Sperm ( $10^{6} / \mathrm{g}$ cauda epididymis $)$ & $833 \pm 52$ & $856 \pm 33$ & $711 \pm 33$ & $760 \pm 46$ \\
\hline
\end{tabular}

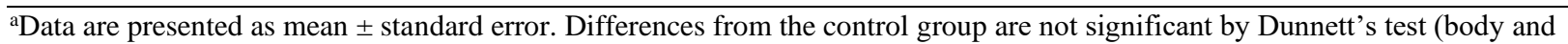
tissue weights) or Dunn's test (spermatid and epididymal spermatozoal measurements). 


\section{Appendix F. Chemical Characterization and Dose Formulation Studies}

\section{Table of Contents}

F.1. Procurement and Characterization of Chitosan

F.2. Preparation and Analysis of Dose Formulations

\section{Tables}

Table F-1. Gel Permeation Chromatography Systems Used in the Six-month Feed Study of Chitosan.

Table F-2. Preparation and Storage of Dose Formulations in the Six-month Feed Study of Chitosan F-4

Table F-3. Results of Analyses of Dose Formulations Administered to Rats in the Six-month Feed Study of Chitosan

\section{Figures}

Figure F-1. Infrared Absorption Spectrum of Chitosan.....................................................F-5

Figure F-2. Proton Nuclear Magnetic Resonance Spectrum of Chitosan 


\section{F.1. Procurement and Characterization of Chitosan}

Chitosan was obtained from Vanson HaloSource, Inc. (Redmond, WA), in one lot (02-ASSF0715), which was used in the 6-month study. Identity, purity, and stability analyses were conducted by the analytical chemistry laboratory at Midwest Research Institute (MRI) (Kansas City, MO) and by the study laboratory at Battelle Columbus Operations (Columbus, $\mathrm{OH}$ ). Reports on analyses performed in support of the chitosan studies are on file at the National Institute of Environmental Health Sciences.

The test article, an off-white powder, was identified as chitosan by the analytical chemistry laboratory using infrared (IR) and proton nuclear magnetic resonance (NMR) spectroscopy and by the study laboratory using IR spectroscopy. The percentage of deacetylation of the test article, determined by proton NMR, ranged from $85.97 \%$ to $87.17 \%$, with an average of $86.5 \%$. All spectra were consistent with the literature spectra ${ }^{38 ; 39}$, and with the Sadtler spectral database. Representative IR and NMR spectra are presented in Figure F-1 and Figure F-2, respectively.

The moisture content for lot 02-ASSF-0715 was determined by the analytical chemistry laboratory using weight loss on drying in a $110^{\circ} \mathrm{C}$ oven for 24 hours; the inorganic content was determined on the dried test article by ashing at $500^{\circ} \mathrm{C}$ for 4 hours. Viscosity was determined at approximately $22.5^{\circ} \mathrm{C}$ using a Brookfield viscometer fitted with an SC4-18/R13 spindle at a speed of $30 \mathrm{rpm}$. Lot $02-\mathrm{ASSF}-0715$ was characterized by the analytical chemistry laboratory using gel permeation chromatography (GPC) with refractive index (RI) detection using system A (Table F-1) to find the most abundant molecular weight. Samples were prepared by transferring approximately $75 \mathrm{mg}$ of the test article into a vial, and adding a $25 \mathrm{~mL}$ aliquot of diluent; vials were sealed with Teflon ${ }^{\circledR}$-lined septa and crimp caps, allowed to stand for 2 hours at ambient temperature, swirled by hand, and placed on a rotary shaker for at least 1 hour. Standards containing a total of six molecular weight dextran markers with known peak molecular weights (Mp) (4,400, 21,400, 43,500, 196,000, 277,000, and 3,900,000 Mp) were prepared; approximately $10 \mathrm{mg}$ of each marker ( $3 \mathrm{mg}$ of 3,900,000 Mp marker) and $10 \mathrm{~mL}$ of diluent were pipetted into vials, sealed with Teflon ${ }^{\circledR}$-lined septa and crimp caps, allowed to stand for a least 2 hours (the 3,900,000 marker was allowed to stand overnight) at ambient temperature to dissolve the standards, then swirled to mix prior to analysis.

For lot 02-ASSF-0715, weight loss on drying indicated $4.50 \%$ water, the average inorganic content by ashing was determined to be $2.13 \%$, and viscosity was 81.3 centipoise. GPC/RI indicated one major peak and the determined molecular weight of the bulk chemical ranged from 62,755 to 87,343 daltons (Da). This resulted in an average molecular weight of $81,644 \mathrm{~g} / \mathrm{mol}$, or approximately $82 \mathrm{kDa}$, classifying the test article as a low molecular weight chitosan (LMWCS). A sample of chitosan was submitted to Covance Laboratories, Inc. (Madison, WI), for nutritional and contaminant testing using standard methods. For lot 02-ASSF-0715, levels of organochlorine and organophosphorous pesticides, nitrosamines, and aflatoxins were below the detection limits of the analytical methods. The purity of lot 02 -ASSF- 0715 was estimated to be approximately $94 \%$ based on the analysis of moisture and inorganic content. Taken together, these data indicated that the test article was chitosan. 
To ensure stability, the test article was stored in sealed amber glass vials at room temperature. Reanalysis of the test article was performed during the study by the study laboratory using GPC/RI by system B, and no degradation of the test article was detected.

\section{F.2. Preparation and Analysis of Dose Formulations}

The dose formulations were prepared approximately monthly by mixing chitosan with feed (Table F-2). Dose formulations were stored in lined plastic buckets sealed with lids and stored at $-30^{\circ} \mathrm{C}$ to $-15^{\circ} \mathrm{C}$ for up to 42 days.

Homogeneity studies of approximately $0.5 \%$ and $9 \%$ formulations $(5,046$ and $90,049 \mu \mathrm{g} / \mathrm{g}$, respectively) and stability studies of an approximately $0.5 \%(5,046 \mu \mathrm{g} / \mathrm{g})$ formulation were performed by the analytical chemistry laboratory using GPC/RI by system C (Table F-1). Two peaks were attributed to chitosan with retention times of approximately 6.9 minutes and 12.1 minutes, respectively. Chitosan quantitation was based on the larger polymeric components of the first peak only because vehicle components co-eluted with the later oligomeric peak. Homogeneity studies of $1 \%$ and $9 \%$ dose formulations $(10 \mathrm{mg} / \mathrm{g}$ and $90 \mathrm{mg} / \mathrm{g}$ in feed, respectively) were performed by the study laboratory using GPC/RI by system B. Homogeneity was confirmed, and stability was confirmed for at least 42 days for dose formulations stored in lined plastic buckets sealed with lids at temperatures up to room temperature and for at least 7 days under simulated animal room conditions.

Periodic analyses of the dose formulations of chitosan were performed by the study laboratory using GPC/RI by system B. Of the dose formulations analyzed, all nine were within $10 \%$ of the target concentrations (Table F-3). Animal room samples of dose formulations were also analyzed; all three were within $10 \%$ of the target concentrations.

Table F-1. Gel Permeation Chromatography Systems Used in the Six-month Feed Study of Chitosan $^{\mathrm{a}}$

\begin{tabular}{|c|c|c|}
\hline Detection System & Column & Solvent System \\
\hline \multicolumn{3}{|l|}{ System A } \\
\hline Refractive index & $\begin{array}{l}\text { In series: NOVEMA } 10,000 \AA \text {, } \\
300 \mathrm{~mm} \times 8 \mathrm{~mm}, 10 \mu \mathrm{m} \text { and NOVEMA } \\
3,000 \AA, 50 \mathrm{~mm} \times 8 \mathrm{~mm} \text { (guard) and } \\
\text { NOVEMA } 3,000 \AA, 300 \mathrm{~mm} \times 8 \mathrm{~mm} \text {, } \\
10 \mu \mathrm{m} \text { (Polymer Standards Service } \\
\text { GmbH, Mainz, Germany) }\end{array}$ & $\begin{array}{l}0.25 \% \text { Trifluoroacetic acid, isocratic, } \\
\text { flow rate } 1.0 \mathrm{~mL} / \text { minute }\end{array}$ \\
\hline \multicolumn{3}{|l|}{ System B } \\
\hline Refractive index & $\begin{array}{l}\text { In series: BioSep-SEC-S2000 } 145 \AA \text {, } \\
300 \mathrm{~mm} \times 4.6 \mathrm{~mm}, 5 \mu \mathrm{m} \text { and BioSep- } \\
\text { SEC-S3000 } 290 \AA, 300 \mathrm{~mm} \times 4.6 \mathrm{~mm} \text {, } \\
5 \mu \mathrm{m}(\text { Phenomenex, Torrance, CA) }\end{array}$ & $\begin{array}{l}1 \% \text { Trifluoroacetic acid, isocratic, flow } \\
\text { rate } 0.35 \mathrm{~mL} / \text { minute }\end{array}$ \\
\hline \multicolumn{3}{|l|}{ System C } \\
\hline Refractive index & $\begin{array}{l}\text { In series: Alltech }{ }^{\circledR} \text { Macrosphere } 100 \AA \text {, } \\
250 \mathrm{~mm} \times 4.6 \mathrm{~mm}, 7 \mu \mathrm{m} \text { and Alltech }{ }^{\circledR} \\
\text { Macrosphere } 300 \AA, 250 \mathrm{~mm} \times 4.6 \mathrm{~mm} \text {, } \\
7 \mu \mathrm{m} \text { (Grace, Columbia, MD) }\end{array}$ & $\begin{array}{l}1 \% \text { Trifluoroacetic acid, isocratic, flow } \\
\text { rate } 0.5 \mathrm{~mL} / \text { minute }\end{array}$ \\
\hline
\end{tabular}




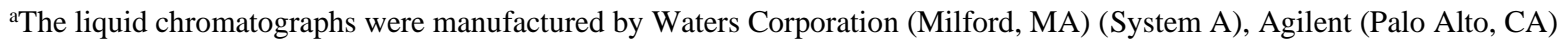
(System B), or Perkin Elmer (Boston, MA) (System C).

Table F-2. Preparation and Storage of Dose Formulations in the Six-month Feed Study of Chitosan Six-month Feed Study

\section{Preparation}

The appropriate amounts of chitosan and AIN-93M feed $(87 \mathrm{~kg}$ for $1 \%$ and $3 \%$ formulations and $79 \mathrm{~kg}$ for the 9\% formulation) were weighed in tared stainless steel buckets and layered into a Patterson-Kelly twin-shell blender. The chitosan beaker was rinsed twice with portions of the blank feed, added to the blender, and the formulation was mixed for 15 minutes. The dose formulations were prepared approximately monthly.

\section{Chemical Lot Number}

02-ASSF-0715

\section{Maximum Storage Time}

42 days

\section{Storage Conditions}

Stored in plastic-lined 5 gallon plastic buckets sealed with lids at $-30^{\circ}$ to $-15^{\circ} \mathrm{C}$

\section{Study Laboratory}

Battelle Columbus Operations (Columbus, $\mathrm{OH}$ )

Table F-3. Results of Analyses of Dose Formulations Administered to Rats in the Six-month Feed Study of Chitosan

\begin{tabular}{ccccc}
\hline Date Prepared & Date Analyzed & $\begin{array}{c}\text { Target Concentration } \\
(\mathbf{m g} / \mathbf{g})\end{array}$ & $\begin{array}{c}\text { Determined } \\
\text { Concentration } \\
(\mathbf{m g} / \mathbf{g})\end{array}$ & $\begin{array}{c}\text { Difference from } \\
\text { Target } \\
(\%)\end{array}$ \\
\hline August 15, 2006 & August 17-18, 2006 & 10 & 9.1 & -10 \\
& & 30 & 27.3 & -9 \\
& October 2-3, 2006 & 90 & 83.5 & -7 \\
& & 10 & 9.99 & 0 \\
October 10, 2006 & October 11-12, 2006 & 30 & 30.3 & +1 \\
& & 90 & 92.4 & +3 \\
& & 30 & 9.5 & -5 \\
January 2, 2007 & January 2-3, 2007 & 90 & 27.0 & -10 \\
& & 10 & 94.2 & +5 \\
& & 30 & 10.6 & +6 \\
& & 90 & 29.5 & -2 \\
\hline
\end{tabular}

${ }^{\mathrm{a}} 10,30$, and $90 \mathrm{mg} / \mathrm{g}$ are equivalent to $1 \%, 3 \%$, and $9 \%$ chitosan concentrations, respectively.

${ }^{\mathrm{b}}$ Results of duplicate analyses.

${ }^{\mathrm{c}}$ Animal room samples. 


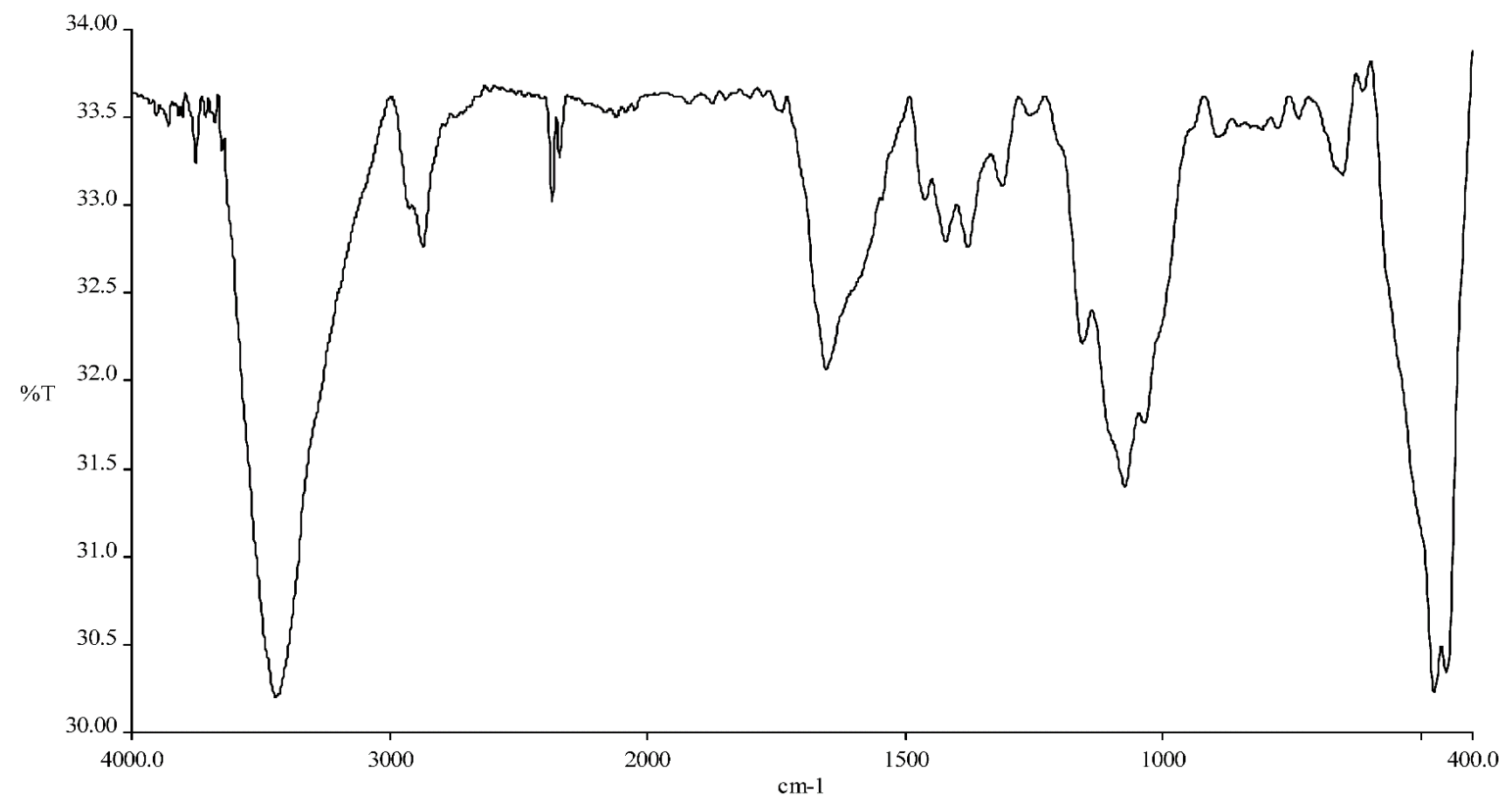

Figure F-1. Infrared Absorption Spectrum of Chitosan

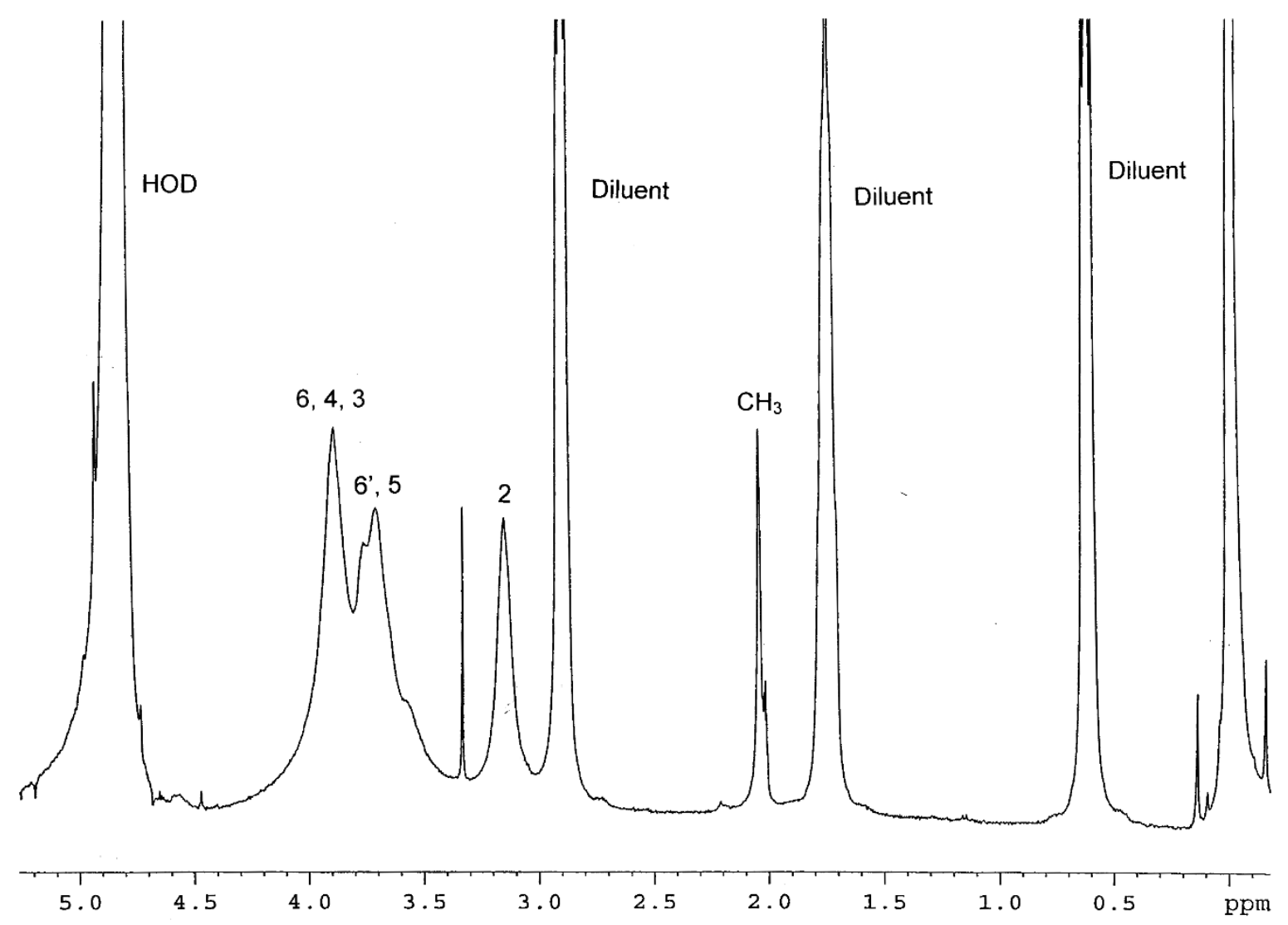

Figure F-2. Proton Nuclear Magnetic Resonance Spectrum of Chitosan 


\section{Appendix G. Feed and Compound Consumption in the Six- month Feed Study of Chitosan}

\section{Tables}

Table G-1. Feed and Compound Consumption by Group A Male Rats in the Six-month Feed Study of Chitosan G-2

Table G-2. Feed and Compound Consumption by Group A Female Rats in the Six-month Feed Study of Chitosan G-3 
Table G-1. Feed and Compound Consumption by Group A Male Rats in the Six-month Feed Study of Chitosan

\begin{tabular}{|c|c|c|c|c|c|c|c|c|c|c|c|}
\hline \multirow[b]{2}{*}{ Week } & \multicolumn{2}{|c|}{$0 \%$} & \multicolumn{3}{|c|}{$1 \%$} & \multicolumn{3}{|c|}{$3 \%$} & \multicolumn{3}{|c|}{$9 \%$} \\
\hline & $\begin{array}{l}\text { Feed }^{\mathrm{a}} \\
(\mathrm{g} / \mathrm{day})\end{array}$ & $\begin{array}{c}\text { Body } \\
\text { Weight } \\
\text { (g) }\end{array}$ & $\begin{array}{c}\text { Feed } \\
\text { (g/day) }\end{array}$ & $\begin{array}{c}\text { Body } \\
\text { Weight } \\
\text { (g) }\end{array}$ & $\begin{array}{c}\text { Dose }^{\mathrm{b}} \\
(\mathbf{m g} / \mathbf{k g})\end{array}$ & $\begin{array}{c}\text { Feed } \\
\text { (g/day) }\end{array}$ & $\begin{array}{c}\text { Body } \\
\text { Weight } \\
\text { (g) }\end{array}$ & $\begin{array}{c}\text { Dose } \\
(\mathbf{m g} / \mathbf{k g})\end{array}$ & $\begin{array}{l}\text { Feed } \\
\text { (g/day) }\end{array}$ & $\begin{array}{c}\text { Body } \\
\text { Weight } \\
\text { (g) }\end{array}$ & $\begin{array}{c}\text { Dose } \\
(\mathbf{m g} / \mathbf{k g})\end{array}$ \\
\hline 1 & 22.2 & 238 & 23.8 & 243 & 980 & 23.6 & 242 & 2,929 & 21.4 & 243 & 7,931 \\
\hline 2 & 21.6 & 297 & 23.1 & 308 & 750 & 23.0 & 303 & 2,278 & 26.9 & 265 & 9,137 \\
\hline 3 & 22.8 & 346 & 24.0 & 359 & 668 & 25.4 & 354 & 2,156 & 27.3 & 307 & 8,002 \\
\hline 4 & 22.6 & 388 & 23.5 & 404 & 582 & 24.9 & 398 & 1,877 & 26.7 & 350 & 6,872 \\
\hline 5 & 22.3 & 421 & 23.5 & 438 & 537 & 25.8 & 436 & 1,774 & 27.4 & 388 & 6,355 \\
\hline 6 & 21.5 & 446 & 21.7 & 465 & 467 & 24.6 & 464 & 1,591 & 26.4 & 413 & 5,759 \\
\hline 7 & 23.1 & 475 & 23.5 & 493 & 477 & 25.7 & 491 & 1,570 & 27.8 & 442 & 5,662 \\
\hline 8 & 22.3 & 496 & 24.1 & 513 & 470 & 25.2 & 514 & 1,471 & 27.1 & 464 & 5,259 \\
\hline 9 & 22.3 & 514 & 24.1 & 535 & 450 & 25.1 & 534 & 1,411 & 26.7 & 483 & 4,980 \\
\hline 10 & 21.8 & 529 & 23.2 & 554 & 419 & 25.1 & 548 & 1,373 & 26.2 & 498 & 4,735 \\
\hline 11 & 21.8 & 543 & 23.3 & 570 & 409 & 25.5 & 566 & 1,353 & 25.5 & 511 & 4,493 \\
\hline 12 & 21.6 & 554 & 23.1 & 585 & 395 & 24.5 & 579 & 1,270 & 26.4 & 521 & 4,557 \\
\hline 13 & 22.3 & 563 & 22.6 & 598 & 378 & 24.8 & 584 & 1,274 & 26.9 & 527 & 4,595 \\
\hline 14 & 21.5 & 578 & 22.9 & 612 & 374 & 25.7 & 602 & 1,280 & 26.4 & 544 & 4,371 \\
\hline 15 & 21.7 & 587 & 22.7 & 622 & 365 & 25.5 & 613 & 1,249 & 26.7 & 557 & 4,315 \\
\hline 16 & 22.2 & 597 & 22.7 & 631 & 360 & 27.0 & 620 & 1,306 & 28.5 & 565 & 4,542 \\
\hline 17 & 23.4 & 607 & 23.7 & 645 & 367 & 28.0 & 634 & 1,325 & 29.2 & 575 & 4,569 \\
\hline 18 & 23.6 & 614 & 24.6 & 657 & 375 & 28.4 & 646 & 1,320 & 29.0 & 584 & 4,468 \\
\hline 19 & 22.3 & 624 & 23.0 & 667 & 345 & 26.6 & 657 & 1,214 & 27.8 & 595 & 4,202 \\
\hline 20 & 23.6 & 633 & 23.2 & 677 & 343 & 25.4 & 664 & 1,148 & 27.4 & 600 & 4,112 \\
\hline 21 & 23.8 & 643 & 23.4 & 689 & 340 & 24.8 & 670 & 1,110 & 28.5 & 606 & 4,230 \\
\hline 22 & 24.1 & 653 & 23.1 & 700 & 330 & 25.7 & 677 & 1,139 & 26.9 & 612 & 3,959 \\
\hline 23 & 22.6 & 665 & 21.3 & 707 & 301 & 25.7 & 686 & 1,125 & 25.4 & 615 & 3,715 \\
\hline 24 & 21.5 & 666 & 19.6 & 704 & 278 & 24.9 & 689 & 1,084 & 25.4 & 612 & 3,738 \\
\hline 25 & 21.2 & & 20.4 & & & 24.7 & & & 27.3 & & \\
\hline \multicolumn{12}{|c|}{ Mean for Weeks } \\
\hline $1-13$ & 22.2 & 447 & 23.3 & 466 & 537 & 24.9 & 462 & 1,717 & 26.4 & 416 & 6,026 \\
\hline $14-24$ & 22.8 & 624 & 22.7 & 665 & 343 & 26.2 & 651 & 1,209 & 27.4 & 588 & 4,202 \\
\hline
\end{tabular}

${ }^{\mathrm{a}}$ Grams of feed consumed per animal per day.

${ }^{\mathrm{b}}$ Milligrams of chitosan consumed per kilogram body weight per day. 
Table G-2. Feed and Compound Consumption by Group A Female Rats in the Six-month Feed Study of Chitosan

\begin{tabular}{|c|c|c|c|c|c|c|c|c|c|c|c|}
\hline \multirow[b]{2}{*}{ Week } & \multicolumn{2}{|c|}{$0 \%$} & \multicolumn{3}{|c|}{$1 \%$} & \multicolumn{3}{|c|}{$3 \%$} & \multicolumn{3}{|c|}{$9 \%$} \\
\hline & $\begin{array}{l}\text { Feed }^{\mathrm{a}} \\
(\mathrm{g} / \text { day })\end{array}$ & $\begin{array}{c}\text { Body } \\
\text { Weight } \\
\text { (g) }\end{array}$ & $\begin{array}{l}\text { Feed } \\
\text { (g/day) }\end{array}$ & $\begin{array}{c}\text { Body } \\
\text { Weight } \\
\text { (g) }\end{array}$ & $\begin{array}{c}\text { Dose }^{\mathrm{b}} \\
(\mathrm{mg} / \mathrm{kg})\end{array}$ & $\begin{array}{l}\text { Feed } \\
\text { (g/day) }\end{array}$ & $\begin{array}{c}\text { Body } \\
\text { Weight } \\
\text { (g) }\end{array}$ & $\begin{array}{c}\text { Dose } \\
(\mathbf{m g} / \mathbf{k g})\end{array}$ & $\begin{array}{l}\text { Feed } \\
\text { (g/day) }\end{array}$ & $\begin{array}{c}\text { Body } \\
\text { Weight } \\
\text { (g) }\end{array}$ & $\begin{array}{c}\text { Dose } \\
(\mathbf{m g} / \mathbf{k g})\end{array}$ \\
\hline 1 & 17.7 & 175 & 22.3 & 173 & 1,286 & 17.3 & 177 & 2,940 & 16.9 & 177 & 8,606 \\
\hline 2 & 15.1 & 199 & 15.4 & 198 & 779 & 15.6 & 197 & 2,381 & 17.6 & 191 & 8,298 \\
\hline 3 & 15.8 & 220 & 16.2 & 217 & 747 & 15.0 & 214 & 2,102 & 16.9 & 206 & 7,371 \\
\hline 4 & 16.2 & 233 & 16.7 & 229 & 728 & 15.6 & 231 & 2,023 & 17.3 & 221 & 7,044 \\
\hline 5 & 16.0 & 248 & 17.4 & 241 & 722 & 15.9 & 242 & 1,974 & 17.3 & 234 & 6,649 \\
\hline 6 & 14.7 & 258 & 17.5 & 252 & 694 & 14.7 & 251 & 1,759 & 16.4 & 243 & 6,067 \\
\hline 7 & 15.9 & 266 & 17.9 & 262 & 683 & 15.2 & 259 & 1,759 & 16.7 & 248 & 6,069 \\
\hline 8 & 15.9 & 274 & 17.3 & 268 & 645 & 15.5 & 267 & 1,739 & 16.7 & 259 & 5,810 \\
\hline 9 & 15.9 & 281 & 17.7 & 276 & 641 & 15.9 & 274 & 1,740 & 16.7 & 266 & 5,656 \\
\hline 10 & 15.9 & 287 & 18.2 & 284 & 641 & 15.7 & 281 & 1,678 & 16.6 & 268 & 5,577 \\
\hline 11 & 15.2 & 294 & 17.4 & 289 & 601 & 15.5 & 286 & 1,624 & 16.2 & 274 & 5,329 \\
\hline 12 & 15.8 & 300 & 17.5 & 295 & 594 & 15.9 & 292 & 1,632 & 15.7 & 279 & 5,071 \\
\hline 13 & 15.3 & 305 & 16.1 & 300 & 537 & 16.9 & 298 & 1,699 & 16.2 & 281 & 5,192 \\
\hline 14 & 15.3 & 312 & 16.8 & 303 & 555 & 16.3 & 304 & 1,609 & 16.5 & 285 & 5,218 \\
\hline 15 & 14.7 & 316 & 16.2 & 307 & 528 & 16.7 & 309 & 1,623 & 16.8 & 288 & 5,258 \\
\hline 16 & 16.2 & 320 & 19.1 & 311 & 615 & 17.7 & 314 & 1,694 & 19.2 & 291 & 5,940 \\
\hline 17 & 15.9 & 325 & 18.2 & 314 & 581 & 16.9 & 315 & 1,611 & 18.0 & 293 & 5,537 \\
\hline 18 & 16.4 & 327 & 19.5 & 317 & 615 & 17.8 & 318 & 1,679 & 19.1 & 296 & 5,803 \\
\hline 19 & 17.8 & 330 & 19.6 & 321 & 610 & 18.9 & 321 & 1,768 & 18.6 & 299 & 5,607 \\
\hline 20 & 17.3 & 328 & 21.7 & 324 & 670 & 18.8 & 321 & 1,757 & 19.2 & 297 & 5,819 \\
\hline 21 & 18.2 & 335 & 21.1 & 332 & 636 & 19.0 & 330 & 1,725 & 19.1 & 302 & 5,688 \\
\hline 22 & 18.5 & 339 & 19.7 & 337 & 584 & 19.2 & 336 & 1,712 & 18.9 & 306 & 5,554 \\
\hline 23 & 17.4 & 343 & 17.5 & 340 & 515 & 17.3 & 339 & 1,532 & 17.7 & 306 & 5,201 \\
\hline 24 & 16.1 & 345 & 17.2 & 340 & 506 & 15.6 & 339 & 1,381 & 16.7 & 309 & 4,863 \\
\hline 25 & 16.4 & & 20.3 & & & 17.1 & & & 18.8 & & \\
\hline \multicolumn{12}{|c|}{ Mean for Weeks } \\
\hline $1-13$ & 15.8 & 257 & 17.5 & 253 & 715 & 15.7 & 251 & 1,927 & 16.7 & 242 & 6,364 \\
\hline $14-24$ & 16.7 & 329 & 18.8 & 322 & 583 & 17.7 & 322 & 1,645 & 18.2 & 297 & 5,499 \\
\hline
\end{tabular}

${ }^{\mathrm{a}}$ Grams of feed consumed per animal per day.

${ }^{\mathrm{b}}$ Milligrams of chitosan consumed per kilogram body weight per day. 


\section{Appendix H. Ingredients and Nutrient Composition in AIN- 93M Maintenance Purified Diet}

\section{Tables}

Table H-1. Ingredients of AIN-93M Maintenance Purified Rodent Diet

H-2

Table H-2. Vitamins, Minerals, and Nutrient Composition of AIN-93M Maintenance

Purified Rodent Diet .... 
Table H-1. Ingredients of AIN-93M Maintenance Purified Rodent Diet

\begin{tabular}{lc}
\hline \multicolumn{1}{c}{ Ingredients } & Percent by Weight \\
\hline Corn starch & 46.5692 \\
Dextrin & 15.5000 \\
Casein (vitamin free) & 14.0000 \\
Sucrose & 10.0000 \\
Powdered cellulose & 5.0000 \\
Soybean oil & 4.0000 \\
AIN-93M mineral mix & 3.5000 \\
AIN-93M vitamin mix & 1.0000 \\
Choline bitartrate & 0.2500 \\
L-Cystine & 0.1800 \\
$t$-Butylhydroquinone & 0.0008 \\
\hline
\end{tabular}

Table H-2. Vitamins, Minerals, and Nutrient Composition of AIN-93M Maintenance Purified Rodent Diet

\section{Amount}

\section{Vitamins}

A

$4.00 \mathrm{IU} / \mathrm{g}$

$\mathrm{D}_{3}$ (added)

$1.00 \mathrm{IU} / \mathrm{g}$

E

$78.80 \mathrm{IU} / \mathrm{g}$

$\mathrm{K}$ (as menadione)

$0.75 \mathrm{ppm}$

Thiamine hydrochloride

$6.00 \mathrm{ppm}$

Riboflavin

$6.50 \mathrm{ppm}$

Niacin

$30.00 \mathrm{ppm}$

Pantothenic acid

$16.00 \mathrm{ppm}$

Folic acid

$2.10 \mathrm{ppm}$

Pyridoxine

$5.80 \mathrm{ppm}$

Biotin

$0.20 \mathrm{ppm}$

$\mathrm{B}_{12}$

$28.00 \mathrm{mcg} / \mathrm{kg}$

Choline chloride

1,250.00 ppm

Ascorbic acid

$0.00 \mathrm{ppm}$

\section{Minerals}

Calcium

$0.50 \%$

Phosphorus

$0.31 \%$

Potassium

$0.36 \%$

Magnesium

$0.05 \%$ 
Chitosan, NTP TOX 93

\begin{tabular}{lc}
\hline & Amount \\
\hline Sodium & $0.13 \%$ \\
Chlorine & $0.20 \%$ \\
Fluorine & $1.00 \mathrm{ppm}$ \\
Iron & $39.00 \mathrm{ppm}$ \\
Zinc & $35.00 \mathrm{ppm}$ \\
Manganese & $11.00 \mathrm{ppm}$ \\
Copper & $6.00 \mathrm{ppm}$ \\
Cobalt & $0.00 \mathrm{ppm}$ \\
Iodine & $0.21 \mathrm{ppm}$ \\
Chromium & $1.00 \mathrm{ppm}$ \\
Molybdenum & $0.14 \mathrm{ppm}$ \\
Selenium & $0.22 \mathrm{ppm}$ \\
\hline Typical Analysis & \\
Protein & $13.06 \%$ \\
Fat & $4.00 \%$ \\
Fiber & $5.00 \%$ \\
Carbohydrate & $73.80 \%$ \\
Metabolizable energy & $3.83 \%$ \\
\hline & \\
\hline
\end{tabular}


Chitosan, NTP TOX 93

\section{Appendix I. Sentinel Animal Program \\ Table of Contents}

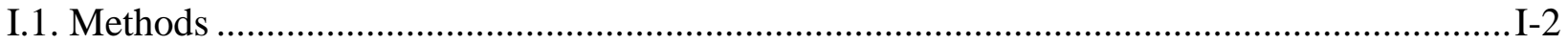

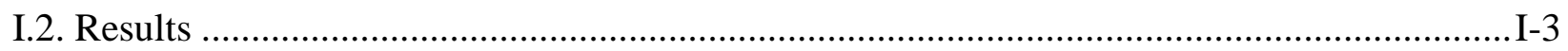

Tables

Table I-1. Laboratory Methods and Agents Tested for in the Sentinel Animal Program............. I-2 


\section{I.1. Methods}

Rodents used in the National Toxicology Program are produced in optimally clean facilities to eliminate potential pathogens that may affect study results. The Sentinel Animal Program is part of the periodic monitoring of animal health that occurs during the toxicological evaluation of test compounds. Under this program, the disease state of the rodents is monitored via sera from extra (sentinel) animals in the study rooms. The sentinel animals and the study animals are subject to identical environmental conditions. Furthermore, the sentinel animals come from the same production source and weanling groups as the animals used for the studies of test compounds.

Blood samples were collected from each rat and allowed to clot and the serum was separated. All samples were processed appropriately and tested for the presence of pathogens at BioReliance Corporation (Rockville, MD) or the Research Animal Diagnostic Laboratory (RADIL), University of Missouri, Columbia, MO. The laboratory methods and agents for which testing was performed are tabulated below; the times at which samples were collected during the studies are also listed.

Blood was collected from five rats per sex per time point, except at study termination when blood was collected from four males and five females.

Table I-1. Laboratory Methods and Agents Tested for in the Sentinel Animal Program

\begin{tabular}{ll}
\hline Method and Test & \multicolumn{1}{c}{ Time of Collection } \\
\hline ELISA & 4 weeks \\
Kilham rat virus (KRV) & End of quarantine, 4 weeks, study termination \\
Pneumonia virus of mice (PVM) & End of quarantine, 4 weeks, study termination \\
Rat coronavirus/sialodacryoadenitis virus (RCV/SDA) & 4 weeks \\
Rat parvovirus (RPV) & End of quarantine, 4 weeks, study termination \\
Sendai & 4 weeks \\
Toolan's H-1 virus (H-1) & \\
Immunofluorescence Assay & 4 weeks \\
H-1 & 4 weeks \\
KRV & End of quarantine, 4 weeks, 6 weeks, study termination \\
Parvovirus & End of quarantine \\
RCV/SDA & 4 weeks \\
RPV & \\
Multiplex Fluorescent Immunoassay & 6 weeks \\
H-1 & 6 weeks \\
KRV & 6 weeks \\
Parvo NS-1 & 6 weeks \\
Rat minute virus & 6 weeks \\
RPV &
\end{tabular}




\section{I.2. Results}

A positive test result for parvovirus occurred in one animal at the 4-week timepoint; additional testing of serum from this animal and other sentinel animals via other testing methodologies deemed the original positive result to be a false positive. All other test results were negative for rodent pathogens. 


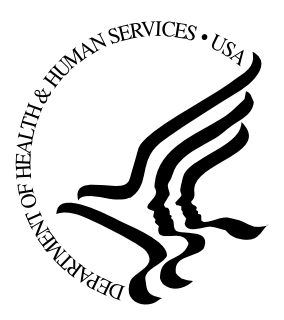

\title{
National Toxicology Program
}

\author{
NTP Central Data Management, MD EC-03
}

National Institute of Environmental Health Sciences

P.O. Box 12233

Research Triangle Park, NC 27709

http://ntp.niehs.nih.gov 